\title{
Two-State and Two-State Plus Continuum Problems Associated with the Interaction of Intense Laser Pulses with Atoms
}

\author{
C. W. Choi \\ M. G. Payne
}

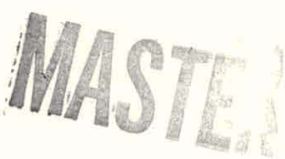




\section{DISCLAIMER}

This report was prepared as an account of work sponsored by an agency of the United States Government. Neither the United States Government nor any agency Thereof, nor any of their employees, makes any warranty, express or implied, or assumes any legal liability or responsibility for the accuracy, completeness, or usefulness of any information, apparatus, product, or process disclosed, or represents that its use would not infringe privately owned rights. Reference herein to any specific commercial product, process, or service by trade name, trademark, manufacturer, or otherwise does not necessarily constitute or imply its endorsement, recommendation, or favoring by the United States Government or any agency thereof. The views and opinions of authors expressed herein do not necessarily state or reflect those of the United States Government or any agency thereof. 


\section{DISCLAIMER}

Portions of this document may be illegible in electronic image products. Images are produced from the best available original document. 


\section{Printed in the United States of America. Available from National Technical Information Service}

U.S. Department of Commerce 5285 Port Royal Road, Springfield, Virginia 22161

Price: Printed Copy $\$ 5.50$; Microfiche $\$ 3.00$

This report was prepared as an account of work sponsored by the United States Government. Neither the United States nor the Energy Research and Development Administration/United States Nuclear Regulatory Commission, nor any of their employees, nor any of their contractors, subcontractors, or their employees, makes any warranty, express or implied, or assumes any legal liability or responsibility for the accuracy, completeness or usefulness of any information, apparatus, product or process disclosed, or represents that its use would not infringe privately owned rights. 
Contract No. W-7405-eng-26

HEALTH PHYSICS DIVISION

TWO-STATE AND TWO-STATE PLUS CONTINUUM PROBLEMS ASSOCIATED WITH THE INTERACTION OF INTENSE LASER PULSES WITH ATOMS

C. W. Choi and M. G. Payne

\begin{abstract}
submitted by $C$. W. Choi as a dissertation to the Graduate School of the University of Kentucky in partial fulfillment of the requirements for the degree of Doctor of Philosophy
\end{abstract}

This report was preporice sponsored by the United Stales Governme of work Research and States nor the United States Enerer their emplnyees, subcontractors, or their of their contractors, warranty. express or implied, or ass. ntakes any or un or responsibility for the accuracy, any legal process discs of any information, apparatus, podeteness infringe privately ouned represents that its use would ot

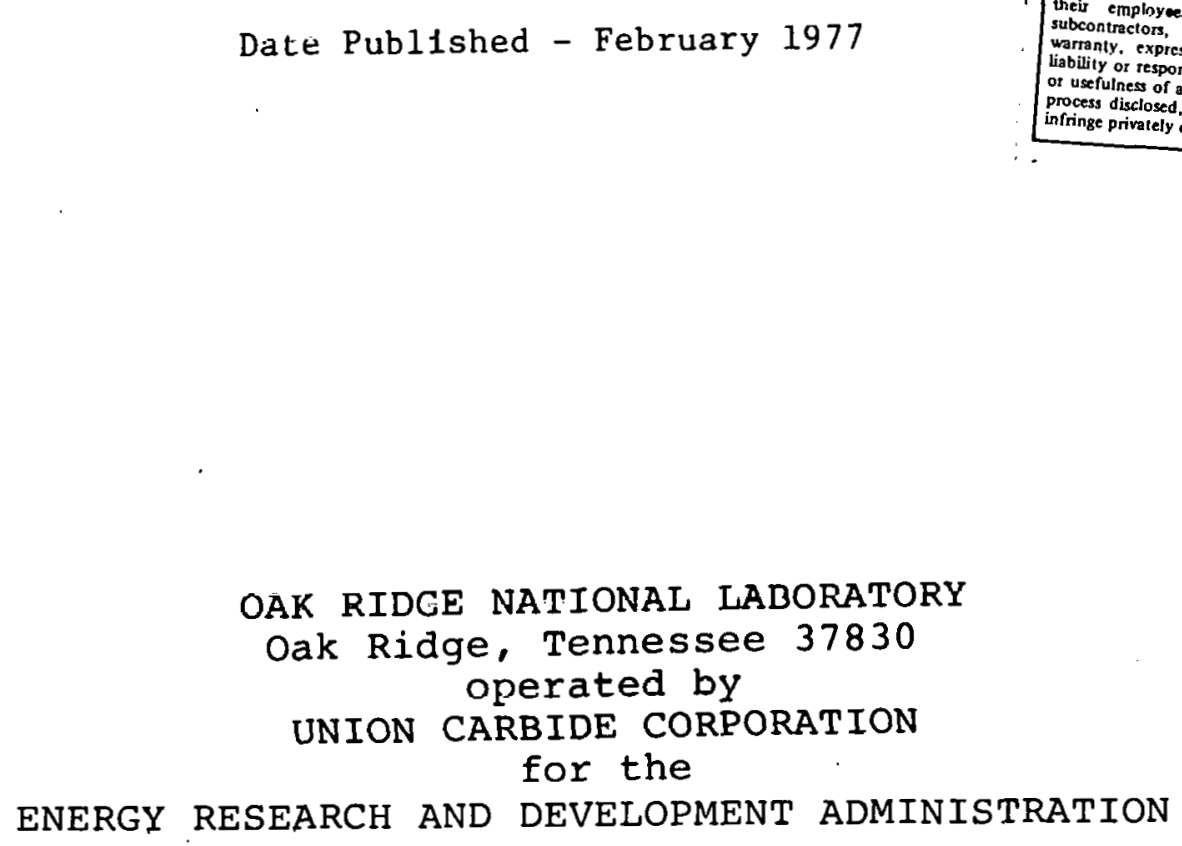

Date Publ1shed - February 1977 
THIS PAGE

WAS INTENTIONALLY

LEFT BLANK 
CONTENTS

LIST OF FIGURES . . . . . . . . . . . . . . . . v v

LIST OF TABLES • • • • • • • • • • • • • • • • • ix

ACKNOWLEDGEMENTS • • • • • • • • • • • • • • •

ABSTRACT . . . . . . . . . . . . . . . xiii

I. INTRODUCTION . . . . . . . . . . . . 1

II. MATHEMATICAL METHODS FOR LASER-MATTER

INTERACTION PROBLEMS . . • . . . . . . 3

A. The Factorization Method . . . . 3

B. Method of Isolated Curve Crossings 11

III. DOPPLER-FREE CONTRIBTUION TO THREE-PHOTON

IONIZATION BY PULSED LASERS . . . . . 18

A. Introduction . . . . . . . 18

B. Statement of Model . . . . . . 21

C. Application of The Factorization

Method ............ 29

D. Application of the Method of

Isolated Curve Crossings to

Three-Photon Ionization. . . . . 47

E. Crossing Effects Due to.Time

of Passage Across Tightly Focused

Laser Beams. . . . . . . . 56

IV. TWO-PHOTON RESONANCE IONIZATION WITH

PULSED LASERS. • • . • . . . . . 71

APPENDICES

A. TABUlation OF THE h FUnCtion . . . . 83

B. EXACT SOLUTIONS FOR SQUARE PULSES, AND

FOR THE GENERAL PULSES WITH $\delta=0$ and $\gamma_{2}=0 \quad 95$ 
CONTENTS (continued)

REFERENCES . . . . . . . . . . . . : 97 


\section{LIST OF FIGURES}

1. Energy Level Diagram, 3-Photon Transition with Lasers at $\mathrm{w}_{1}^{1}$ and $\mathrm{w}_{2}$. . . . . . . . 22

2. Photoionization Probability Comparison, for the Analytical Solution, o for the numerical solution with $I_{0}=10^{8} \mathrm{w} / \mathrm{cm}^{2}$ and for the numerical solution with $I_{0}=10^{7} \mathrm{w} / \mathrm{cm}^{2}$. . . . . . . . . . . . .

3. Photoionization Probability $\left(I_{0}=5 \times 10^{8}\right.$ $\left.w / \mathrm{cm}^{2} \tau=10^{-8} \mathrm{sec}\right),-$ for $\mathrm{g}(\mathrm{t})=[1+$ $\left.\left(\frac{t}{\tau}\right)^{2}\right]^{-3}$ and -- for $g(t)=\frac{3 \pi}{8}$.......

4. Photoionization Probability $\left(I_{0}=10^{8}\right.$

$$
\begin{aligned}
& \left.\mathrm{w} / \mathrm{cm}^{2}, \tau=10^{-8} \mathrm{sec}\right),- \text { for } g(t)=[1+ \\
& \left.\left(\frac{t}{\tau}\right)^{2}\right]^{-3} \text { and }--- \text { for } g(t)=\frac{3 \pi}{8} \cdot . \cdot \cdot \cdot .
\end{aligned}
$$

5. Photoionization Probability $\left(I_{0}=10^{7}\right.$

$\left.w / \mathrm{cm}^{2}, \tau=10^{-8} \mathrm{sec}\right)$, for $\mathrm{g}(t)=[1+$

$\left.\left(\frac{t}{\tau}\right)^{2}\right]^{-3}$ and -- for $g(t)=\frac{3 \pi}{8}$.
Blow-up Graph Near $\delta=0\left(I_{0}=10^{7}\right.$

$\left.\mathrm{w} / \mathrm{cm}^{2}, \tau=10^{-8} \mathrm{sec}\right),---$ for the numerical solution and $x$ for the analytical solution. . . . . . . . . .

7. Photoionization Probability $\left(I_{0}=10^{6}\right.$

$\left.w / \mathrm{cm}^{2}, \tau=10^{-8} \mathrm{sec}\right), x$ for the analytical

solution and - for the numerical solution

with $g(t)=\left[1+\left(\frac{t}{\tau}\right)^{2}\right]^{-3} \quad . . . \cdot . \cdot . \cdot \cdot$ 
LIST OF FIGURES (continued)

8. Photoionization Probability $l_{0}=10^{5}$ $\left.\mathrm{w} / \mathrm{cm}^{2}, \tau=10^{-8} \mathrm{sec}\right)$, numerical solution for $g(t)=\left[1+\left(\frac{t}{\tau}\right)^{2}\right]^{-3}$............ 46

9. Photoionization Probability (isolated crnssings), $\left|\frac{\alpha}{\mu}\right|^{2}|u \tau|=1, P_{0} \tau=1$ and $g(t)=\left[1+\left(\frac{t}{\tau}\right)^{\frac{1}{2}}\right]^{-3}$. . . . . . . . . . .

10. Photoionization Probability (isolated

crossings), $\left|\frac{\alpha}{\mu}\right|^{2}|\mu \tau|=1, P_{0} \tau=0.1$ and $g(t)=\left[1+\left(\frac{t}{\tau}\right)^{2}\right]^{-3} \quad . . . . . . .$.

11. Photoionization Probability (isolated crossings), $\left|\frac{\alpha}{\mu}\right|^{2}|\mu \tau|=1, \mu_{0} \tau=0.001$ and $g(t)=\left[1+\left(\frac{t}{\tau}\right)^{2}\right]^{-3} \quad . . . . . . .$.

12. Photoionization Prohability (isolated crossings), $\left|\frac{\alpha}{\mu}\right|^{2}|\mu \tau|=10, \mathrm{P}_{\mathrm{O}} \tau=1$ and $g(t)=\left[1+\left(\frac{t}{\tau}\right)^{2}\right]^{-3}$...........

13. $H\left(\left|z_{0}\right|^{2}, \Gamma\right)$. spontaneous decay feeds $|0\rangle$ state without time delay (case 1) . . . . .

14. Fluorescence (case 1 with $\Gamma_{\mathrm{OO}}=0.05$ and

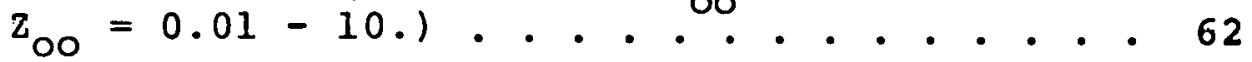

15. Fluorescence (case 1 with $\Gamma_{00}=0.5$ and

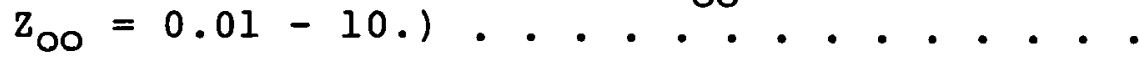

16. Fluorescence (case 1 with $\Gamma_{00}=1.0$ and

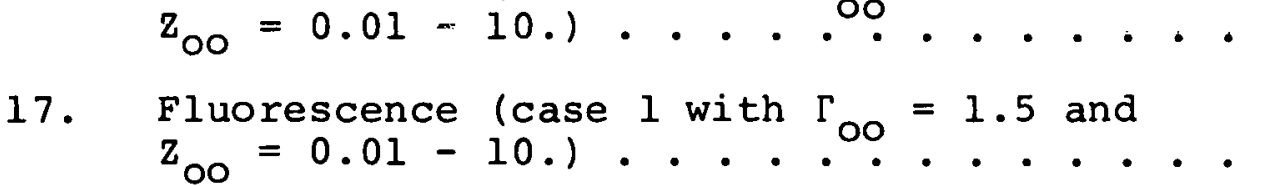




\section{LIST OF FIGURES (continued)}

18. $\mathrm{H}\left(\left|\mathrm{z}_{\mathrm{O}}\right|^{2}, \Gamma\right)$ Spontaneous decay does not repopulate $|0\rangle$ state (case 2). . . . . 66

19. Fluorescence (case 2 with $\Gamma_{00}=0.05$ and $\mathrm{z}_{00}=0.01-10.1 \cdot \cdot \cdot \cdot \cdot \cdot \cdot \cdot \cdot \cdot \cdot \cdot \cdot 67$

20. Fluorescence (case 2 with $\Gamma_{00}=0.5$ and
$\left.\mathrm{Z}_{00}=0.01-10.\right) \cdot . \cdot . \cdot . \cdot . \cdot . \cdot . \cdot 68$

21. Fluorescence (case 2 with $\Gamma_{00}=1.0$ and $\mathrm{Z}_{\mathrm{OO}}=0.01-10.1 \cdot \cdot \cdot \cdot .90 . \cdot \cdot \cdot \cdot \cdot . \cdot 69$

22. Fluorescence (case 2 with $\Gamma_{\circ \circ}=1.5$ and $\left.\mathrm{z}_{00}-0.01-10.\right) \cdot . \cdot . \cdot . \cdot . \cdot . \cdot . \cdot 70$

23. Energy Level Diagram of 2-Photon Transition

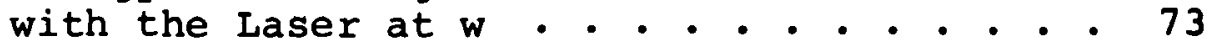

24. Photoionization Probability, $g(t)=[1+$ $\left.(t / \tau)^{2}\right]^{-3 / 2}$, 2-Photon Transition. . . . . 
THIS PAGE

WAS INTENTIONALLY LEFT BLANK 
LIST OF TABLES

1. $\quad \mathrm{H}\left(\frac{\delta}{\mu},\left|\frac{\alpha}{\mu}\right|\right) \ldots \ldots \ldots . \ldots . \ldots . . \ldots 84$ 
THIS PAGE

\section{WAS INTENTIONALLY \\ LEFT BLANK}




\section{ACKNOWLEDGEMENTS}

The authors wish to express gratitude to G. S. Hurst, F. Gabbard, and W. R. Garrett for their support and useful discussions.

During the research work, one of the authors (CWC) received financial support through the Laboratory Graduate Participation Program of the Oak Ridge Associated Universities. 
THIS PAGE

\section{WAS INTENTIONALLY \\ LEFT BLANK}




\section{ABSTRACT}

Due to the development of high power tunable lasers, a series of interesting new laser interaction problems have emerged. These have to do with phenomena occurring when a high power pulsed laser is tuned near either a one-photon or a multiphoton resonance. In the latter situation, one finds that the time dependence of the a.c. Stark shifts and power broadening leads to several novel effects. For instance, Grischkowsky and Loy have shown that a strong pulsed laser tuned between the ground state and a two-photon resonance can lead to a nearly completely inverted population.

In the present work we have utilized two mathematical methods (one a form of adiabatic approximation, and the other closely related to the zener method from collision theory) in order to calculate the probability of threephoton ionization when strong counter propagating pulses are tuned very near a two-photon resonant state. In this case the inverted populations predicted by Grischkowsky and Loy for smooth laser pulses lead to larger ionization probabilities than would be obtained for a square pulse of equal peak power and energy per pulse. The line shape of the ionization probability is also quite unusual in the above problem. A sharp onset in the ionization probability occurs 
as the lasers are tuned through the exact unperturbed twophoton resonance. Under proper conditions, the change can be from a very small value to one near unity. It occurs in a very small frequency range determined by the larger of the residual Doppler effect and the reciprocal duration of the pulse. Thus, the line shape retains a Doppler-free aspect even at power levels such that power broadening would dwarf even the full Doppler etfect in the case of a square pulse of equal energy and peak power. The same mathematical methods have been used to calculate line shapes for the. twophoton excitation of fluorescence when the atoms see a pulsed field due to their time of passage across a tightly focused cw laser beam. Thus, the mathematical methods used above permitted accurate analytical calculations under a set of very interesting conditions.

We have also utilized one of the mathematical methods in order to treat two-photon ionization by a pulsed laser tuned near a resonance transition. These works are believed to represent the first nonperturbational treatment of multiphoton ionization due to a pulsed laser tuned near a one-photon or multiphoton resonance. 


\section{CHAPTER I}

\section{INTRODUCTION}

In recent years lasers have been applied in many fields of physics, particularly in atomic physics and precision spectroscopy. ${ }^{1-9}$ In addition, there have been many suggestions as to how to use lasers for isotope separation. 10-13 other applications of lasers have been suggested ${ }^{14-15}$ and demonstrated, 16 and numerous theoretical studies ${ }^{17-20}$ have been devoted to the use of $\mathrm{cW}$ lasers for these applications.

Our present work involves theoretical estimation of photoionization probability and fluorescence due to tunable pulsed lasers, and the development of mathematical methods which enable us to approach the problems with considerable ease. We find that by using proper pulse shapes and high power levels it is possible to enhance photoionization probabilities of atoms or molecules approximately $100 \%$ in comparison with the case of using square pulses with identical energy per pulse, resulting in superior efficiency (see Figs. 3 and 4 ). In addition to higher efficiency, we will. show that, in some cases, there is higher selectivity when smooth pulses are used for near resonance multiphoton processes due to a sharp onset of the process at the unperturbed resonance which is totally masked at such power levels with Cw lasers because of power broadening. In some cases 
it is possible to have a photoionization probability of unity with existing high power lasers (see Figs. 3 and 12). Some ${ }^{21-24}$ have studied the case with $\mathrm{cw}$ lasers, but there has been no thorough understanding of the effect of the pulses with time-dependent amplitude until our present studies.

In addition, we dso emphasize the experimental applications in the production of very short but intense pulses of metastable atoms for crossed beam scattering experiments employing abrupt change of pulse amplitude, and in the lifetime measurement of excited states by way of the time-gating technique. Using a similar saturated photoionization concept, Hurst et al. ${ }^{16}$ have developed and demonstrated a one-atom detection technique.

Considerable effort has been devoted to verification, through the use of a computer, of the validity of our "Factorization Method," which is simple but powerful in solving a set of coupled differentlal equations. We have also applied a mathematical technique which we call the "Method of Isolated Curve Crossings" to laser-atom interaction problems. The latter method is mathematically equivalent to zener's method ${ }^{25}$ from collision theory. The Factorization Method and the Method of Isolated Curve Crossings complement each other such that many pulsed laseratom interactions can be dealt with by applying one of these methods. 
CHAPTER II

\section{MATHEMATICAL METHODS FOR LASER-MATTER \\ INTERACTION PROBLEMS}

\section{A. The Factorization Method}

We begin by describing a non-perturbative method for solving the time dependent Schrödinger equation, in cases where the problem reduces to one for a system with a finite basis of state functions. For simplicity, we restrict the discussion to the case where a two-state description is a good approximation. The problems that we will discuss later will show that this simplification is not as restrictive as it first seems.

As we shall see later, many interesting problems involving either collisions or the interaction of a powerful laser pulse with a low density gas involve the solution of a special case of the following set of differential equations:

$$
\begin{gathered}
\frac{d a_{0}}{d t^{\prime}}=i u(t) e^{i q(t)} a_{2}, \\
\frac{d a_{2}}{d t}=-\gamma(t) a_{2}+i u^{*}(t) e^{-i q(t)} a_{0} .
\end{gathered}
$$


In Eqs. (1) we shall assume that $q(t)$ and $\gamma(t)$ are real and that

$$
\begin{aligned}
& \frac{d g}{d t}=\delta+\alpha_{01} g\left(s_{1} t\right)+\alpha_{02} g^{2}(s, t)+\alpha_{03} f^{2}\left(s_{2} t\right), \\
& Y(t)=\alpha_{11} g\left(s_{1} t\right)+\alpha_{12} g^{2}\left(s_{1} t\right)+\alpha_{13} f^{2}\left(s_{2} t\right)+r_{2} / 2, \\
& u(t)=\alpha_{21} g\left(s_{1} t\right)+\alpha_{22} g^{2}\left(s_{1} t\right)+\alpha_{23} g\left(s_{1} t\right) f\left(s_{2} t\right),
\end{aligned}
$$

where $s_{1}$ and $s_{2}$ are small positive numbers having units of frequency, the $\alpha_{i j}$ 's are constants having units of frequency, and $g(x)$ and $f(x)$ are smooth functions having a single maximum of unit magnitude at $x=0$ while dropping off monotonically to zero at $x= \pm \infty$. An example of a suitable $g(x)$ and $f(x)$ is $\left[1+x^{2}\right]^{-n}, n \geq 1$.

Typisally, in a laser interastion problem, $a_{0}$ and $a_{2}$ would be probability amplitudes for being in states $|0\rangle$ and $|2\rangle$ at $t, \delta$ would represent an amount of detuning in frequency from a resonance by the laser pulse, $u(t)$ is a laser or collision (or both) induced coupling term and $\gamma(t)$ is partly a rate of collision or laser-induced ionization or dissociation out of state $|2\rangle$ and partly $\left(i . e ., \gamma_{2} / 2\right)$ spontaneous emission. The remainder of $\mathrm{dq} / \mathrm{dt}$ would usually represent a frequency detuning effect due either to collisional interaction or a.c. Stark shift. We will not 
be more precise about physical interpretation at this point since examples where Eqs. (1) arise will be discussed in later chapters.

We will now discuss the solution of Eqs. (1) subject to the initial conditions $a_{0}(-\infty)=1, a_{2}(-\infty)=0$. We proceed by eliminating $a_{0}(t)$ as follows:

$$
\frac{d^{2} a_{2}}{d t^{2}}+F_{1}(t) \frac{d a_{2}}{d t}+F_{2}(t) a_{2}=0,
$$

where

$$
\begin{gathered}
F_{1}(t)=\gamma(t)-\frac{d}{d t} \ln u^{\star}(t)+i \frac{d q}{d t}, \\
F_{2}(t)=\frac{d \gamma}{d t}(t)-\gamma(t) \frac{d}{d t} \ln u^{\star}(t)+i \gamma(t) \frac{d q}{d t}+|u(t)|^{2}
\end{gathered}
$$

As mentioned earlier, we want to solve in a way that takes full advantage of the fact that $S_{1}$ and $S_{2}$ are very small. Depending on the problem being investigated, $s_{1}^{-1}$ and $s_{2}^{-1}$ are either related to a time of collision or to the length of the laser pulse. Thus, the method would apply to laser interaction problems with long smooth amplitudes for the laser field or to slow collisions.

With very small $S_{1}$ and $S_{2}$ the functions $F_{1}(t)$ and $F_{2}(t)$ are slowly varying functions of $t$ with $F_{2}( \pm \infty)=$ 
$i \gamma_{2} \delta / 2^{\prime}$ and $F_{1}( \pm \infty)=i \delta+\gamma_{2} / 2$. Both are generally complex numbers. We want to take advantage of the slow variation of $F_{1}$ and $F_{2}$ with $t$. To do this, we write

$$
\left(\frac{d}{d t}+g_{1}\right)\left(\frac{d}{d t}+g_{2}\right) a_{2}=0,
$$

where $g_{1}$ and $g_{2}$ must satisfy

$$
g_{1}+g_{2}=F_{1}(t)
$$

$$
\frac{d g_{2}}{d t}+g_{1} g_{2}=F_{2}(t) .
$$

One scheme for finding $a_{2}$ is immediately obvious. In the limit of exactly constant $F_{1}$ and $F_{2}$ (or in the limit $s_{1}+0$ and $\left.s_{2}+0\right), g_{1}$ and $g_{2}$ Eatiofy $\left(g_{10}(\ldots)=i \delta, y_{20}\right.$ $\left.(-\infty)=\frac{\gamma_{2}}{2}\right)$

$$
\begin{aligned}
& g_{10}+g_{20}=F_{1}(t), \\
& g_{10} g_{20}=F_{2}(t) .
\end{aligned}
$$

Thus, when $s_{1}$ and $s_{2}$ are very small, but not zero, the true $g_{1}$ and $g_{2}$ are expected to be close to $g_{10}$ and $g_{20^{\circ}}$ We let 


$$
\begin{aligned}
& g_{1}=g_{10}+\varepsilon_{1}, \\
& g_{2}=g_{20}+\varepsilon_{2} .
\end{aligned}
$$

and find

$$
\varepsilon_{1}=-\varepsilon_{2}
$$

and

$$
\frac{d \varepsilon_{2}}{d t}+\left(g_{10}-g_{20}\right) \varepsilon_{2}-\varepsilon_{2}^{2}=-\frac{d g_{20}}{d t} .
$$

Now, $g_{20}$ depends only on $s_{1} t$ and $s_{2} t$ and should yield a small $d g_{20} / d t ;$ also, $d \varepsilon_{2} / d t$ and $\varepsilon_{2}^{2}$ are expected to be of even higher degree of smallness. The situation is suggestive of a rapidly converging iterative method. Take the zeroth iterate of $\varepsilon_{2}\left(i . e ., \varepsilon_{2,0}\right)$ to be zero; then the $n+1$ iterate, $\varepsilon_{2, n+1}$, satisfies

$$
\varepsilon_{2, n+1}=-\frac{\mathrm{dg}_{20} / \mathrm{dt}}{\mathrm{g}_{10}-\mathrm{g}_{20}}+\frac{\left[\varepsilon_{2, \mathrm{n}}\right]^{2}-\mathrm{d} \varepsilon_{2, \mathrm{n}} / \mathrm{dt}}{g_{10}-g_{20}} .
$$

Typically, one or two iterations are sufficient if

$$
s_{1} / \delta \leqslant 0.1 \text { and } s_{2} / \delta \leqslant 0.1 \text {, }
$$


assuming that $\left|\sum_{i} \alpha_{0 i}\right|$ is order of $\left|\sum_{i} \alpha_{2 i}\right|$. This condition can be relaxed a bit if the $\alpha_{i j}$ 's are very large compared with $\delta$; but, typically, to achieve convergence at all $t$, one cannot deviate far from Eq. (11). If Eq. (11) is satisfied, the method is valid for large or intermediate $\alpha_{i j}$ with greater accuracy being attained with large $\alpha_{i j}$. Once $g_{1}$ and $g_{2}$ are known, we let

$$
\frac{d a_{2}}{d t}+g_{2} a_{2}=z(t)
$$

and $f$ ind

$z(t)=i u^{*}(t) e^{-i q(-\infty)} \exp \left[\int_{-\infty}^{t}\left(g_{l}\left(t^{\prime}\right)+\frac{d}{d t^{\top}} \ln u^{*}\left(t^{\prime}\right)\right) d t^{\prime}\right]$.

Thus,

$$
\begin{aligned}
& a_{2}(t)=i e^{-i q(-m)} \exp \left[-\int_{-\infty}^{t} g_{2}\left(t^{\prime \prime}\right) d t^{\prime \prime}\right] \int_{-\infty}^{t} u^{\star}\left(t^{\prime}\right) d t^{\prime} \\
& \times \exp \left[\int^{\prime}\left(g_{2}\left(t^{\prime \prime}\right)-g_{1}\left(t^{\prime \prime}\right)-\frac{d}{d t^{\prime \prime}} \ln u^{*}\left(t^{\prime \prime}\right)\right) d t^{\prime \prime}\right] .
\end{aligned}
$$

If $t$ is not extremely large and positive, the same conditions which make valid the method used to find $g_{1}$ and $g_{2}$ 
allow the approximate evaluation of $a_{2}(t)$ :

$$
\begin{aligned}
& \left|a_{2}(t)\right|^{2}=|u(t) / D(t)|^{2} \exp \left[2 \operatorname{ReY}_{1}(t)\right] \quad \text { if } \delta \neq 0, \\
& \left|a_{2}(t)\right|^{2}=|u(t)|^{2}\left|\exp \left[Y_{1}(t)\right] / D(t)-\exp \left[Y_{2}(t)\right] / D(-\infty)\right|^{2} \\
& \text { for all } \delta,
\end{aligned}
$$

where

$$
\begin{aligned}
& D(t)=g_{20}(t)-g_{10}(t), \\
& Y_{1}(t)=-\int_{-\infty}^{t}\left[g_{1}\left(t^{\prime}\right)+\frac{d}{d t} \ln u^{*}\left(t^{\prime}\right)\right] d t^{\prime}, \\
& Y_{2}(t)=-\int_{-\infty}^{t}\left[g_{2}\left(t^{\prime}\right)+\frac{d}{d t} \ln u^{*}\left(t^{\prime}\right)\right] d t^{\prime} .
\end{aligned}
$$

Equations (15) are particularly useful when they are a probability of an ionization or a dissociation that is desired and $\gamma_{2}=0$. In such a case, one desires $1-\left|a_{0}\right|^{2}-\left|a_{2}\right|^{2}$, and Eqs. (1) imply

$$
\begin{gathered}
-\int_{-\infty}^{\infty}\left(a_{0}^{*} \frac{d a_{0}}{d t^{\prime}}+a \frac{d a_{0}^{*}}{d t^{\prime}}+a_{2}^{*} \frac{d a_{2}}{d t^{\prime}}+a_{2} \frac{d a_{2}^{*}}{d t^{\prime}}\right) d t^{\prime} \\
=1-\left|a_{0}(\infty)\right|^{2}-\left|a_{2}(\infty)\right|^{2}=2 \int_{-\infty}^{\infty} \gamma(t)\left|a_{2}\left(t^{\prime}\right)\right|^{2} d t^{\prime}, \\
\equiv R .
\end{gathered}
$$


Thus, one only needs $\left|a_{2}(t)\right|^{2}$ while $\gamma(t)$ is large; consequently, Eqs. (15) are adequate for calculating R. It should be noted that $\left|a_{2}(\infty)\right|^{2}$ cannot be calculated from Eqs. (15) since Eqs. (15) predict zero, while the remainder integral that is neglected in integrating by parts is not zero and is consequently no longer negligible. In evaluating Eq. (14). or Eqs. (15), one does not need to integrate from the limiting value $-\infty$, but from the time when very small population changes begin to occur, $a_{0} \simeq 1$ and $a_{2} \simeq 0$. Of course, for the square pulse cases one needs to integrate only for the time span of the pulse duration. It should be noted that when $u(t) \rightarrow 0$, one can assume $\frac{F_{2}(t)}{F_{1}(t)} \simeq 0$, and Eq. (14) approaches the first urder tille-dependent perturbation rocult. The method described abuve will hereafter be dcrignated as the factorization method. It can be used (with more difficulty) in cases where there are more than two simultaneous equations and the equations are of a different form. For instance, it is very useful for obtaining solutions of the equations for the density matrix elements in laser interaction problems.

The above method was first used by Payne 26 in connection with inelastic collisions that are switched by the presence of an intense laser beam. It was subsequently used by Payne and Nayfeh ${ }^{27}$ in connection with a scattering 
problem and the interaction of a laser pulse with a twolevel atom.

\section{B. Method of Isolated Curve Crossings}

We describe here a method that is closely analogous to the Landau-zener method ${ }^{25}$ in scattering theory. At the time that most of the work described here was done the method had not been used in connection with laser interaction problems. However, in a recent work $\mathrm{Lau}^{28}$ has used the method to predict the transition probability for two photon excitation of the $\mathrm{Na}(3 \mathrm{~s}) \rightarrow \mathrm{Na}(5 \mathrm{~s})$ transition. In a later chapter we will use the method to solve another laser interaction problem.

In this case we desire a solution to the equations

$$
\begin{gathered}
\frac{d a_{0}}{d t}=i \alpha F(t) e^{i \phi(t)} a_{2} \\
\frac{d a_{2}}{d t}=-\gamma(t) a_{2}+i \alpha^{\star} F(t) e^{-i \phi(t)} a_{0^{\prime}}
\end{gathered}
$$

where

$$
\phi(t)=-\mu \int_{-\infty}^{t} h\left(t^{\prime}\right) d t^{\prime}+\delta t,
$$

and $F(t)$ as well as $h(t)$ are slowly varying functions which 
satisfy $F\left( \pm^{\infty}\right)=h\left( \pm^{\infty}\right)=0$. Both $F(t)$ and $h(t)$ are real, positive and continuous functions having a single maximum of unit amplitude at $t=0$. However, $F(t)$ and $h(t)$ need not be symmetric about $t=0$. We assume $a_{0}(-\infty)=1$ and $a_{2}(-\infty)=0$.

We deal here with situations where $\tau_{m}$ is a measure of the smalier full width at half maximum of $\bar{F}(t)$ and $h(t)$ and $|\mu| \tau_{m}>1$ where $\mu$ is a real quantity having units of angular frequency. It is typically a measure of the maximum detuning due to the a.c. Stark shifts or, in collision problems, of the detuning due to the atom-atom interaction. When $|\alpha / \mu|<1 \quad\left(|\alpha|^{-1}\right.$ is a measure of the shortest time over which $a_{0}$ or $a_{2}$ can change appreciably), we see that, except for points where $\mu h(t) \simeq \delta, e^{i \phi(t)}$ will oscillate many times over a time $|\alpha|^{-1}$ so that no change in $a_{0}$ or $a_{2}$ can occur, even in cases where $|\alpha| \tau_{m}>1$. Consequentially, $a_{0}$ and $a_{2}$ change only at times very near $t_{01}$ and $t_{02}$, where these are the two solutions of

$$
\mu h(t)-\delta=0 ;
$$

of course, $t_{01}$ is negative and $t_{02}$ is positive. Thus, when $|\mu| \tau_{\mathrm{m}}>>1,|\alpha / \mu|<<1$, and $\delta$ is not too small, changes in $a_{0}$ and $a_{2}$ come from very short time intervals (compared with ${ }^{\prime} m^{\prime}$ about crossings which are isolated. The Landau-Zener 
method is then applicable. The factorization method would require that at points where $\mu h(t)-\delta=0$, the term $\alpha F(t)$ be large enough so that changes in $a_{0}$ and $a_{2}$ are saturated. However, in the present method, $\alpha$ can be rather small. Correspondingly, the factorization method does not require $|\alpha / \mu|<<1$ so that the two methods complement each other and enable one to solve a rather wide range of laser interaction problems involving high power pulses which vary smoothly with time.

With the assumptions $|\mu| \tau>>1$ and $|\alpha / \mu|<<1$, we expect that $\left|a_{0}\right|^{2}$ and $\left|a_{2}\right|^{2}$ remain 1 and 0 , respectively, until just before the negative time at which $\mu h(t)=\delta$. If $\delta$ is not of the same sign as $\mu$, such a point will not exist; and $\left|a_{0}\right|^{2}$ and $\left|a_{2}\right|^{2}$ will remain near 1 and 0 , respectively, throughout the pulse. If $\mu$ and $\delta$ are of the same sign, we can approximate near the negative time crossing by

$$
\begin{aligned}
& \frac{d a_{0}}{d v}=i \alpha_{1} e^{i \beta_{1} v^{2}} a_{2}, \\
& \frac{d a_{2}}{d v}=i \alpha_{1}^{\star} e^{-i \beta_{1} v^{2}} a_{0}
\end{aligned}
$$

where $\alpha_{1}=\alpha F\left(t_{01}\right) e^{i \phi\left(t_{01}\right)}, \beta_{1}=-\frac{\mu}{2} \frac{d h\left(t_{01}\right)}{d t}$, and $v=t-t_{01}$. 
Thus, to find $a_{0}$ and $a_{2}$ just after the first crossing we solve Eqs. (19) at $\mathrm{V} \rightarrow \infty$ using $\mathrm{a}_{0}(\mathrm{~V} \doteq-\infty)=1, \mathrm{a}_{2}(\mathrm{~V}=$ $-\infty)=0$. We have assumed that the time interval over which $a_{0}$ and $a_{2}$ change is so short that the damping (i.e. $-\gamma(t) a_{2}$ ) can be neglected during the crossing. In order to replace $F(t)$ by a constant and $h(t)$ by $h\left(t_{n .1}\right)+$ $\frac{d n\left(t_{01}\right)}{d t} v$ we must be able to choose a $\left|v_{m}\right|<\left|t_{01}\right|$ which satisfies $\left|2 \beta_{1} v_{m}\right| \gg\left|\alpha_{1}\right|$. The latter condition leads to $\left|\alpha_{1} / \mu\right| \ll\left|\frac{d h\left(t_{01}\right)}{d t} t_{01}\right|$, whici will be true for $|\alpha / \mu|<<1$ and $\left|\mu \tau_{m}\right| \gg 1$ until either $|\delta|$ becomes very many times smaller than $|\mu|$ or $\delta$ approaches $\mu$ and $t_{01}$ becomes too small.

We eliminate $a_{0}$ from Eqs. (19) and let

$$
a_{2}=U \exp \left(-\beta_{1} v^{2} / 2\right)
$$

and

$$
z=\left(2 \rho_{1}\right)^{1 / 2} \exp (-i \pi / 4) \cdot v_{i}
$$

then

$$
\frac{d^{2} u}{d z^{2}}+\left(i \frac{\left|\alpha_{1}\right|^{2}}{2 f_{1}}+\frac{1}{2}-\frac{z^{2}}{4}\right) u=0
$$

Eq. (22) has a general solution in terms of parabolic cylinder functions (Weber functions) $D_{n}(z)$, where 


$$
\frac{d^{2} D_{n}(z)}{d z^{2}}+\left(n+\frac{1}{2}-\frac{z^{2}}{4}\right) D_{n}(z)=0 .
$$

Applying the boundary conditions $\left|a_{2}(V=-\infty)\right|^{2}=0$ and $\left|a_{0}(v=-\infty)\right|^{2}=1$, we find the asymptotic solution ${ }^{25}$ $|U(V+\infty)|^{2}=1-\exp \left[-2 \pi\left|z_{1}\right|^{2}\right]$ where $\left|z_{1}\right|^{2}=\frac{\left|\alpha_{1}\right|^{2}}{2\left|\beta_{1}\right|}$. Thus, just after $t_{01}$ we have

$$
\left|a_{2}\right|^{2}=1-\exp \left[-2 \pi\left|z_{1}\right|^{2}\right]
$$

When $t_{01} \leq t \leq t_{0.2}$ we can neglect coupling between $a_{0}$ and $\mathrm{a}_{2}$ and

$$
\begin{gathered}
\frac{d a_{2}}{d t} \simeq-\gamma(t) a_{2}, \\
\left|a_{2}\right|^{2}=\left[1-\exp \left(-2 \pi\left|z_{1}\right|^{2}\right)\right] \exp \left[-2 \int_{t_{01}}^{t} \gamma\left(t^{\prime}\right) d t^{\prime}\right] .
\end{gathered}
$$

When $t$ approaches $t_{02}$ ' the values of $a_{0}$ and $a_{2}$ will start to change again and equations analogous to Eqs. (19) will apply • 
Then,

$$
\begin{aligned}
& \frac{d a_{0}}{d V}=i \alpha_{2} e^{i B_{2} v^{2}} a_{2}, \\
& \frac{d a_{2}}{d v}=1 \alpha_{2} e^{-i B_{2} V^{2}} a_{0},
\end{aligned}
$$

with $V=t-t_{02}, \alpha_{2}=\alpha F\left(t_{02}\right)$ exp $\left[i \phi\left(t_{02}\right)\right]$ and $\beta_{2}=-$ $\frac{\mu}{2} \frac{d h\left(t_{02}\right)}{d t}$. The relative phase of $a_{0}$ and $a_{2}$ at the second crossing is very sensitive to the exact details of the first crossing. Different pulses having nearly the same $\left|z_{1}\right|$ can lead to very different relative phases at the second crossing. Let $\left|a_{2}\left(t_{02^{-}}\right)\right|^{2}$ and $\left|a_{0}\left(t_{02^{-}}\right)\right|^{2}$ be values of $\left|a_{2}\right|^{2}$ and $\left|a_{0}\right|^{2}$ just before the second crossing. Averaging over pulses that are repeatable on $\left|\mathrm{z}_{1}\right|$, wut a bit different we find ró: $\left|a_{2}\right|^{2}$,just after the crossing

$$
\begin{aligned}
\left|a_{2}\left(t_{02}+\right)\right|^{2} & =\left|a_{0}\left(t_{02}-\right)\right|^{2}\left(1-e^{-2 \pi\left|z_{2}\right|^{2}}\right) \\
& +\left|a_{2}\left(t_{02}-\right)\right|^{2} e^{-2 \pi\left|z_{2}\right|^{2}},
\end{aligned}
$$

where $\left|z_{2}\right|^{2}=\left|\alpha_{2}\right|^{2} /\left(2\left|B_{2}\right|\right)$ and $\left|a_{2}\left(t_{02}-\right)\right|^{2}$ is determined from Eqs.(25) but $\left|a_{0}\left(t_{02^{-}}\right)\right|^{2}$ depends on the interpretation of $\gamma(t)$. (i.e., whether it repopulates the initial state or represents a loss). 
The considerations given above can be generalized considerably, but we have given all that will be needed for our application. 
CHAPTER III

DOPPLER-FREE CONTRIBUTION TO THREE-PHOTON

IONIZATION BY PULSED LASERS

A. INTRODUCTION

We consider an atom bathed in counter propagating laser beams of frequency $w_{1}^{\prime}$ and $w_{2}^{\prime}$. The laser beams are assumed to be pulsed with the counter propagating pulses at frequencies $w_{i}^{\prime}$ and $w_{2}^{\prime}$ overlapping in both space and time. The laser pulses are very monochromatic with the band width being limited entirely by the pulse length. A fairly tractable mathematical situation is obtained if the pulses are of nearly equal length with the timing being such that one pulse begins to arrive at the atom's location at about the same time as the other and if the peak power density is $\geq 10^{5} \mathrm{w} / \mathrm{cm}^{2}$ so that the laser field can be treated classically.*

The case where $w_{1}^{\prime}=w_{2}^{\prime}$ has been studied fairly extensively $y^{17-20}$ fur cw lasers in cases where $2 \hbar^{\prime}{ }_{1}^{\prime}$ is nearly equal to $E_{2}-E_{0}=n\left(w_{2}-w_{0}\right)$, with $E_{2}$ and $E_{0}$ being the energies of two levels of the atom which are connected by

"Semiclassical treatment is valid if $s \lambda^{3} / \mathrm{C} \gg 1$, where $\mathrm{C}$ is the speed of light and $S$ and $\lambda$ are the photon flux and the wave length of the laser field. J.J. Sakuri discusses more details in Ch. 2 of his Dook, Advanced Quantum Mechanics. 
an allowed two-photon transition. In such a case, two-photon absorption is dominated by a Doppler-free contribution in the region very near the two-photon resonance, providing (1) the lifetime of the upper state, ' ${ }_{2}$ ' is such that $\tau_{2}^{-1} \ll \bar{V} w_{1}^{\prime} / C ;(2)$ the peak power is sufficiently low that power broadening does not approach $\bar{v} w_{1}^{1} / C$. Intuitively, the reason for the Doppler-free contribution is obvious. By absorbing one photon going one direction and another going the opposite direction, the total energy intake by an atom of velocity $v_{\varepsilon}$ is $\simeq \hbar w_{1}^{\prime}\left(1-v_{\varepsilon} / C\right)+\hbar w_{1}^{\prime}\left(1+v_{\varepsilon} / C\right) \simeq 2 \hbar w_{1}^{\prime}$. Thus, if $2 \hbar w_{1}^{\prime}$ is very near the excitation energy, this process is resonant for any $\mathrm{V}_{\mathbf{z}}$. On the other hand, the absorption of photons with the same propagation direction leads to an energy mismatch $\simeq\left(v_{z} / C\right) 2 \hbar w_{1}^{\prime}$ which, for typical $V_{z}$, is sufficient to suppress the contribution unless power broadening or the line width due to the state's lifetime can overcome the energy defect.

If two lasers of frequencies $w_{1}^{\prime}$ and $w_{2}^{\prime}$ (such that $\left.w_{1}^{\prime}+w_{2}^{\prime}-\left(w_{2}-w_{0}\right) \simeq 0\right)$ are used, one achieves far greater versatility.7-8 Firstly, the coupling for a two-photon transition can be made far greater at a given power level by tuning $w_{1}^{\prime}$ to be rather near an intermediate state. Thus, a.c. stark shifts and two-photon transition rates can be large at moderate power without the necessity of an intermediate state lying almost exactly halfway between the initial and final 
states. Secondly, if the two laser beams propagate in opposite directions and $w_{1}^{\prime}$ and $w_{2}^{\prime}$ are different by at least a few percent, then the only resonant situation corresponds to absorbing one photon propagating in one direction and another propagating in the opposite direction. (Generally, absorption of two photons propagating in the same direction is far out of resonance.) In such a situation the only remaining Doppler shift for the two-photon transition is $\left|w_{1}^{\prime}-w_{2}^{\prime}\right| v_{\varepsilon} / c$, which is very small if $w_{1}^{\prime}$ and $w_{2}^{\prime}$ differ by only a few percent. In the present case we write the field in the general form

$$
\begin{aligned}
E(z, t) & =E_{1}(t) \cos \left(w_{1}^{\prime} t-k_{1} V_{z} t\right) \\
& +E_{2}(t) \cos \left(w_{2}^{\prime} t+k_{2} V_{z} t+B\right) .
\end{aligned}
$$

The Doppler-free aspect of both the one-laser and two-laser situations with counter-propagating beams was first recognized by Vasilenko et al. 5 In the two-laser beam case, Doppler effects can be neglected if (1) $\tau_{2}^{-1} \gg\left|w_{1}^{\prime}-w_{2}^{\prime}\right| \times$ $\left|\bar{v}_{\mathbf{z}}\right| / C ;$ (2) $\tau^{-1} \gg\left|w_{1}^{\prime}-w_{2}^{\prime}\right|\left|\bar{v}_{z}\right| / c$, where $\tau$ is laser pulse length; (3) a.c. Stark shifts or power broadening are large compared with the residual Doppler shift. The Doppler-free two-photon process has been studied experimentally by Levinson and Bloembergen, ${ }^{3}$ Biraben et al., 6 and others. ${ }^{4-5}$ In the present work we will assume counter-propagating beams. 
However, much of the present work will emphasize high power levels where the line widths for the two-photon process is larger than the full Doppler width. We will show that even in the above case, sharp features in the line shape remain which are characteristic of the near absence of Doppler effect.

The present work differs from other work by simultaneously taking into account the pulsed nature of the laser field (which is necessary if high power levels are to be reached) and the calculation of three-photon ionization in the neighborhood of a two-photon resonance. The ionization provides an extremely sensitive way to monitor the line shape of the two-photon transitions.

\section{B. STATEMENT OF MODEL}

The atom interacting with the highly monochromatic counter propagating laser pulses is assumed to be part of a very low density gas or vapor so that it can be considered isolated. We further assume that it has energy levels something like that shown in Fig. 1. In Fig. I the states $|0\rangle$ and $|2\rangle$ are assumed, for convenience, to be $s$ states and no p states are closer than a few hundreths of an electron volt to being in resonance for a one-photon transition driven by either pulse. In particular, $k w_{1}^{\prime}$ is most resonant for the transition $|0\rangle$ to $|p, j\rangle$, and $\hbar w_{2}^{\prime}$ is most resonant for a transition $|p, j\rangle$ to $|2\rangle$. Generally, only a few intermediate states $|p, j\rangle$ will dominate because, by choice, $w_{1}^{\prime}$ and $w_{2}^{\prime}$ are 


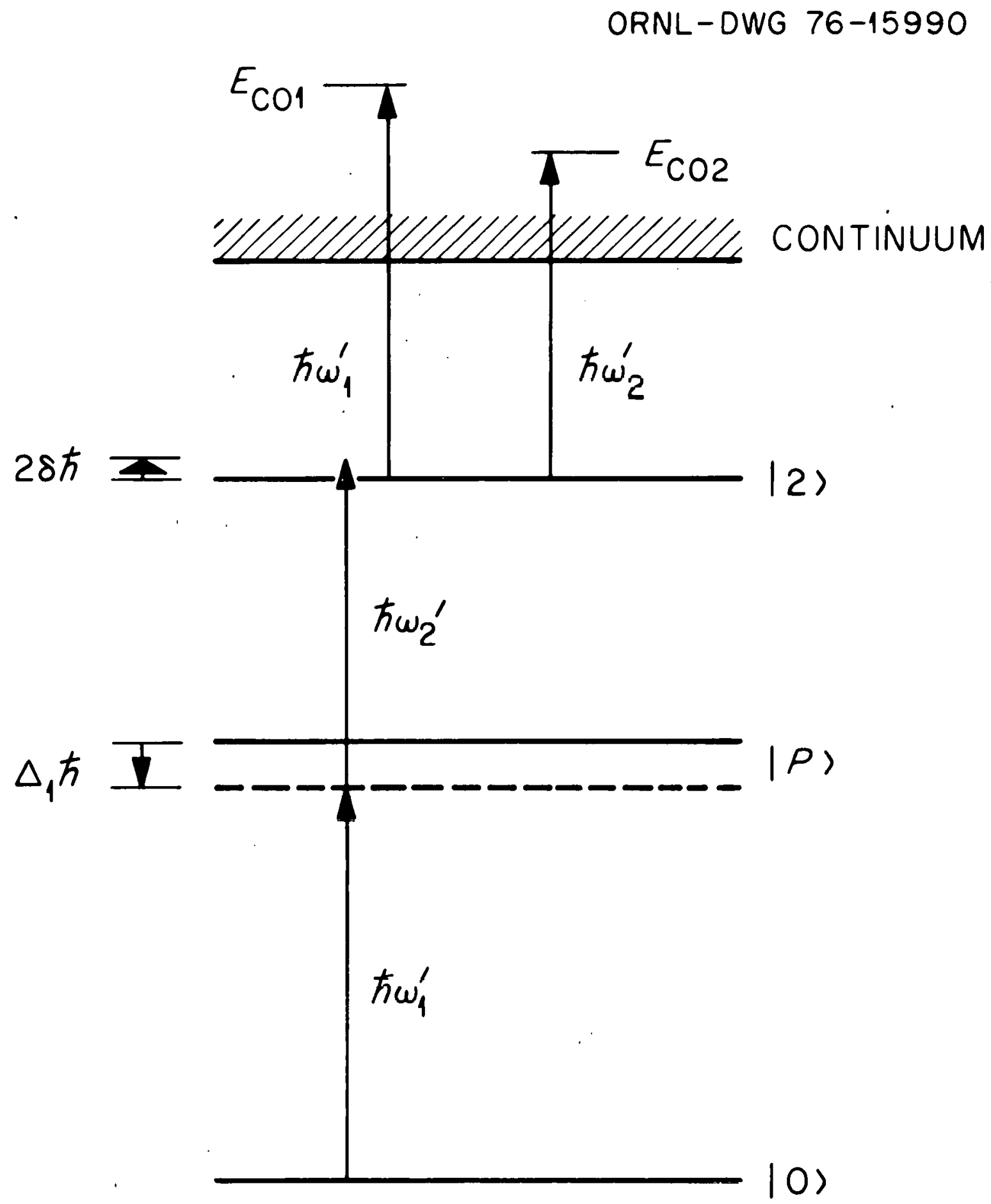

Figure 1. Energy Level Diagram, 3-Photon Transition with Lasers at $\mathrm{w}_{1}^{\prime}$ and $\mathrm{w}_{2}^{\prime}$. 
chosen to be rather close to resonance, but far enough away so that line broadening due to the state's lifetime or due to power broadening do not permit real transitions. We write the state vector of the atom as

$$
\begin{aligned}
|\psi(t)\rangle & =a(t) e^{-i w_{0} t}|0\rangle+a_{2}(t) e^{-i w_{2} t}|2\rangle \\
& +\sum_{j} a_{p, j}(t) e^{-i w_{p j} t}|p, j\rangle \\
& +\sum_{k} \int d E_{c} c_{p, k}\left(E_{c}, t\right) e^{-i w_{c} t}\left|E_{c}, k\right\rangle,
\end{aligned}
$$

where $|0\rangle,|2\rangle$, and $|p, j\rangle$ are all orthogonal discrete states and $\left|E_{c}, k\right\rangle$ is a continuum state. The continuum states are normalized so that.

$$
\left\langle E_{r^{\prime}}, k \mid E_{r^{\prime}}^{\prime}, k^{\prime}\right\rangle=\delta\left(E_{r}-E_{c}^{\prime}\right) \delta_{k, k^{\prime}}
$$

Assuming that the wavelength is very large compared with the size of the atom and treating the EM field classically, we have

$$
\hat{\mathrm{H}}=\hat{\mathrm{H}}_{0}-\hat{\mathrm{p}}_{\mathbf{X}} E(\mathbf{z}(t), t)-i \hbar \frac{\gamma_{2}}{2}|2><2| \text {. }
$$

In Eq. (31), $\hat{\mathrm{H}}_{0}$ is the electronic Hamiltonian of the isolated 
atom, $\hat{p}_{x}$ is the $x$-component of the electric dipole operator for the atom, $\gamma_{2}$ is the spontaneous decay rate of the state $|2\rangle$ (we treat this phenomenologically), $\mathbf{z}(t)$ is the $\mathbf{z}$ coordinate of the atom evaluated along a straight line classical path, and $|p, j\rangle$ are sufficiently far off resonance so that their spontaneous decay can be neglected (i.e., $\left|\Delta w_{j}\right|=$ amount $|p, j\rangle$ are off resonance satisfles $\left.\left|\Delta w_{j}\right| / \gamma_{p j} \gg 1\right)$. The laser fields are assumed to be plane polarized along the $x$-axis and pulses propagate parallel to the $\pm \mathbf{z}$ axis. Applying the time-dependent Schröinger equation to Eqs. (29) and (31) and keeping only the least rapidly oscillating coupling terms, we find

$$
\begin{aligned}
& \frac{d a_{0}}{d t}=\frac{i E_{l}(t)}{2 \pi} \sum_{j}\left\langle 0\left|p_{x}\right| p, j\right\rangle a_{p, j} e^{i\left(w_{0}-w_{p j}+w_{1}^{\prime}-k_{1} v_{z}\right) t} \\
& \left.\frac{d a_{p, j}}{d t}=\frac{i E_{1}(t)}{2 \hbar}<p, j\left|\hat{p}_{x}\right| 0\right\rangle e^{i\left(w_{p j}-w_{0}-w_{1}^{\prime}+k_{1} v_{z}\right) t} a_{0} \\
& \left.+\frac{i E_{2}(L)}{2 h}<p, j\left|\hat{p}_{x}\right| 2\right\rangle e^{i \beta} e^{i .\left(w_{p j}-w_{2}+w_{2}^{\prime}+k_{2} v_{z}\right) t} a_{2} \\
& \frac{d a_{2}}{d t}=\frac{i E_{2}(t)}{2 \hbar} \sum_{j}\left\langle 2\left|\hat{p}_{x}\right| p, j\right\rangle a_{p, j} e^{-i \beta} e^{-i\left(w_{p j}-w_{2}+w_{2}^{\prime}+k_{2} v_{z}\right) t}-\frac{\gamma_{2}}{2} a_{2} \\
& +i \sum_{k} \int d E_{c} E_{p, k}\left(E_{c^{\prime}}, t\right) \frac{\left\langle 2\left|\hat{p}_{x}\right| E_{c^{\prime}}, k\right\rangle}{2 h}\left[E_{1}(t) e^{-i\left(w_{c}-w_{2}=w_{1}^{\prime}+k_{1} v_{z}\right) t}\right. \\
& \left.+E_{2}(t) e^{i \beta} e^{-i\left(w_{c}-w_{2}-w_{2}^{\prime}-k_{2} V_{z}\right) t}\right],
\end{aligned}
$$




$$
\begin{aligned}
\frac{d C_{p, k}}{d t} & =i \frac{\left\langle E_{c^{\prime}} k\left|\hat{p}_{x}\right| 2\right\rangle}{2 \hbar} a_{2}\left[E_{1}(t) e^{i\left(w_{c}-w_{2}-w_{1}^{\prime}+k_{1} v_{z}\right) t}\right. \\
& \left.+E_{2}(t) e^{-i \beta} e^{i\left(w_{c}-w_{2}-w_{2}^{\prime}-k_{2} v_{z}\right) t}\right] .
\end{aligned}
$$

In the above equations it is important to reemphasize that the states $|p, j\rangle$ include only those which are rather close to resonance for allowed dipole transitions driven between $|0\rangle$ and $|p, j\rangle$ by the laser at $w_{1}^{\prime}$, and that these states are much farther from resonance for the laser at $w_{2}^{\prime}$. Further, such states must not exist for the transition $|0\rangle$ to $\left|p, j^{\prime}\right\rangle$ for the laser at $w_{2}^{\prime}$. Similar comments apply to the laser at $w_{2}^{\prime}$ being much closer to resonance for the transition $|p, j\rangle$ to $|2\rangle$. Without these restrictions, other intermediate states must be included and both $E_{1}(t)$ and $E_{2}(t)$ must couple $|0\rangle$ to $|p, j\rangle$ and $|p, j\rangle$ to $|2\rangle$. Further, the rotating wave 29 approximation used above must be refined to generate more accurate a.c. Stark shifts. We will now show how Eqs. (32) can be simplified. Let $\Delta_{1 j}=-w_{p j}+w_{0}+w_{1}^{\prime}-k_{1} v_{z^{\prime}} \Delta_{2 j}=-w_{p j}+w_{2}-w_{2}^{\prime}-k_{2} v_{z}$ and integrate the second of these equations

$$
\begin{aligned}
a_{p, j} & =\frac{i}{2 \hbar}\left\langle p, j\left|\hat{p}_{x}\right| 0\right\rangle \int_{-\infty}^{t} E_{1}\left(t^{\prime}\right) a_{0}\left(t^{\prime}\right) e^{-i \Delta} 1 j^{t^{\prime}} d t^{\prime} \\
& \left.+\frac{i}{2 \hbar}<p, j\left|\hat{p}_{x}\right| 2\right\rangle e^{i \beta} \int_{-\infty}^{t} E_{2}\left(t^{\prime}\right) a_{2}\left(t^{\prime}\right) e^{-i \Delta} 2 j^{t^{\prime}} d t^{\prime} .
\end{aligned}
$$


If we assume that $\Delta_{m}$ (the smaller of $\left|\Delta_{1 j}\right|$ and $\left|\Delta_{2 j}\right|$ ) is much greater than $E_{1}(t) \sum_{j}\left|\left\langle 0\left|\hat{p}_{x}\right| p, j\right\rangle\right|(2 \pi)^{-1}, \gamma_{2}, \tau^{-1}$, $E_{2}(t) \sum_{j}|<2| \hat{p}_{x}|p, j\rangle \mid(2 \pi)^{-1}$, and $\sum_{k} \int d E_{c}|<2| \hat{p}_{x}\left|E_{c}, k>\right|\left[E_{1}(t)+\right.$ $\left.E_{2}(t)\right](2 \pi)^{-1}$, then we also have $\Delta_{m} \gg\left|\frac{d}{d t} \operatorname{lna} a_{0}\right|,\left|\frac{d}{d t} \operatorname{lna} a_{2}\right|$, $\left|\frac{d}{d t} \ln E_{1}(t)\right|$ and $\left|\frac{d}{d t} \ln E_{2}(t)\right|$. Thus, we can do the time integrations by parts and neglect the remaining integrals:

$$
\begin{aligned}
a_{p, j}(t)= & -\frac{\left\langle p, j\left|\hat{p}_{x}\right| 0\right\rangle}{2 \hbar \Delta \Delta_{1 j}} E_{1}(t) e^{-i \Delta_{1 j} t} a_{0}(t) \\
& -\frac{\left\langle p, j\left|\hat{p}_{x}\right| 2\right\rangle}{2 \hbar \Delta \Delta_{2 j}} E_{2}(t) e^{-i\left(\Delta_{2 j} t-\beta\right)} a_{2}(t) .
\end{aligned}
$$

Thus, all of the $a_{p j}(t)$ can be eliminated, leaving a set of equations for $a_{0}, a_{2}$, and $c_{p k}$. If the continumm malrix elements $\left\langle E_{C}, k\left|\hat{p}_{X}\right| 2\right\rangle$ vary so slowly with $E_{C}$ that they are highly constant over a region of energy $2 \Delta \mathrm{E}$ such that $\Delta E / \mathfrak{h}=\Delta_{m}$, we can eliminatc the $C_{p k}$. We note

$$
\begin{aligned}
c_{p, k}\left(E_{c^{\prime}} t\right) & =i \frac{\left\langle E_{c, k}\left|\hat{p}_{x}\right| 2\right\rangle}{2 \hbar} \int_{-\infty}^{t} a_{2}\left(t^{\prime}\right)\left[E_{1}\left(t^{\prime}\right) e^{i \Delta_{c 1} t^{\prime}}\right. \\
& \left.+E_{2}\left(t^{\prime}\right) e^{i\left(\Delta_{c 2} t^{\prime}-B\right)}\right] d t^{\prime},
\end{aligned}
$$

where $\Delta_{c 1}=w_{c}-w_{2}-w_{1}^{\prime}+k_{1} v_{z}, \Delta_{c 2}=w_{c}-w_{2}-w_{2}^{\prime}-k_{2} v_{z}$. If $E_{c}=\hbar w_{c}$ 
is such that both $\left|\Delta_{c l}\right|>\Delta E / h \equiv \Delta$ and $\left|\Delta_{c 2}\right|>\Delta$, we can integrate by part and find

$$
\begin{aligned}
c_{p, k}\left(E_{c}, t\right) & =\frac{\left\langle E_{c}, k\left|\hat{p}_{x}\right| 2\right\rangle}{2 \hbar} a_{2}(t)\left[\frac{E_{1}(t) e^{i \Delta_{c l} t}}{\Delta_{c l}}\right. \\
& \left.+\frac{E_{2}(t) e^{i\left(\Delta_{c 2} t-\beta\right)}}{\Delta_{c 2}}\right] .
\end{aligned}
$$

In either the interval $\left|\Delta_{c 1}\right| \leq \Delta$ or $\left|\Delta_{c 2}\right| \leq \Delta_{-}$, we can replace $\left\langle E_{c}, k\left|\hat{p}_{x}\right| 2\right\rangle$ by its value at the center of the interval and otherwise keep the integral form of Eq. (35). If we use the above simplifications in the third of Eqs. (32) and further assume $\left|w_{1}^{\prime}-w_{2}^{\prime}\right| \gg \Delta$, we can show that constancy of $\left.<E_{c}, k\left|\hat{p}_{x}\right| 2\right\rangle$ over $\left|\Delta_{c 1}\right| \leq \Delta$ and $\left|\Delta_{c 2}\right| \leq \Delta$ leads to a Dirac delta function contribution in the integration over these intervals, while the integration over $\mathrm{dE}_{c}$ outside these intervals leads to a principle value integration. After some algebra, we obtain ( $A_{0}$ differs only by a phase factor from $a_{0}$ and $A_{2}$ differs only by a phase factor from $a_{2}$ )

$$
\begin{aligned}
\frac{d A_{0}}{d t}= & i \Omega_{4}(t) A_{2}(t) \exp \left[i \int_{-\infty}^{t}\left(\Omega_{2}\left(t^{\prime}\right)-\Omega_{3}\left(t^{\prime}\right)+\Delta w\left(t^{\prime}\right)+2 \delta\right) d t^{\prime}\right], \\
\frac{d A_{2}}{d t}= & -\left(\frac{\gamma_{2}}{2}+p(t)\right) A_{2}+i \Omega_{4}^{*}(t) A_{0}(t) \\
& \times \exp \left[-i \int_{-\infty}^{t}\left(\Omega_{2}\left(t^{\prime}\right)-\Omega_{3}\left(t^{\prime}\right)+\Delta w\left(t^{\prime}\right)+2 \delta\right) d t^{\prime}\right]
\end{aligned}
$$


where

$$
\begin{aligned}
& P(t)=\left.\sum_{l=1}^{2} \frac{\pi E_{l}^{2}(t)}{4 \hbar} \sum_{k}|<2| \hat{p}_{x}\left|E_{c 0, \ell}, k\right\rangle\right|^{2}, \\
& \Delta w(t) \equiv \sum_{\ell=1}^{2} \frac{E_{l}^{2}(t)}{4 \hbar^{2}} \Gamma \int \frac{\sum_{k}\left|\left\langle E_{c}, k\left|\hat{p}_{x}\right| 2\right\rangle\right|^{2} d E_{c}}{\Delta_{c l}}, \\
& \Omega_{2}(t)=-\sum_{j} \frac{\left|\left\langle p, j\left|\hat{p}_{x}\right| 2\right\rangle\right|^{2} E_{2}^{2}(t)}{4 \hbar^{2} \Delta_{2 j}}, \\
& \Omega_{3}(t)=-\sum_{j} \frac{\left|\left\langle 0\left|\hat{E}_{x}\right| p, j\right\rangle\right|^{2} E_{1}^{2}(t)}{1 \hbar^{2} \Delta_{1 j}} \\
& \Omega_{4}(t)=-\sum_{j} \frac{\left\langle 0\left|\hat{p}_{x}\right| p, j\right\rangle\left\langle p, j\left|\hat{p}_{x}\right| 2\right\rangle}{4 \hbar^{2} \Delta_{2 j}} E_{1}(t) E_{2}(t) e^{i \beta}
\end{aligned}
$$

and

$$
2 \delta=w_{1}^{\prime}+w_{2}^{\prime}-w_{2}+w_{0}-\left(k_{1}-k_{2}\right) v_{z} \cdot
$$

The quantity $2 \hbar \delta$ is a measure of the excess energy available 
in the two-photon process. Of course, $\delta$ must be restricted so that the states $|p, j\rangle$ can be eliminated as described earlier. The quantity $p(t)$ represents a damping of the populations of $|0\rangle$ and $|2\rangle$ due to photoionization, $\Delta w(t)$ is an a.c. Stark shift due to coupling with continuum states, $\Omega_{2}(t)$ is the a.c. Stark shift of the state $|2\rangle$ due to the states $|p, j\rangle, \Omega_{3}(t)$ is the a.c. Stark shift of state $|0\rangle$ due to states $|p, j\rangle$ and $\Omega_{4}(t)$ is the two-photon coupling coefficient.

Except for the inclusion of photoionization by a pulsed laser the 3-level atom problem discussed above has been formulated and discussed by several authors. ${ }^{30-37}$ In particular if $\gamma_{2}$ and $p(t)$ are neglected even the pulsed nature of the field can be dealt with by using conventional adiabatic perturbation theory of the type used in atom-atom collisions. Much of the above work has been formulated in terms of the optical Bloch equations; which is equivalent to the schrödinger equation approach except for the possibility of including incoherent sources for the population, as well as collisional relaxation, by phenomenological parameters.

C. APPLICATION OF THE FACTORIZATION METHOD

In this section we will apply the factorization method described in Chapter II to three-photon ionization as described by Eqs. (37) . 


$$
\begin{aligned}
& E_{1}^{2}(t)=E_{10}^{2} g(t), \\
& E_{2}^{2}(t)=E_{20}^{2} g(t),
\end{aligned}
$$

where $g(t)$ is a smooth, slow varying function as described in Eq. (2). We then get

$$
\frac{d A_{0}}{d t}=i \alpha g(t) A_{2} \exp \left[i\left(2 \delta t-\mu \int_{-\infty}^{t} g\left(t^{\prime}\right) d t^{\prime}\right)\right],
$$

$$
\frac{d A_{2}}{d t}=-\left(\frac{\gamma_{2}}{2}+p_{0} g(t)\right) A_{2}+i \alpha^{\star} g(t) A_{0} \exp \left[-i\left(2 \delta t-\mu \int_{-\infty}^{t} g\left(t^{\prime}\right) d t^{\prime}\right)\right],
$$

where $\delta$ and $r_{2}$ are as defined earlier and

$$
\begin{aligned}
& \mu=-\sum \frac{\left.|\cdot 0| \hat{p}_{x}|p, j\rangle\right|^{2} E_{10}^{2}}{4 n^{2} \Delta_{i j}}+\sum_{j} \frac{\left|-p_{i} j\right| p_{x}|2 \cdot|^{2} E_{20}^{2}}{4 n^{2} \Delta_{2 j}} \\
& -\sum_{\ell=1}^{2} \frac{E^{2} \ell O}{4 \pi^{2}} \mathrm{p} \int \frac{\sum_{k}\left|<E_{c}, k\right| \hat{p}_{x}|2,|^{2} \mathrm{dE}_{c}}{\Delta_{c \ell}}, \\
& \alpha=-\tau, \frac{\left\langle 0\left|\hat{p}_{X}\right| p, j\right\rangle\left\langle p, j\left|\hat{p}_{X}\right| 2\right\rangle}{4 h^{2} \Delta_{2 j}} E_{10} E_{20} e^{i \beta}, \\
& P_{0}=\sum_{\ell=1}^{2} \frac{\pi E_{l 0}^{2}}{4 \pi} \sum_{k}\left|\left\langle 2\left|\hat{p}_{x}\right| E_{c 0, \ell}, k\right\rangle\right|^{2} \text {. }
\end{aligned}
$$

\# $\mathrm{P}_{0}$ is proportional to the photon flux of the laser field times photoionization cross section of the state $|2\rangle$. The cross section is, in general, order of $10^{-17} \mathrm{~cm}^{2}$ to 
If we let

$$
\begin{gathered}
\frac{d q}{d t}=2 \delta-\mu g(t), \\
u(t)=\alpha g(t), \\
\gamma(t)=\frac{r_{2}}{2}+p_{0} g(t),
\end{gathered}
$$

the factorization method is immediately applicable. We get

$$
\left(\frac{d}{d t}+g_{1}(t)\right)\left(\frac{d}{d t}+g_{2}(t)\right) A_{2}=0 \text {, }
$$

where

$$
\begin{gathered}
g_{1}+g_{2}=i(2 \delta-\mu g)-\frac{d}{d t} l n g+p_{o} g+\frac{r_{2}}{2}, \quad(42) \\
g_{1} g_{2}+\frac{d q_{2}}{d t}=|\alpha|^{2} g^{2}+i(2 \delta-\mu g)\left(p_{0} g+\frac{\gamma_{2}}{2}\right)-\frac{\gamma_{2}}{2} \frac{d}{d t} l n g .
\end{gathered}
$$

We choose: $g_{1}=g_{10}+\varepsilon_{1}, g_{2}=g_{20}+\varepsilon_{2}$, where we have defined

$$
g_{10}+g_{20}=i(2 \delta-\mu g),
$$

$$
g_{10} g_{20}=|a|^{2} g^{2} \text {. }
$$


We obtain

$$
\begin{aligned}
& g_{10}=\frac{i(2 \delta-\mu g)+i \varepsilon J}{2}, \\
& g_{20}=\frac{i(2 \delta-\mu g)-i \varepsilon j}{2},
\end{aligned}
$$

where

$$
J=\sqrt{(2 \delta-\mu g)^{2}+4|\alpha|^{2} g^{2}},
$$

and

$$
\varepsilon=\delta /|\delta| \text {. }
$$

Intuitively, we expect that if $g(t)$ is a very slowly varying function of time and if $|\alpha|$ is large then $\varepsilon_{1}$ and $\varepsilon_{2}$ can be treated as small slowly varying function of time. Thus, neglecting $\varepsilon_{1} \varepsilon_{2}$ and $d \varepsilon_{2} / d t$ compared with $g_{10} \varepsilon_{2} \cdot g_{20} \varepsilon_{1}$ and $\mathrm{dg}_{20} / \mathrm{dt}$ we find

$$
\begin{aligned}
\varepsilon_{2}= & \left(\frac{r_{2}}{2}+p_{0} g\right)\left[\frac{1}{2}+\frac{\varepsilon(2 \delta-\mu g)}{2 J}\right]+\frac{1}{2} \frac{d}{d t} \ell n J \\
& +\left[\frac{|\delta|}{J}-\frac{1}{2}+i \frac{\varepsilon \gamma_{2}}{2 J}\right] \frac{d}{d t} l n g,
\end{aligned}
$$


$\varepsilon_{1}=\left(\frac{\gamma_{2}}{2}+p_{o} g\right)\left[\frac{1}{2}-\frac{(2 \delta-g)}{2 J}\right]-\frac{1}{2} \frac{d}{d t} \ln J-\left[\frac{|\delta|}{J}+\frac{1}{2}+\frac{i \varepsilon \gamma_{2}}{2 J}\right] \frac{d}{d t} \operatorname{lng}$.

The above method is not exactly equivalent to the iterative scheme described in Chapter II, but it is more convenient for analytical work.

The expressions obtained for $g_{1}$ and $g_{2}$ by using $g_{10}$ ' $g_{20}$ and our approximate values of $\varepsilon_{1}$ and $\varepsilon_{2}$ are not always accurate. The most severe restrictions are related to obtaining accurate $g_{1}$ and $g_{2}$ functions when $g(t)$ is small or when $t$ is near a value at which $2 \delta=\mu \mathrm{g}$. In order to obtain accuracy when $g(t)$ is small, we must restrict $\delta$ such that

$$
|\delta| \tau>10
$$

where $\tau$ is the full width at half maximum of $g(t)$. The condition $|\delta| \tau>10$ is not obvious, but its enforcement yields excellent accuracy in a large variety of numerical examples. The approximate $g_{1}$ and $g_{2}$ functions are accurate near times such that $2 \delta=\mu g$, providing that at these times

$$
\begin{aligned}
& \frac{|\mu|}{2|\alpha|^{2}} g^{-2}(t) \frac{d g}{d t} \ll 1 \\
& \left|P_{0} / \alpha\right| \ll 1,
\end{aligned}
$$

and

$$
\frac{\gamma_{2}}{|\alpha| g(t)} \ll 1
$$


The above conditions arise because it is obvious that when $2 \delta=\mu g$, unless $|\alpha| g$ is large, the values of $g_{10}$ and $g_{20}$ will become small, while $\varepsilon_{1}$ and $\varepsilon_{2}$ take on their largest values. Thus, the expressions are obtained by requiring that the neglected terms $\varepsilon_{1} \varepsilon_{2}$ and $d \varepsilon_{2} / d t$ be small compared with $g_{10} \varepsilon_{2}, g_{20} \varepsilon_{1}$ and $\mathrm{dg}_{20} / \mathrm{dt}$ which were retained. Thus, if $|\mu| \tau \gg 1,|\alpha| \tau \gg 1,|\alpha| / \gamma_{2} \gg 1,\left|\alpha / \mathrm{P}_{0}\right| \gg 1$ and $|\delta| \tau>10$, we will obtain accurate solutions as long as $|\delta|$ does not become so small that the validity conditions fail or unless $|\alpha / \mu|$ is very small. Very crudely, we can rewrite conditions $(46)$ as

$$
\begin{aligned}
& 2|\alpha / \mu|^{2}\left|\mu_{1} \tau\right|=4\left|\frac{\alpha}{\mu}\right|^{2}|\delta \tau|>1, \\
& \left|P_{0} / \alpha\right| \ll 1,
\end{aligned}
$$

and

$$
\gamma_{2} /\left|\alpha_{1}\right| \ll 1
$$

where $t_{0}$ is a time such that $2 \delta=\mu g\left(t_{0}\right),\left|\alpha_{1}\right|=|\alpha| g\left(t_{0}\right)$, and $\left|\mu_{1}\right|=|\mu| g\left(t_{0}\right)$. Conditions (45) and (47) are sufficient for all times as long as (47) is satisfied at all "crossings." The validity equations all indicate that the results apply to long pulses and very high power levels. However, we shall 
see later that the power levels and pulse lengths are easily available with present nitrogen laser pumped dye lasers. Further, the factorization method enables one to calculate accurately almost all of the lineshape for ionization.

After applying Eqs. (15) of Chapter II we find

$$
\begin{aligned}
& \left|A_{2}(t)\right|^{2}=\left[1 / 2-\frac{\varepsilon(2 \delta-\mu g)}{2 J}\right] \\
& \times \exp \left[-2 \int_{-\infty}^{t}\left(\frac{r_{2}}{2}+p_{0} g\left(t^{\prime}\right)\right)\left(\frac{1}{2}-\frac{\varepsilon\left(2 \delta-\mu g\left(t^{\prime}\right)\right)}{2 J\left(t^{\prime}\right)}\right) d t^{\prime}\right], \\
& =\left|A_{20}(t)\right|^{2} \exp \left[-2 \int_{-\infty}^{t}\left(\frac{r_{2}}{2}+p_{0} g\left(t^{\prime}\right)\right)\left|A_{20}\left(t^{\prime}\right)\right|^{2} d t^{\prime}\right],(48)
\end{aligned}
$$

whero

$$
\left|\mathrm{A}_{20}(t)\right|^{2}=\frac{1}{3}-\varepsilon(2 \delta-\mu g)(2 \mathrm{~J})^{-1} \text {. }
$$

$\left|A_{20}(t)\right|^{2}$ is the probability of the upper resonance state being populated at time $t$ in the absence of spontaneous decay or photoionization. $\left|A_{20}(t)\right|^{2}$ has some very interesting properties that are worth pointing out. We write Eq. (49) as

$$
\left|A_{20}(t)\right|^{2}=\frac{1}{2}-\frac{\varepsilon^{\prime}\left(\frac{2 \delta}{\mu}-g\right)}{2 \sqrt{\left(\frac{2 \delta}{\mu}-g\right)^{2}+4\left|\frac{\alpha}{\mu}\right|^{2} g^{2}}},
$$


where $\varepsilon^{\prime}=\delta \mu /|\delta \mu|$. From the last equation we see that if $\left|\frac{\alpha}{\mu}\right|^{2} \leq 0.1$ then $\left|A_{20}(t)\right|^{2}$ remains small at all times if $\delta / \mu<0$; but that when $\delta / \mu>0$ it remains zero until the first "crossing" (i.e., $2 \delta=\mu g)$, then rapidly rises to a value near unity until the second crossing where it falls again to a value near zero. Thus, for reasonably small values of $\delta$ a large population inversion is induced and it peraists for a large portion of the pulse. When $|\alpha / \mu|^{2}$ is near unity a population inversion still exists for $\delta / \mu>0$ but it is smaller.

In order to calculate $R$, the probability of an atom being ionized, we use

$$
R=\int_{k}\left|c_{p, k}\left(E_{c, \infty}\right)\right|^{2} d E_{c}
$$

$\left.C_{p, k}{ }^{(E}{ }_{c}, t\right)$ was eliminated, but we can return to the initial coupled equations and with the same requirements for elimination of $c_{p, k}\left(z_{c}, L\right)$ show Lhal

$$
\begin{gathered}
R=2 p_{0} \int_{-\infty}^{\infty} g(t)\left|A_{2}(t)\right|^{2} d t, \\
=2 p_{0} \int_{-\infty}^{\infty} g(t)\left|A_{20}(t)\right|^{2} \\
\times \exp \left[-2 \int_{-\infty}^{t}\left(r_{2} / 2+p_{0} g\left(t^{\prime}\right)\right)\left|A_{20}\left(t^{\prime}\right)\right|^{2} d t^{\prime}\right] d t .
\end{gathered}
$$


We choose $g(t)=\left[1+(t / \tau)^{2}\right]^{-3}$ and $V=t / \tau$. Then, noting that $\left|A_{20}(t)\right|^{2} \equiv F(V)$ we find

$$
\begin{gathered}
R=2 p_{0} \tau \int_{-\infty}^{\infty} \operatorname{dVg}(V) F(V) \\
\times \exp \left[-2 \int_{-\infty}^{V}\left(\frac{\gamma_{2}^{\tau}}{2}+P_{0} \tau g\left(V^{\prime}\right)\right) F\left(V^{\prime}\right) d V^{\prime}\right], \\
=R\left(p_{0} \tau, r_{2} \tau, \frac{\delta}{\mu},\left|\frac{\alpha}{\mu}\right|\right)
\end{gathered}
$$

In many cases $\gamma_{2}{ }^{\top} \ll 1$ and we find

$$
R=1-\exp \left[-p_{O} T H\left(\delta / \mu,\left|\frac{\alpha}{\mu}\right|\right)\right],
$$

where

$$
H(\delta / \mu,|\alpha / \mu|)=2 \int_{-\infty}^{m} g\left(V^{\prime}\right) F\left(V^{\prime}\right) d V^{\prime},
$$

with

$$
F(v)=\frac{1}{2}-\frac{\varepsilon^{\prime}\left(\frac{2 \delta}{\mu}-g(V)\right)}{2 \sqrt{(2 \delta / \mu-g(V))^{2}+4|\alpha / \mu|^{2} g^{2}(V)}} .
$$

In the special case $E_{10}=E_{20}$ the ratio $|\alpha / \mu|$ is independent 
of power and we see that a graph of $-\left(p_{0} \tau\right)^{-1} \ln (1-R)$ versus $\delta / \mu$ should yield the same curve for all peak power and pulse length such that $\gamma_{2} \tau \ll 1$ and such that the other validity conditions are met. (See Appendix A for tabulation of the $H$ function.)

To illustrate the validity of the above results, we have chosen $\tau=10^{-8}$ sec, $\mu=1.38 \times 10^{3} I_{\Omega}$, and $\alpha=3.7 \times 10^{2} \mathrm{I}_{0}$. Figure 2 shows a graph of a numerically calculated plot of $-\left(p_{0} \tau\right)^{-1} \ln (1-R)$ versus $\delta / \mu$ for $I_{0}=10^{7} \mathrm{w} / \mathrm{cm}^{2}$ and $10^{8} \mathrm{w} / \mathrm{cm}^{2}$, where $I_{0}$ is the peak power density of the laser pulse. On the same graph we have shown the result calculated from Eq. (54). Note that the only discrepancy occurs when $|\delta \tau|<10$. When $\delta=0$, Eqs. (39) can be solved by letting $u=\int_{-\infty}^{t} g\left(t^{\prime}\right) d t^{\prime}$ (see Appendix $\left.B\right)$. Using $g(V)=\left(1+v^{2}\right)^{-3}$, we find

$$
R=1-\exp \left[-\frac{3 \pi}{2} \mathrm{p}_{U} \tau|\alpha / \mu|^{2}\left(1+4|\alpha / \mu|^{2}\right)^{-1}\right] .
$$

This simple expression was used to check the numerical calculations at $\delta=0$, and agreement was excellent. Eqs. (39) can also be solved exactly if the two lasers give identical square pulses (see Appendix B). LeL 


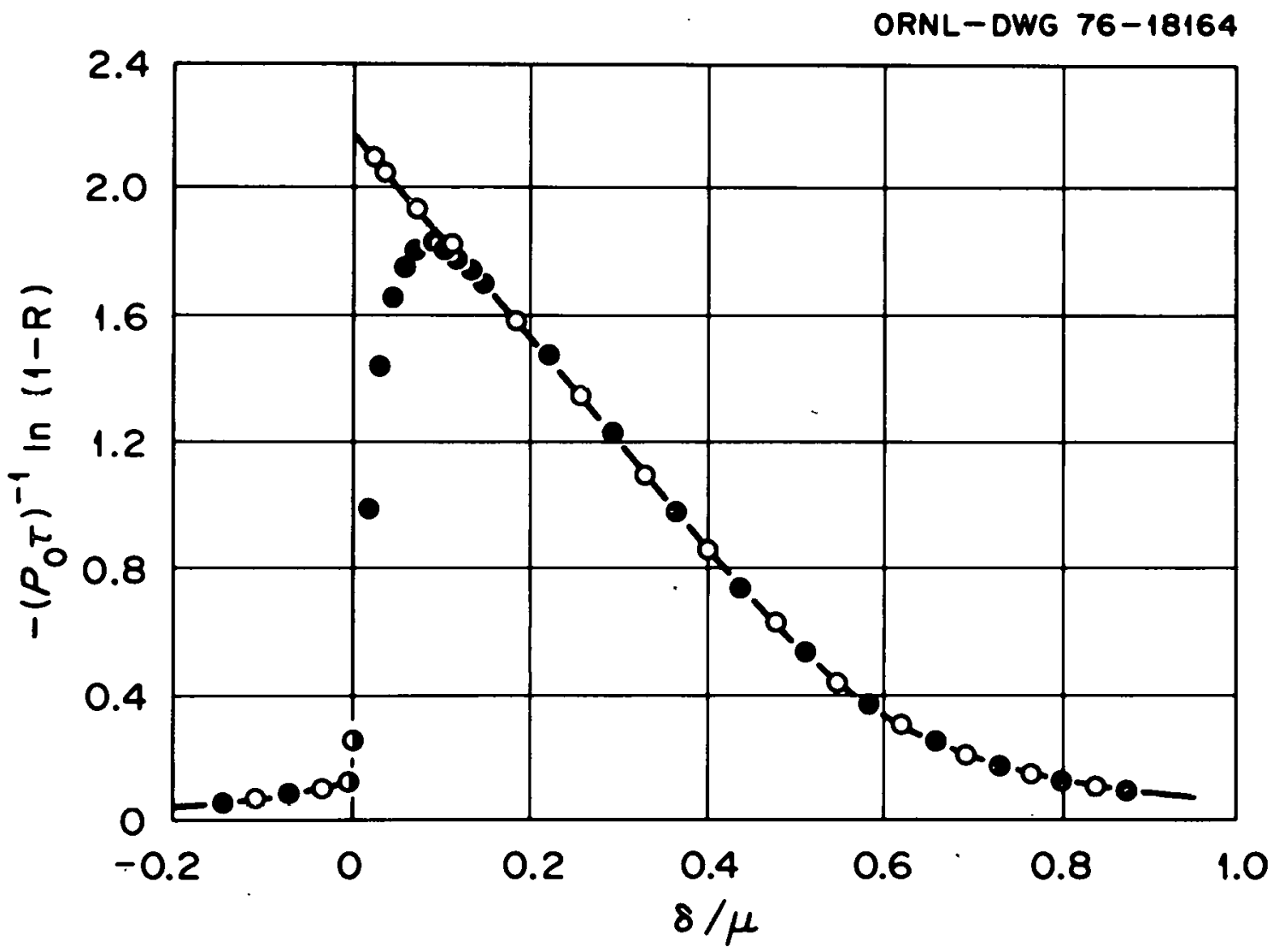

Figure 2. Photoionization Probability Comparison, - for the analytical solution, o for the numerical solution with $I_{O}=10^{8} \mathrm{w} / \mathrm{cm}^{2}$ and 0 for the numerical solution with $I_{0}=10^{7} \mathrm{w} / \mathrm{cm}^{2}$. 


$$
\begin{aligned}
g(t) & =0, t<0 ; \\
& =\frac{3 \pi}{8}, 0 \leq t \leq \tau ; \\
& =0, t>\tau .
\end{aligned}
$$

We have solved analytically for $R$ in cases where $\alpha \tau \gg 1$. In Figs. 3-8 we have graphed $R$ versus $\delta$ for various $I_{0}$ and $\tau=10^{-8} \mathrm{sec}, \mu=1.38 \times 10^{3} \mathrm{I}_{0}, \alpha=3.7 \times 10^{2} \mathrm{I}_{\mathrm{O}}$ and $\mathrm{p}_{0}=0.08 \mathrm{I}_{0}$. Both the square pulse and $\mathrm{g}=\left[1+\mathrm{V}^{2}\right]^{-3}$ cases are shown in Figs. 3-5, The reader should note that the square pulse result peaks at $2 \delta=\mu \mathrm{g}$ and the only width is due to power broadening which is approximately $2|\alpha|$. The line shape for $g(V)=\left(1+v^{2}\right)^{-3}$ is extremely different due to the curve crossings (i.e., $20-\mu g(V)$ ) which occur for $\delta / u>0$ and for $|\delta|<|\mu / 2|$. When $|\mu| \gg|\alpha|$ the width is almost entirely determined by $|\mu|$ and is many times wider than the width for the square pulse case. With smooth pulses the values of $R$ are larger due to the fact that inverted populations exist in this case. For square pulses and $|\alpha \tau|$ > 1 Rabi flopping ${ }^{2}$ occurs and when $\left|A_{2}\right|^{2}$ is averaged over several cycles it is always $\leq \frac{1}{2}$; thereby, leading to smaller $R$.

The analytical expression for $\left|\mathrm{A}_{2}\right|^{2}$ is discontinuous at $\delta=0$; being small on the $\delta / \mu<0$ side and larger than $1 / 2$ on the $\delta / \mu>0$ side. The discontinuity is due to deviations 


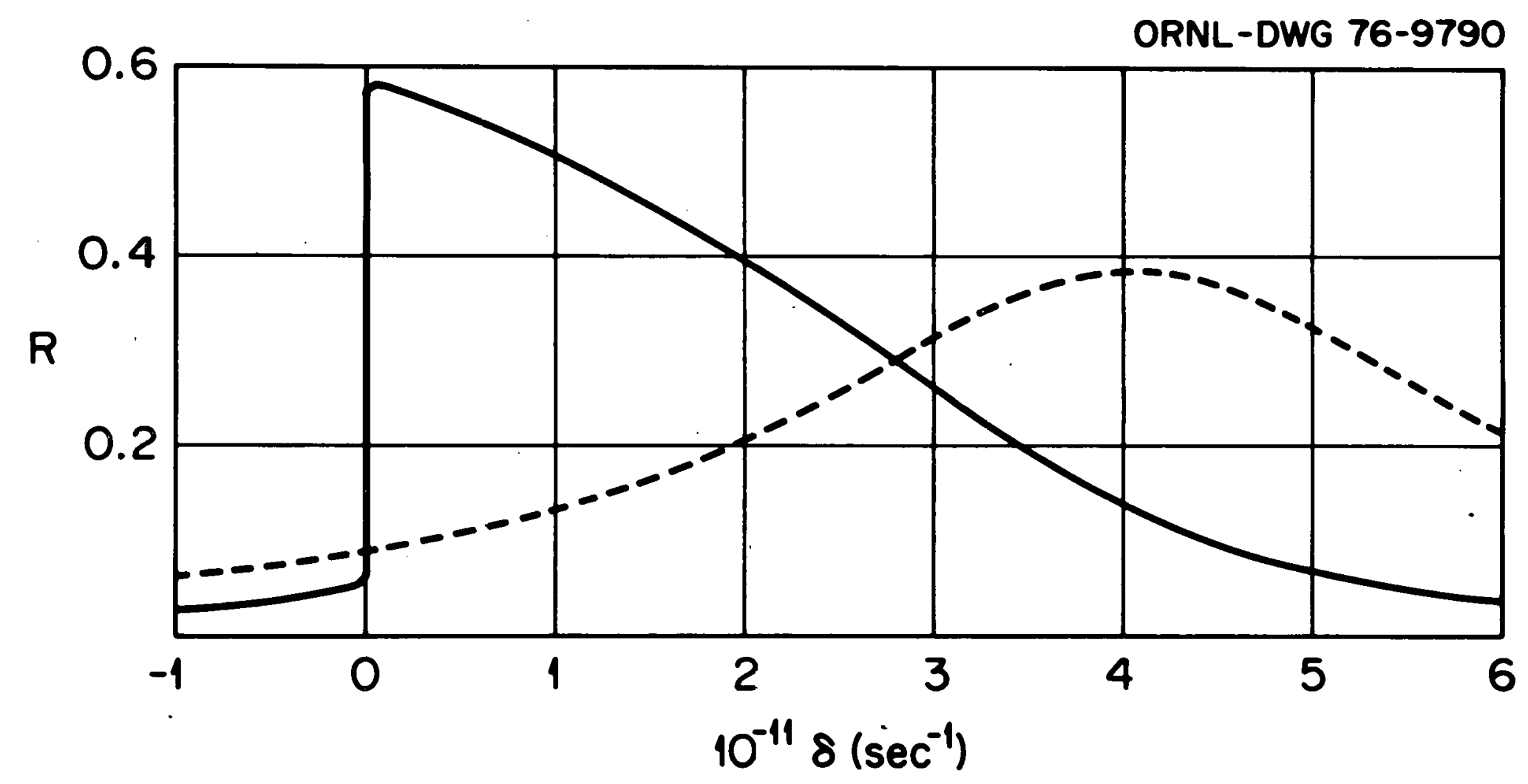

Figure 3. Photoionization Probability $\left(I_{0}=5 \times 10^{8} \mathrm{w} / \mathrm{cm}^{2}\right.$,

$\tau=10-8 \mathrm{sec}),-$ for $g(t)=\left[1+(t / \tau)^{2}\right]^{-3}$ and

- for $g(t)=3 \pi / 8$. 


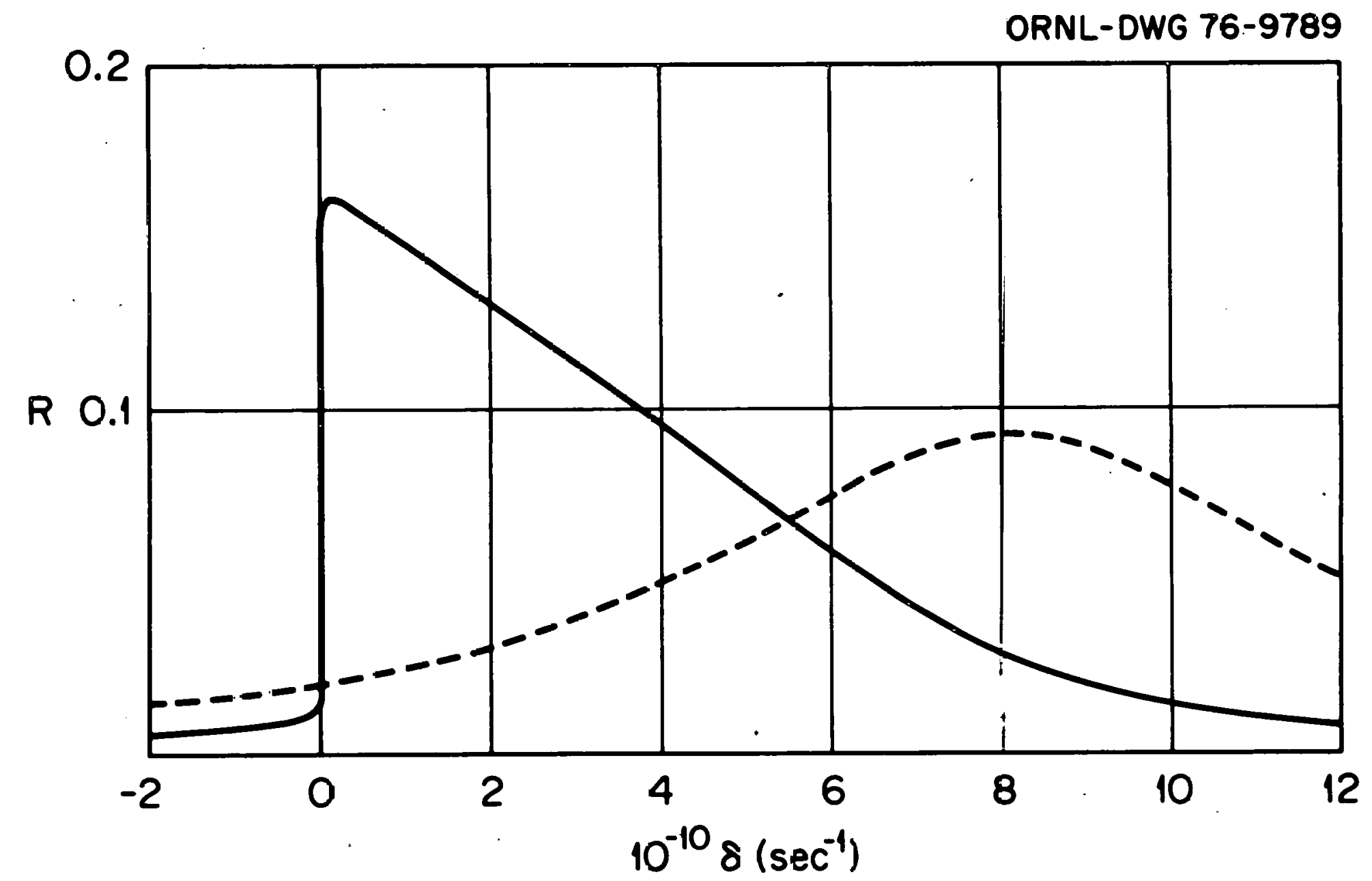

Figlere 4. Photcionization Probability $\left(I_{O}=10^{8} \mathrm{w} / \mathrm{cm}^{2}\right.$
$\left.\tau=10^{-8} \mathrm{sec}\right)$, for $\left.g(t)=[1+i t / \tau) 2\right]^{-3}$ and --- for $g(t)=3 \pi / 8$. 


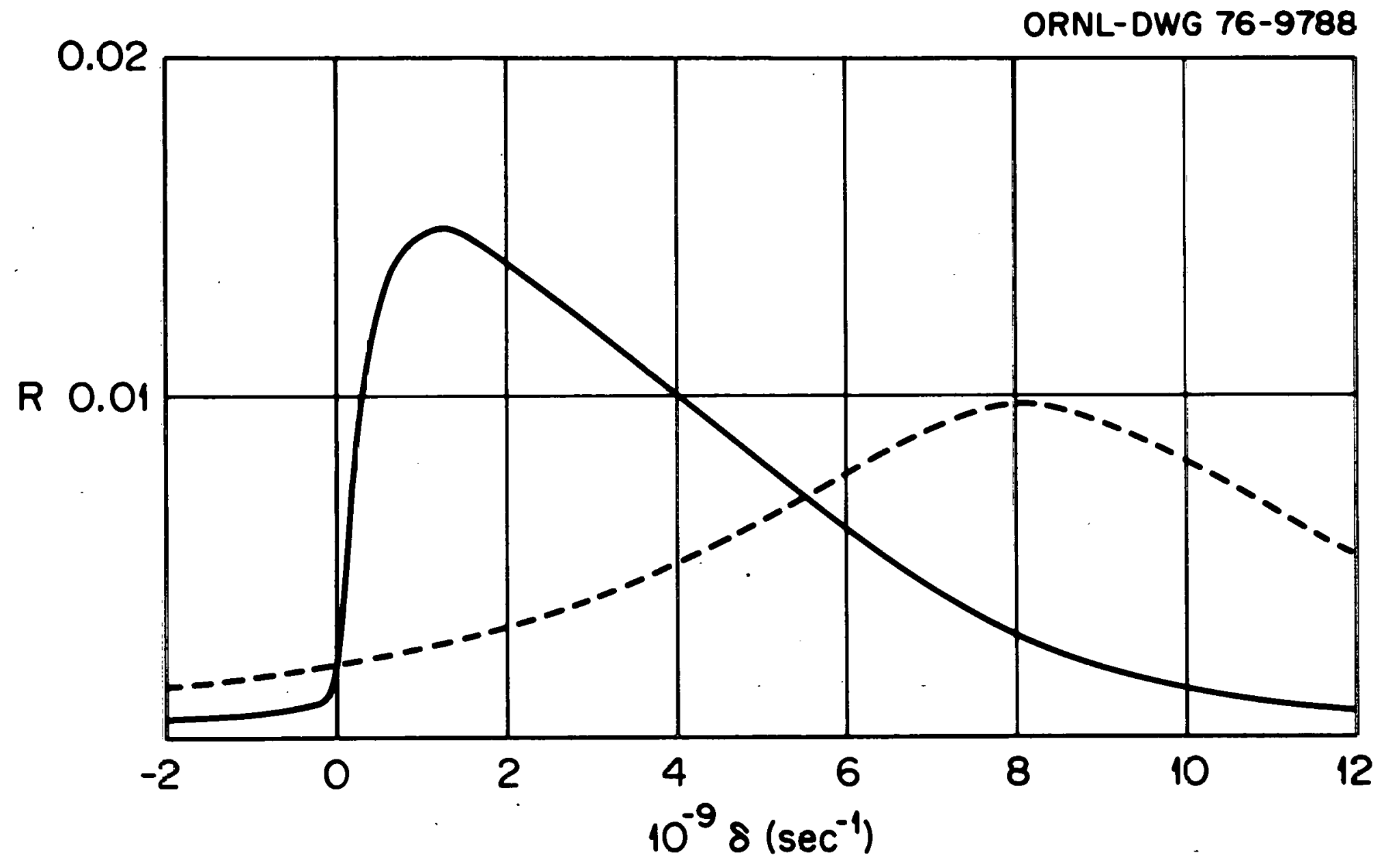

Figure 5. Photoionization Probability $\left(I_{O}=10^{7} \mathrm{w} / \mathrm{cm}^{2}\right.$.

$\left.\tau=10^{-8} \mathrm{sec}\right)$, for $g(t)=\left[1+(t / \tau)^{2}\right]-3$ and 


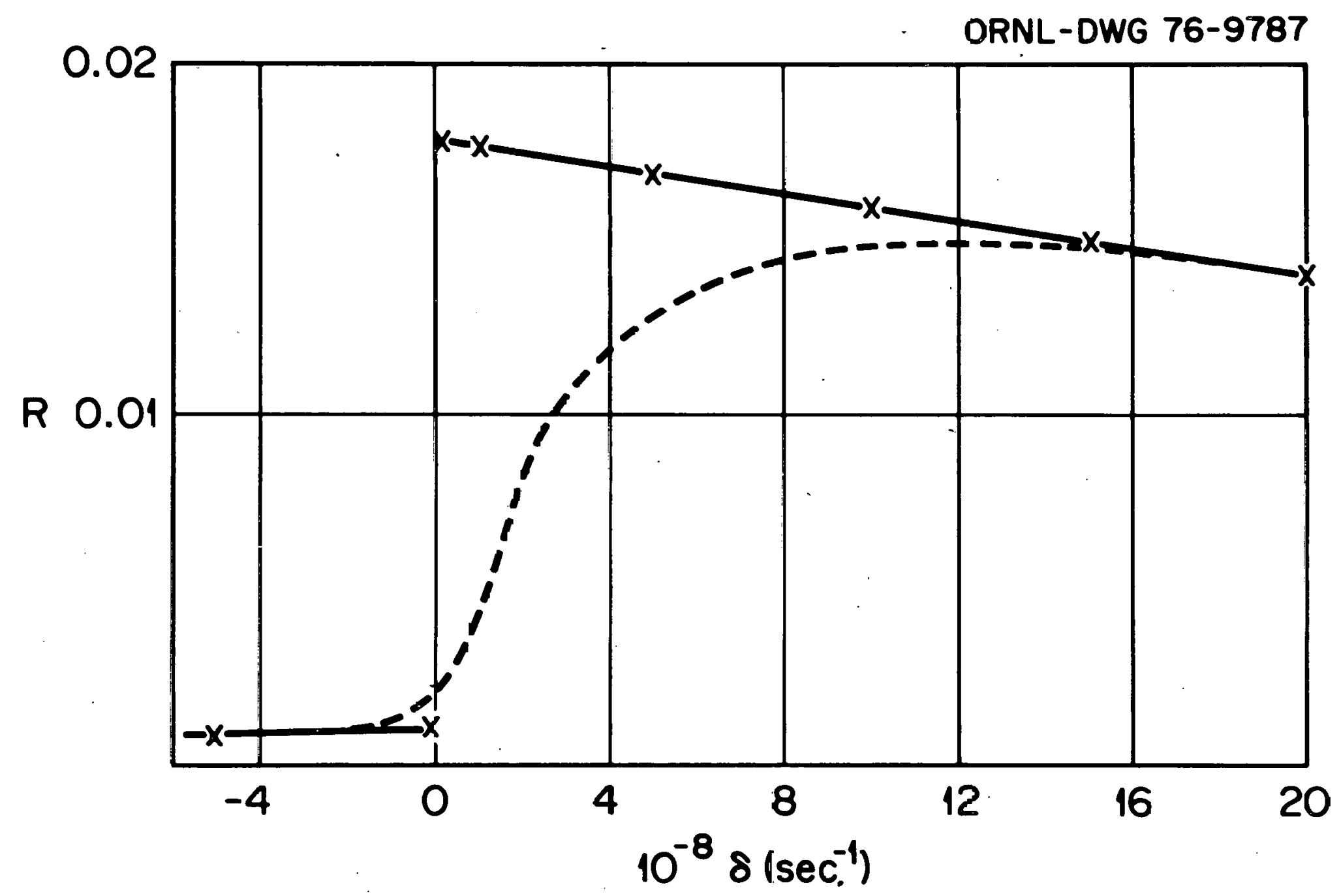

Figure 6. Blow-u’ Grapi Near $\delta=0\left\{I_{0}=10^{7} \mathrm{w} / \mathrm{am}^{2}, \tau=10^{-8}\right.$ sec), - for the numerical solution and $x$ for the analytical solution. 


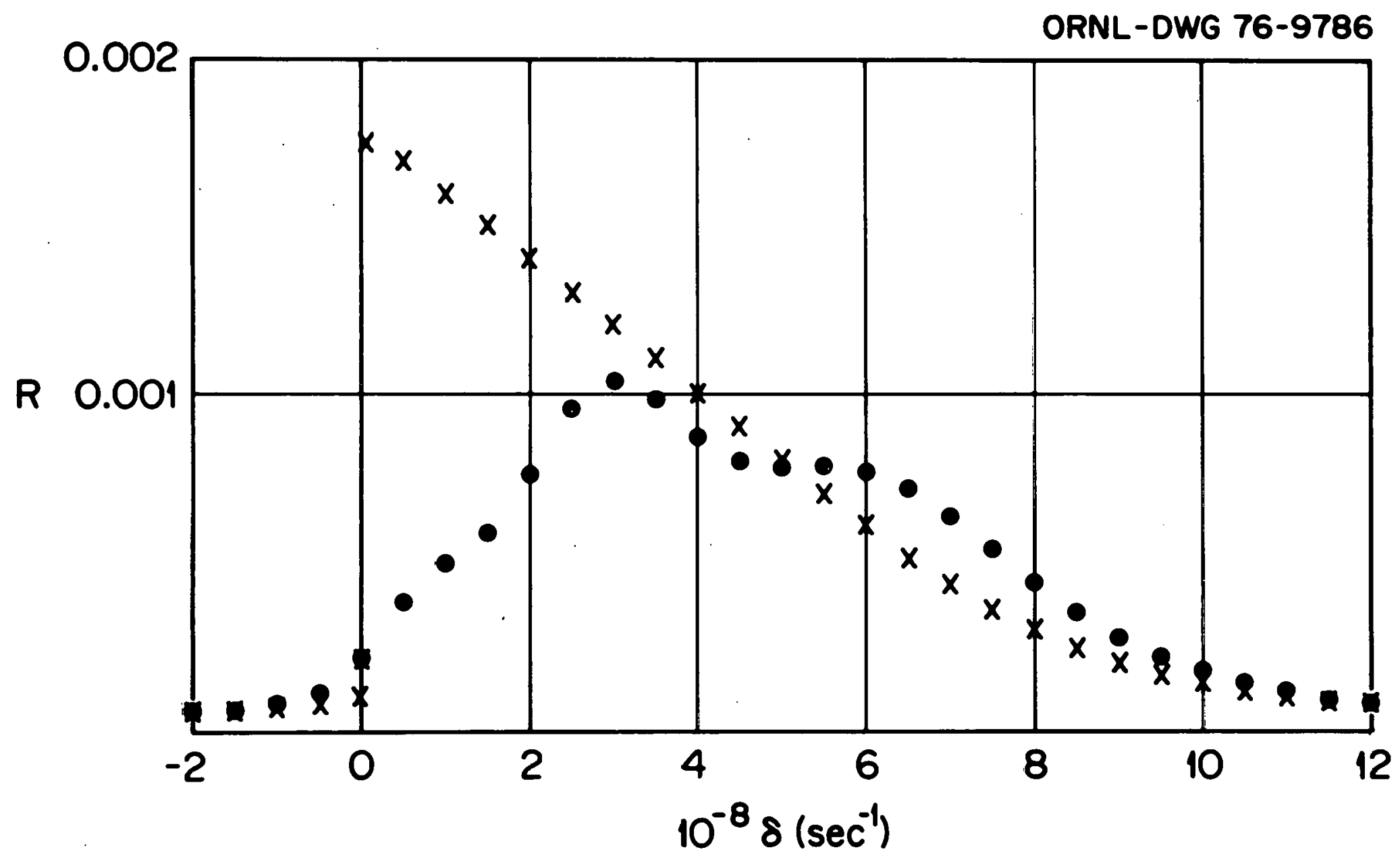

Figure 7. Photoionization Probability $\left(I_{0}=106 \mathrm{w} / \mathrm{cm}^{2}\right.$,

$\left.\tau=10^{-8} \mathrm{sec}\right), x$ for the analytical solution and - for the numerical solution with $g(t)=$

$\left[1+(t / \tau)^{2}\right]-3$. 


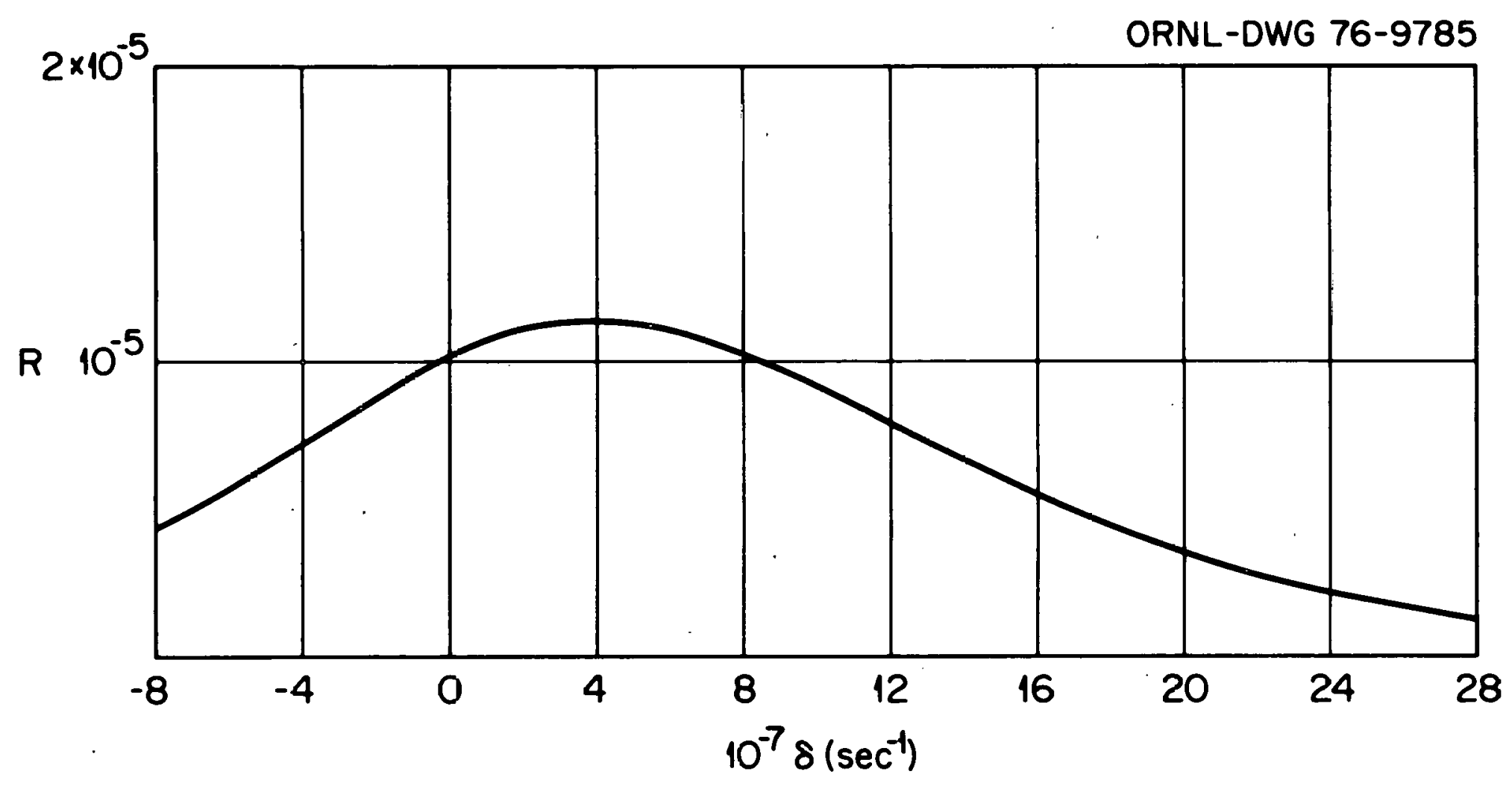
Figure 8. Fhotoionization Probability $\left(I_{0}=10^{5} \mathrm{w}^{\prime} \mathrm{cm}^{2}\right.$,
$\left.\tau=10^{-8} \mathrm{sec}\right)$, numerical solution for $\mathrm{g}(\mathrm{t})=$ $\left[1+(t / \tau)^{2}\right]-3$. 
Erom adiabatic behavior when $|\delta| \tau<10$. When non-adiabatic effects are taken into account $R$ rises sharply, but continuously in $a$ region $\Delta \delta$ given by $|\Delta \delta| \simeq 10 / \tau$. Thus, for long pulses the rise can be very sharp compared with the full Doppler width. In this sense a Doppler-free aspect of the line shape survives even at very large power levels. Making use of this sharp rise, one could selectively ionize one atom in the presence of another with a very nearby twophoton resonance. By most methods high $R$ is impossible without a correspondingly high value for the nearby level due to power broadening effects.

We have noted in condition (47) that the case of small $|\alpha / \mu|$ requires extremely large values of $|\alpha| \tau$ (the present method requires fairly large values of $|\alpha| \tau$ even when $|\alpha / \mu| \propto 1)$. In the next section we require $|\alpha / \mu| \ll 1$ but we will not require $|\alpha| \tau \gg$. The latter situation is very interesting if one of the laser pulses is much more powerful than the other.

D. APPLICATION OF THE METHOD OF ISOLATED CURVE CROSSINGS TO THREE-PHOTON IONIZATION

We consider the same situation as in section $c$ except now $|\alpha / \mu| \ll 1$ and $|\mu \tau| \gg 1$. In comparing with Chapter II, Section $B$ we note that $h(t)=F(t)=\left[1+(t / \tau)^{2}\right]^{-3}=g(t)$. We take $\gamma_{2}=0$ so that $y(t)=p_{0} g(t)$. We have for all $t$ 


$$
\left|A_{2}(t)\right|^{2} \simeq 0 \text {, if } \delta / \mu<0 \text { or } 2 \delta / \mu>1 \text {. }
$$

When $\delta / \mu>0$ and $2 \delta / \mu<1$ we obtain

$$
\begin{gathered}
\left|A_{2}(t)\right|^{2}=0, t<t_{01} ; \\
=T \exp \left[-2 p_{0} \int_{-t_{02}}^{t} g\left(t^{\prime}\right) d t^{\prime}\right], t_{01} \leq t \leq t_{02^{\prime}} \\
=T(1-T)\left[1+\exp \left(-2 p_{0} \int_{-t_{02}}^{t_{02}} g\left(t^{\prime}\right) d t^{\prime}\right)\right] \\
\times \exp \left[-2 p_{0} \int_{t_{02}}^{L^{\prime}} g\left(t^{\prime}\right) d t^{\prime}\right], t>t_{02} ;
\end{gathered}
$$

whore

$$
\begin{gathered}
t_{02}=1\left[\left(\frac{\mu}{2 \delta}\right)^{1 / 3}-1\right]^{1 / 2}=-t_{01}, \\
\left|z_{2}\right|^{2}=\frac{|\mu \tau|}{6}\left|\frac{\alpha}{\mu}\right|^{2}\left(\frac{2 \delta}{\mu}\right) 1 / 2\left[1-\left(\frac{2 \delta}{\mu}\right) 1 / 3\right]-1 / 2, \\
T=1-\exp \left(-2 \pi\left|z_{1}\right|^{2}\right) .
\end{gathered}
$$


As explained in the mathematical discussion of Chapter II, the only appreciable changes in $A_{2}(t)$ occur in a narrow time interval about times where $2 \delta=\mu \mathrm{g}$. Except in these time intervals the lasers are far out of resonance and only photoionization and spontaneous decay are effective in changing $\mathrm{A}_{2}$. In our case we assume $\gamma_{2}{ }^{\tau} \ll 1$ and the only effect in changing the population of either $|0\rangle$ or $|2\rangle$ is photoionization.

Using Eqs. (58) and (59)-(60) we find

$$
R=0 \text { if } \delta / \mu<0 \text { or } 2 \delta / \mu>1 \text {; }
$$

and for $0 \leq 2 \delta / \mu \leq 1$ we have

$$
\begin{aligned}
\mathbf{R} & =T\left[1-Q^{2}\left(V_{02}\right)\right]+T(1-T)\left[1+Q^{2}\left(V_{02}\right)\right]\left[1-\frac{Q(\infty)}{Q\left(V_{02}\right)}\right], \\
& =R\left(\left.\left|\frac{\alpha}{\mu}\right|^{2}\right|_{\mu T} \mid, P_{O} T, \frac{\delta}{\mu}\right)
\end{aligned}
$$

where

$$
\begin{gathered}
V=t / \tau \\
Q(V)=\exp \left(-2 p_{0} \tau m(V)\right)
\end{gathered}
$$


and

$$
\begin{gathered}
m(V)=\int_{0}^{V} \frac{d V^{\prime}}{\left(1+v^{2}\right)^{3}} \\
=\frac{1}{8}\left[\frac{3 V}{1+v^{2}}+\frac{2 V}{\left(1+v^{2}\right)^{2}}+3 \tan ^{-1} v\right]
\end{gathered}
$$

Thus, if one fixes $|\alpha|^{2} \tau /\left.\right|_{\mu} \mid$ and $P_{0}{ }^{\tau}$, plotc of $R$ verous $2 \delta / \mu$ are the same curve for all $\mu$. ('l'he term $p_{0}{ }^{\top}$ is fixed by producing most of the ionization by a third laser pulse $E_{3}(t) \cos \left(w_{3}^{\prime} t-k_{3} v_{2} t+\beta_{3}\right)=E_{30} g^{1 / 2}(t) \cos \left(w_{3}^{\prime} t-k_{3} v_{2} t+\beta_{3}\right)$; with $w_{3}^{\prime}$ being far from resonance as far as participation in the two-photon resonance is concerned.) This is illustrated in Figs. 9-12.

A second interesting application of the present mathematical problem is to consider a situation identical to that described above except that we now assume $\gamma_{2} \neq 0$. Thus for all $t$ :

$$
\left|A_{2}(t)\right|^{2}=0 \text {, if } \delta / \mu<0 \text { or } 2 \delta / \mu>1
$$

when $0 \leq 3 \delta / \mu \leq 1$ we obtain

$$
\begin{gathered}
\left|A_{2}(t)\right|^{2}=0, t<t_{01} ; \\
=T \exp \left[-r_{2}\left(t+t_{02}\right)-2 p_{0} \int_{-t_{02}}^{t} g\left(t^{\prime}\right) d t^{\prime}\right],
\end{gathered}
$$




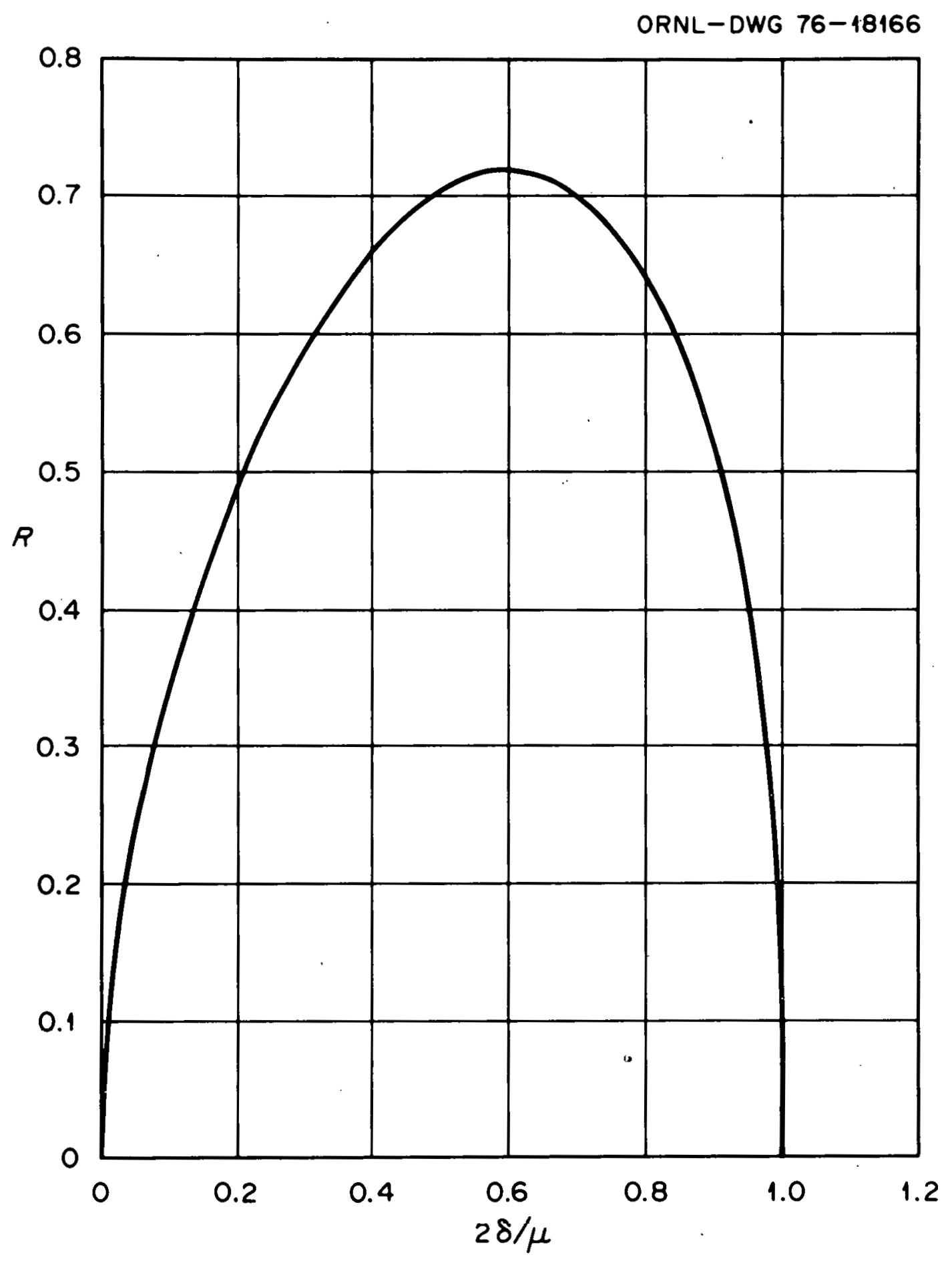

Figure 9. Photoionization Probability (isolated crossings), $|\alpha / \mu| 2|\mu \tau|=1, \mathrm{P}_{0} \tau=1$ and $\mathrm{g}(\mathrm{t})=[1+(t / \tau) 2]-3$. 


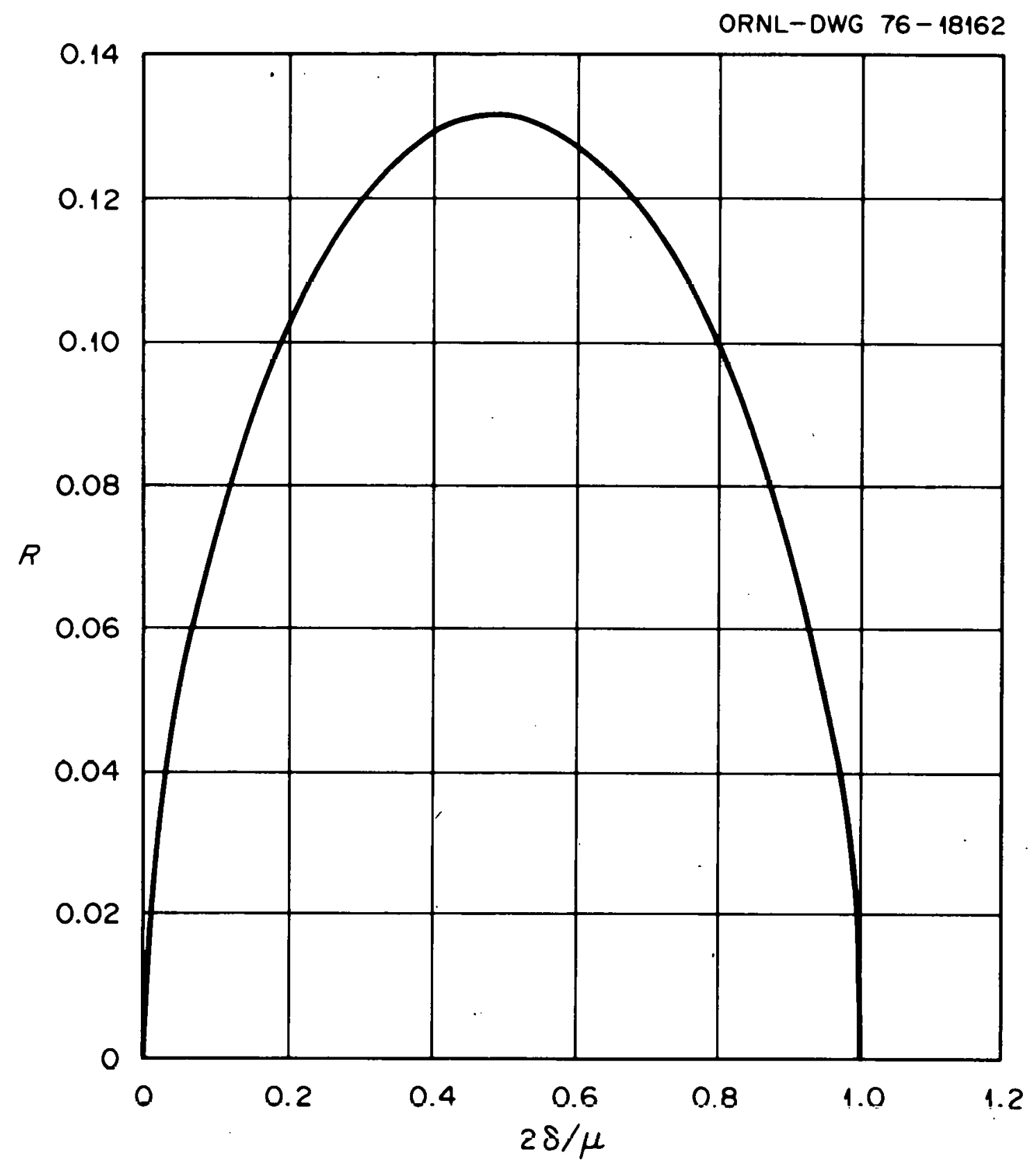

Figure 10. Photoionization Probability (isolated crossings), $|\alpha / \mu|^{2}|\mu \tau|=1, P_{0} \tau=0.1$ and $g(t)=\left[1+(t / \tau)^{2}\right]-3$. 


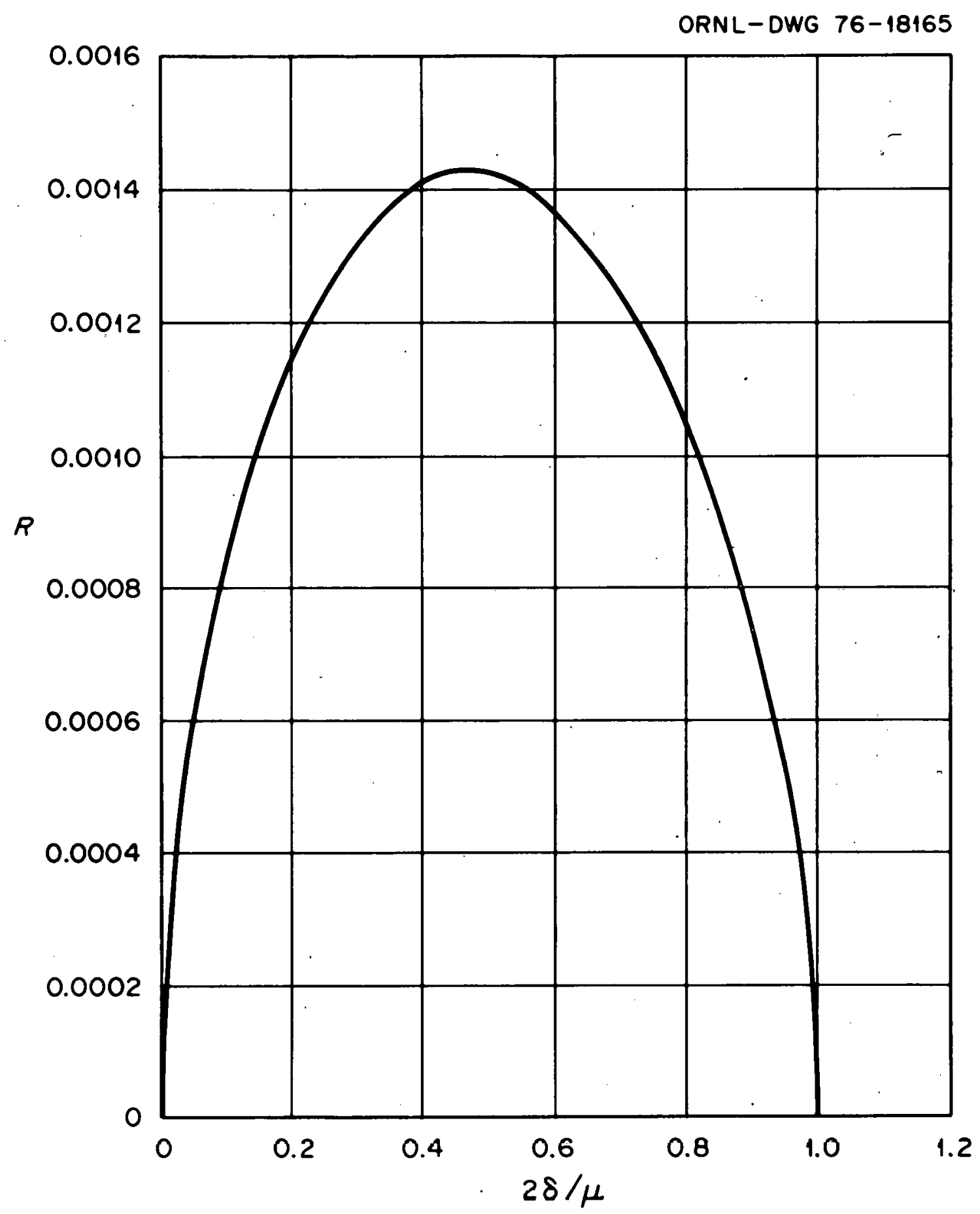

Figure 11. Photoionization Probability (isolated crossings), $|\alpha / \mu| 2|\mu \tau|=1, P_{O} \tau=0.001$ and $g(t)=[1+(t / \tau)]^{-3}$. 


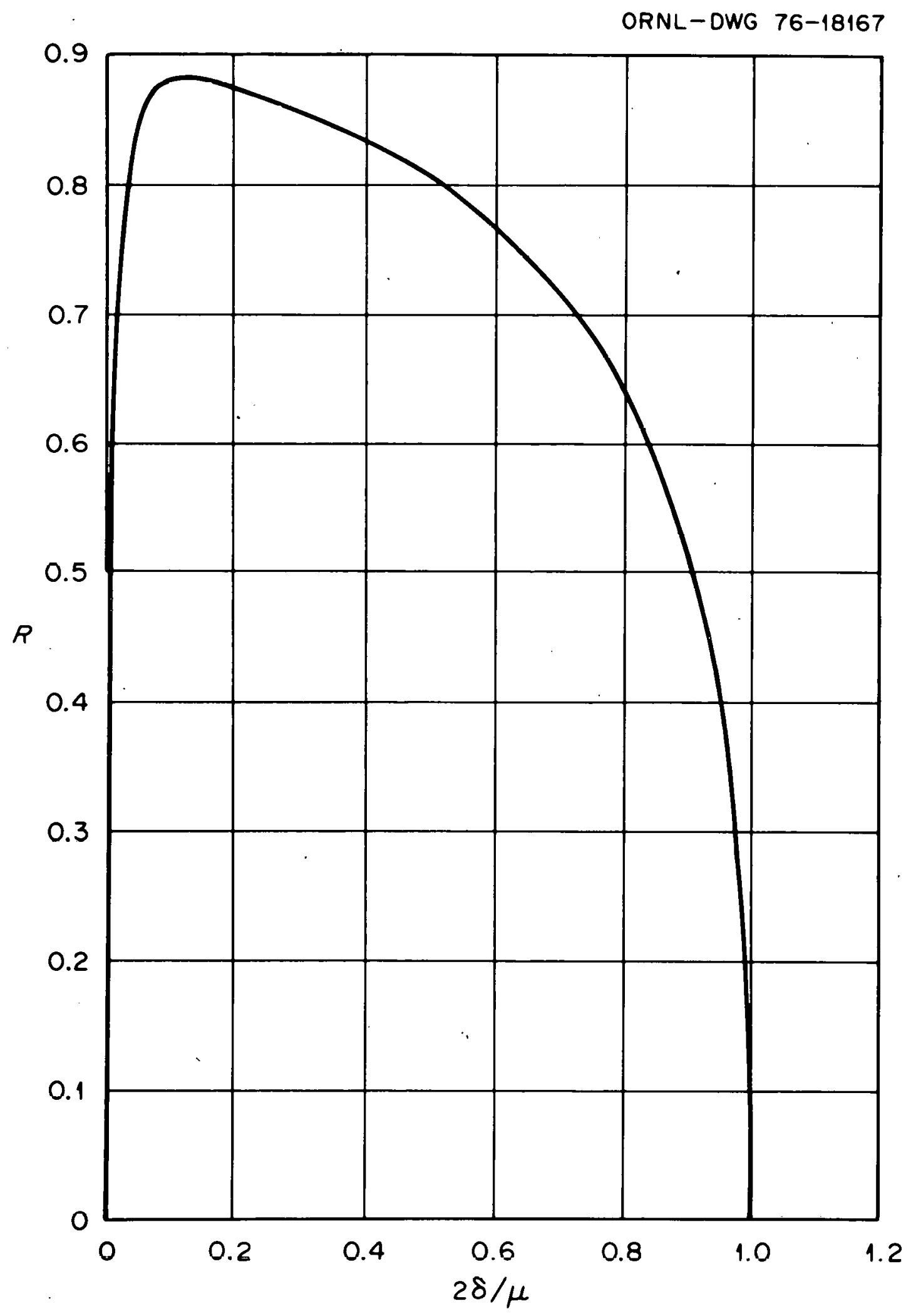

Figure 12. Photoionization Probability (isolated crossings), $|\alpha / \mu| 2|\mu \tau|=10, P_{O} \tau=1$ and $g(t)=\left[1+(t / \tau)^{2}\right]-3$. 


$$
\begin{gathered}
-t_{02} \leq t \leq t_{02} ; \\
=T(1-T)\left[1+\exp \left(-2 \gamma_{2} t_{02}-2 p_{0} \int_{-t_{02}}^{t_{02}} g\left(t^{\prime}\right) d t^{\prime}\right)\right] \\
\times \exp \left[-r_{2}\left(t-t_{02}\right)+2 p_{0} \int_{t_{02}}^{t} g\left(t^{\prime}\right) d t^{\prime}\right],
\end{gathered}
$$

$t>t_{02}$ The probability of emission of a fluorescence photon per unit time at $t$ is then

$$
S(t)=r_{2}\left|A_{2}(t)\right|^{2}
$$

If $|\alpha / \mu|^{2} \frac{|\mu \tau|}{6}>>1$, we see that $T \simeq 1$ for nearly all $\delta$ satisfying $0 \leq 2 \delta / \mu \leq 1$. In such a circumstance nearly all fluorescence occurs in the time interval $-t_{02} \leq t \leq t_{02}$ By adjusting $\delta / \mu$ the time interval during which the fluorescence occurs can be changed as indicated by Eqs. (60). If $\gamma_{2}{ }^{\top} \ll 1$ and $\mathrm{p}_{\mathrm{O}}{ }^{\tau}<1$ we have a situation where the entire population jumps from the state $|0\rangle$ to the state $|2\rangle$ at time $-t_{02}$ ' fluoresces until time $t_{02}$, and then almost all atoms return to the ground state. All fluorescence occurs in a time short compared with the excited states lifetime; but during this time all atoms in the state |2> are fluorescing. Such an effect should be relatively easy to demonstrate with commercially available electronic time gating equipment. 
In the situation $\left|\frac{\alpha}{\mu}\right|^{2} \frac{|\mu \tau|}{6} \gg 1$ the population is completely inverted in passing through the first crossing. By using slowly growing pulses which are terminated abruptly it may be possible to have situations where $T$ is nearly unity at a first crossing and small compared with unity at a second. In such a circumstance one should be able to produce very large populatione of metastable atoms in olements such as those in the second column of the periodic table. Such a possibility might be of interest as a way to produce very short but intense pulses of metastable atoms for crossed beam scattering experiments.

E. CROSSING EFFECTS DUE TO TIME OF PASSAGE ACROSS TIGHTLY FOCUSED LASER BEAMS

In this section we consider two counter propagating Cw laser beams at frequencies $w_{1}^{\prime}$ and $w_{2}^{\prime}$. The beams are brought to a common focus in a small cell occupied by a low concentration of atoms having enerqy levels similar to those described in section $A$ of the present chapter. If the laser at $w_{1}^{\prime}$ is much more powerful as well as more tightly focused, we have a situation in which two-photon excitation is only possible in the region of space where both laser fields are strong. This region can be as small in radius as $\sim 10^{-4} \mathrm{~cm}$; so that at thermal equilibrium the time of passage of atom across the high field region is $\sim 10^{-8}$ second. Thus, in such a situation every atom moving through the beam sees a pulsed 
field of very high intensity. With the most powerful tunable cw dye lasers, the peak power density may reach a level $\geq 10^{6} \mathrm{w} / \mathrm{cm}^{2}$ at the beam center.

We begin by assuming that the laser at $w_{2}^{\prime}$ is much less tightly focused so that in the region of overlap its amplitude can be taken as a constant given by $\mathrm{E}_{20^{\circ}}$ The laser beams propagate parallel to the $z$ axis and the radial dependance of the amplitude of the laser at wis

$$
E_{1}(t)=E_{10} \exp \left[-r^{2} / 2 \sigma_{1}^{2}\right]
$$

Thus, an atom approaching the beam sees $E_{1}(t)$ given by

$$
E_{1}(t)=E_{10} \exp \left[-\frac{b^{2}}{2 \sigma_{1}{ }^{2}}-\frac{v_{x}{ }^{2} t^{2}}{2 \sigma_{1}{ }^{2}}\right] \text {, }
$$

where $b$ is the distance of closest approach to the beam axis and $\mathrm{V}_{\mathbf{X}}$ is the component of velocity perpendicular to the $\mathrm{Z}$ axis. Obviously the probability of being in $|2\rangle$ at time $t$, if initially in $\mid 0>$, can be obtained by solving Eqs. (37) with the present interpretation of $E_{1}(t)$ and $E_{2}(t)$. Further, here we can have $|\mu \tau| \gg 1$ but $|\alpha / \mu|^{2} \ll 1$ so that the method of isolated curve crossing can be applied. The same restrictions (for permitting the derivation of Eqs. (37)) apply here as in the previous sections of the present chapter.

$$
\text { The number of photons emitted per second per unit }
$$


length of the laser beam is given by (using collisionless kinetic theory and assuming thermal equilibrium)

$$
\begin{aligned}
R= & \frac{2 m N_{0}}{k T} \int_{0}^{\infty} d v_{x} \int_{0}^{b m} d b v_{x}^{2} \exp \left(-m v_{x}^{2} / 2 k T\right) \\
& \times P\left(v_{x}, b, E_{20}, F_{10}, \sigma_{1}, r_{2}, 2 \delta\right)
\end{aligned}
$$

. where $N_{0}$ is the atom concentration, $m$ is the mass of an atom, $T$ is absolute temperature, $k$ is the Boltzmann's constant and $b_{m}$ is the maximum value of $b, p\left(v_{x}, b, E_{20}, E_{10}, \sigma_{1}, r_{2}\right.$, 28) is the probability that a passage at $V_{x}$ and $b$ will lead to the emission of a photon with the laser parameters $\mathrm{E}_{20}$ ' $E_{10}, \sigma_{1}$ and $2 \delta$ and with the spontaneous decay rate. Here we have assumed that photoionization does not occur. It remains for us to find $p$ and to use it in Eq. (68)., Using the same considerations as in Section $D$ of this chapter we find $P$ and obtain

$$
R=4 N_{0} \sqrt{\frac{2 k T}{m}} i_{1}\left(\ell n \frac{K_{1}}{\Delta}\right) l / 2 H\left(\left|z_{0}\right|^{2}, I^{\prime}\right)
$$

where

$$
\left|z_{0}\right|^{2}=\frac{K_{2} \sigma_{1}}{2\left(\ln \frac{K_{1}}{\Delta}\right) 1 / 2 \sqrt{\frac{2 k T}{m}}},
$$




$$
\begin{aligned}
& \Gamma=\frac{\gamma_{2} \sigma_{1}}{\sqrt{\frac{2 k T}{m}}}\left(\ln \frac{K_{1}}{\Delta}\right)^{1 / 2}, \text { note } \tau=\frac{\sigma_{1}}{\sqrt{\frac{2 k T}{m}}} ; \\
& K_{1}=-\frac{|<0| \hat{P}_{x}|P>|^{2} E_{10}}{4 \hbar^{2} \Delta_{1}}, \\
& K_{2}=-\frac{\mid\left\langle P\left|\hat{P}_{x}\right| 2>\left.\right|^{2} E_{20} 2\right.}{4 \hbar^{2} \Delta_{2}} .
\end{aligned}
$$

Note that we have assumed that there is a single dominant virtual state and $k_{1} v_{\varepsilon}$ and $k_{2} v_{g}$ in $\Delta_{1}$ and $\Delta_{2}$ are ignored; and also note that $\mu=k_{1} \exp \left(-b^{2} / \sigma_{1}{ }^{2}\right)$ and $|\alpha|=\sqrt{K_{1} K_{2}} \exp \left(-b^{2} / 2 \sigma_{1}{ }^{2}\right)$,

$$
\begin{aligned}
& \Delta=\mathrm{K}_{2}+2 \delta, \\
& \mathrm{K}_{2} / \mathrm{K}_{1}<1, \\
& 0<\Delta / K_{1}<1 \text {, } \\
& H\left(\left|z_{0}\right|^{2}, P\right)=2 \int_{0}^{\infty} y^{2} e^{-y^{2}} \int^{1} \frac{u d u}{\sqrt{1-u^{2}}}\left(1-e^{-\frac{2 \pi\left|z_{0}\right|^{2}}{y u}}\right) \\
& x\left(1-e^{-\frac{2 P u}{y}}+e^{-\frac{2 P u}{y}-\frac{2 \pi\left|z_{0}\right|^{2}}{y u}}\right) d y
\end{aligned}
$$


if the spontaneous decay feeds the ground state immediately (case 1) and

$$
\begin{aligned}
& H\left(\left|z_{o}\right|^{2}, \Gamma\right)=\int_{0}^{\infty} y^{2} e^{-y^{2}} \int_{0}^{1} \frac{u d u}{\sqrt{1-u^{2}}}\left(1-e^{\frac{-2 \pi\left|z_{o}\right|^{2}}{y u}}\right) \\
& \times \quad\left(1-e^{\frac{-2 \Gamma u}{y}}+e^{\frac{-2 \pi\left|z_{o}\right|^{2}}{y u}}+e^{\frac{-2 \Gamma u}{y}-\frac{2 \pi\left|z_{o}\right|^{2}}{y u}}\right) d y
\end{aligned}
$$

if the spontaneous decay does not appreciably repopulate $\mid 0>$ state during the duration of the laser pulse (case 2). Fig. 13 and Fig. 18 show $H\left(\left|z_{0}\right|^{2}, \Gamma\right)$ for the two cases. Figs. 14-17 and Figs. 19-22 show some of the examples of $R /\left(4 \mathrm{~N}_{0} \sigma_{I} \sqrt{2 \mathrm{kT} / \mathrm{m}}\right)$ versus $\Delta / \mathrm{K}_{1}$ for various values of $\Gamma_{\text {oo }}=\gamma_{2} \sigma_{1} / \sqrt{2 \mathrm{kT} / \mathrm{m}}$ and $\mathrm{z}_{00} \doteq \frac{1}{2} \mathrm{~K}_{2} \sigma_{1} / \sqrt{2 \mathrm{kT} / \mathrm{m}}$. The general line shapes are similar. to the one which was observed by Liao and Bjorkholm. ${ }^{7}$ Fig. 14 and Fig. 19 show an interesting aspect which was discussed earlier in section D of this chapter. With large $z_{00}$ and omall $\Gamma_{00}$ a large population inversion occurs at the first crossing, a small decay occurs between crossings and $\mid 2>$ population becomes nearly null at the second crossing, thereby leaving almost nothing to decay thereafter. With smaller $z_{\text {oo }}$ (but not too small), there remains more upper state population just after the second crossing. Thus, the latter case produces more fluorecence than the former case. 


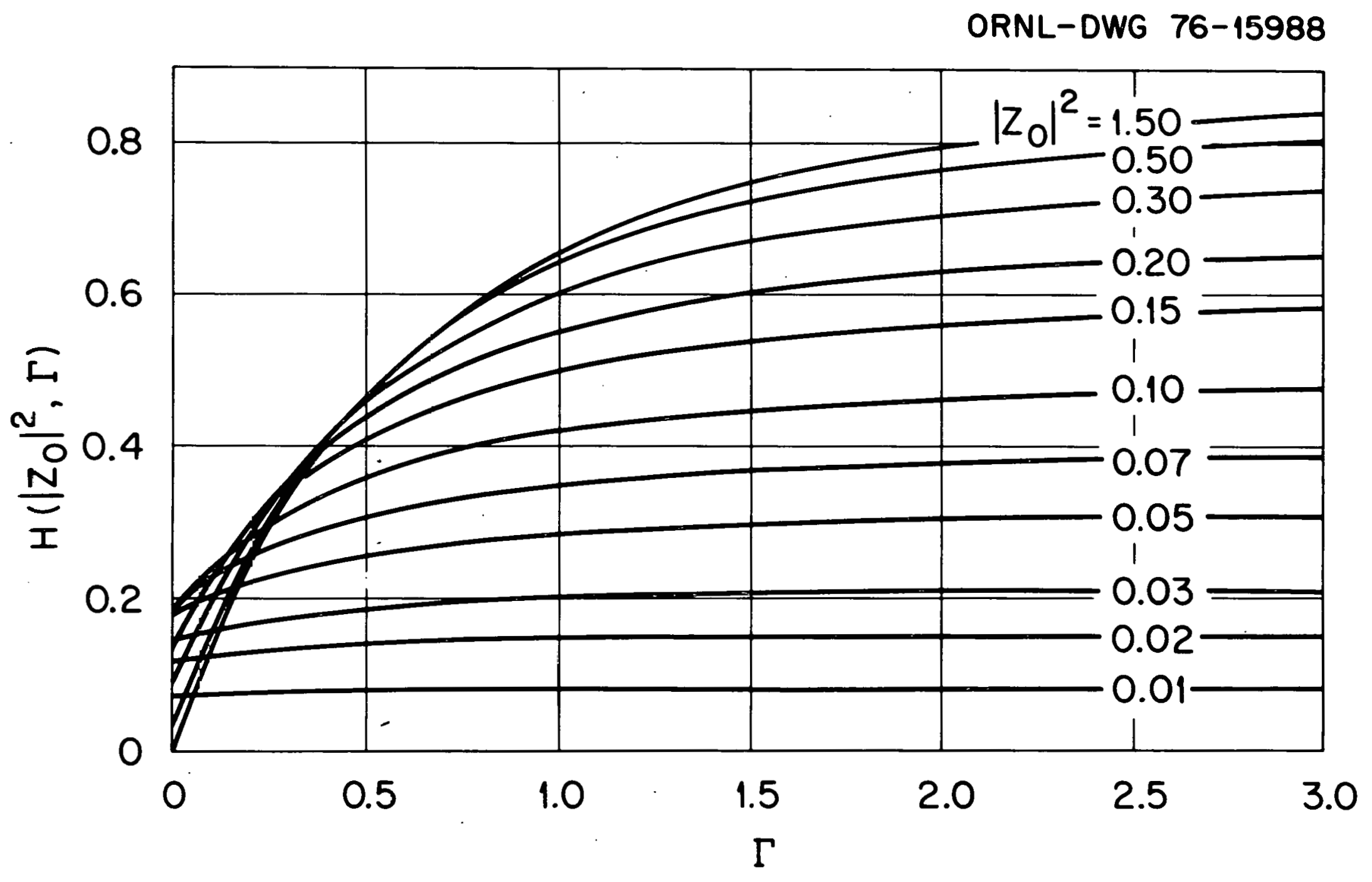

Figure 13. $\mathrm{H}\left(\left|\mathrm{z}_{\mathrm{O}}\right|^{2}, \Gamma\right)$. Spontaneous decay feeds $|0\rangle$ state without time delay. (case 1). 


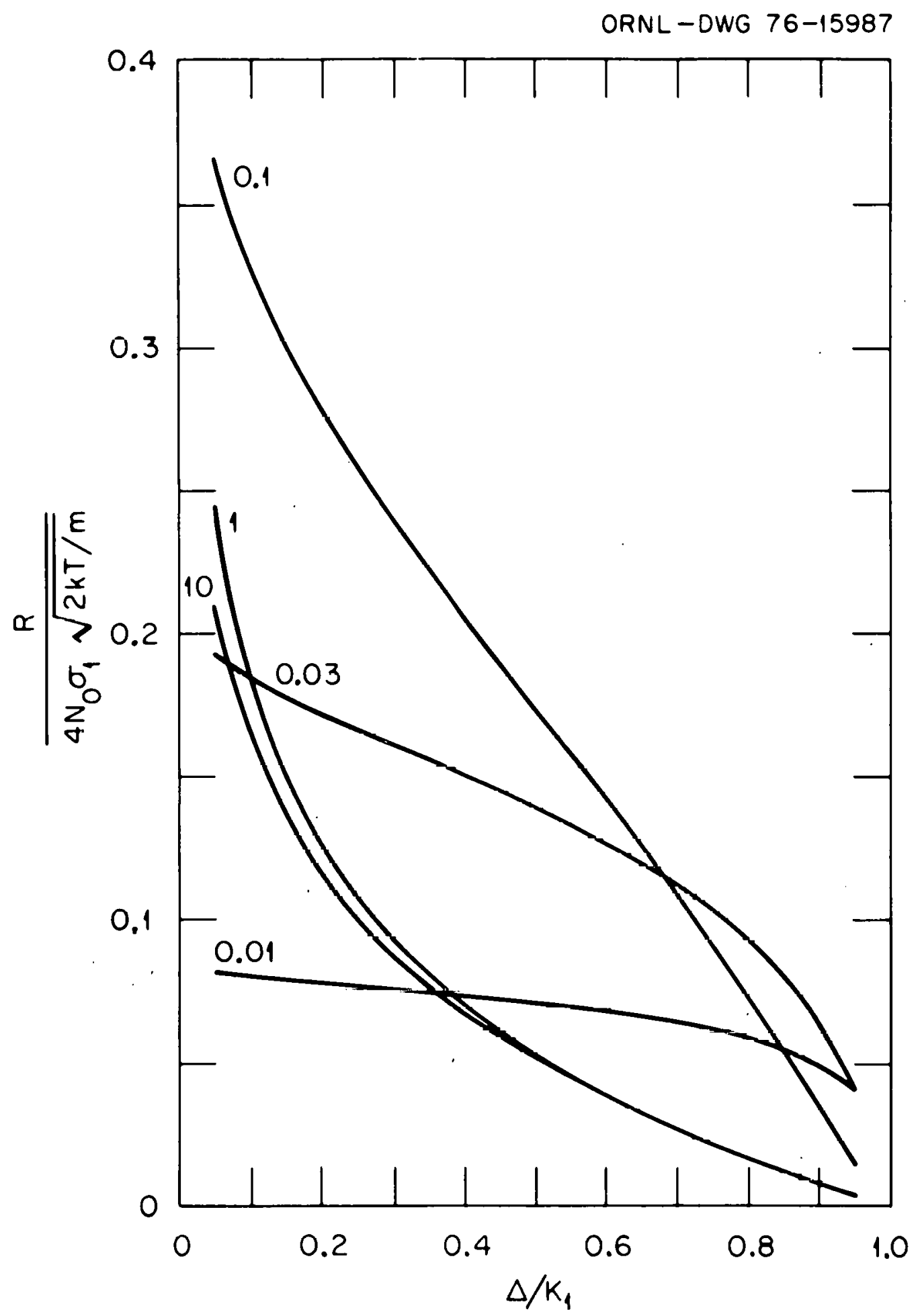

Figure 14. Fluorescence (case 1 with $\Gamma_{O O}=0.05$ and $z_{O O}=$ $0.01-10)$. 
$-63-$

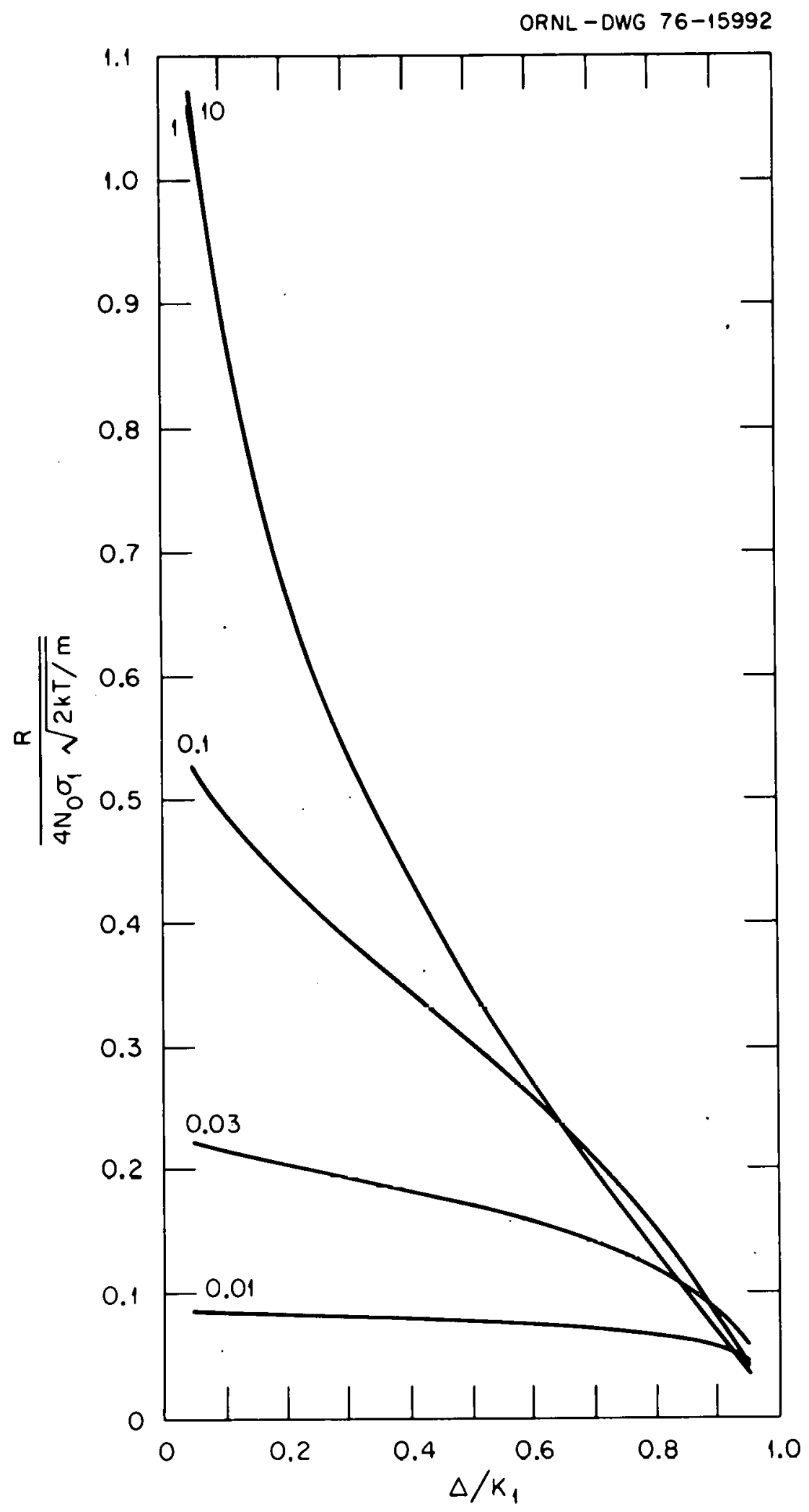

Figure 15. Fluorescence (case 1 with $\Gamma_{00}=0.5$ and $z_{0 O}=$ $0.01-10$ ). 


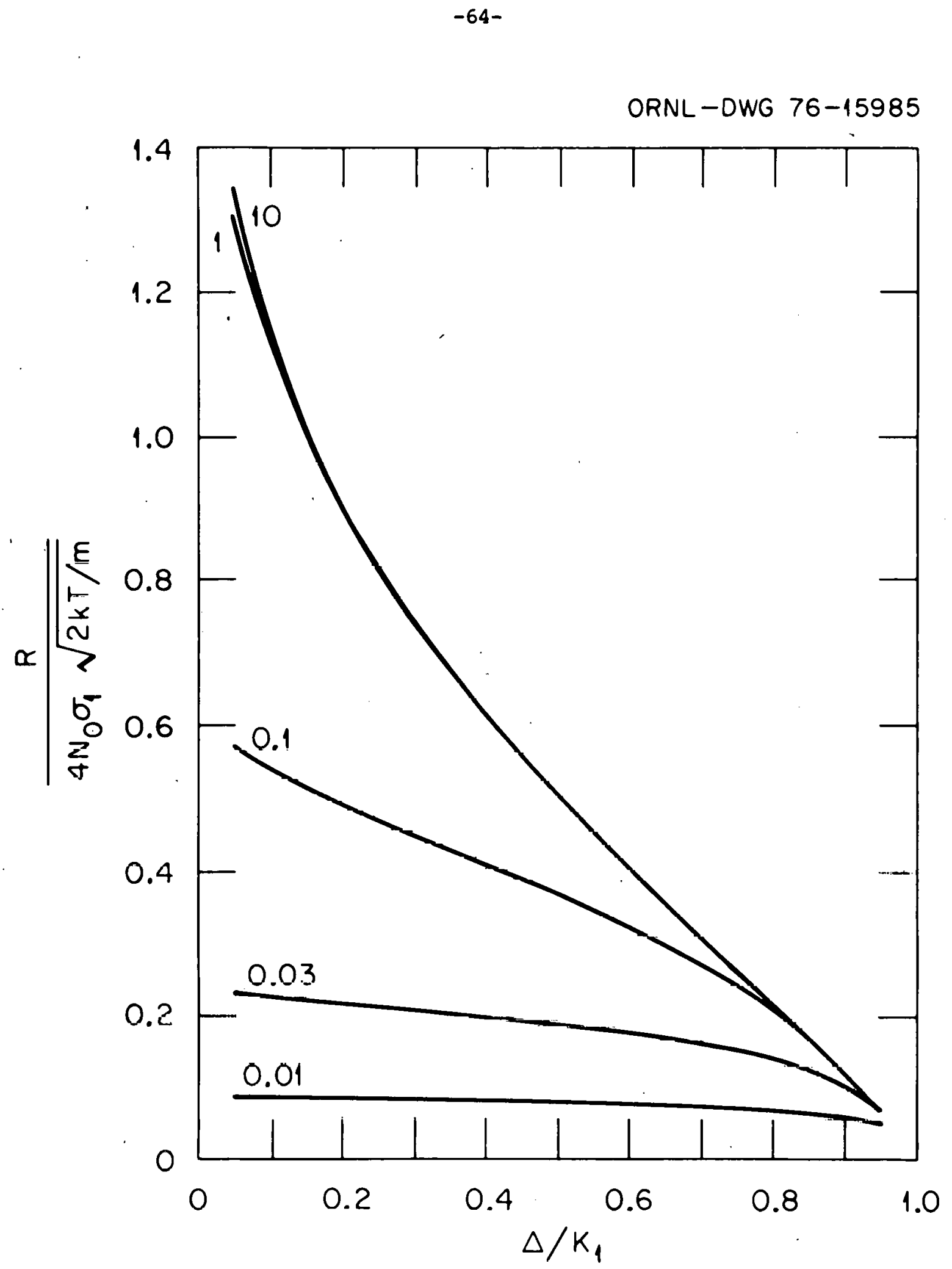

Figure 16. Fluorescence (case 1 with $\Gamma_{O O} \equiv 1.0$ and $z_{O O}=$ 0.01 - 10). 


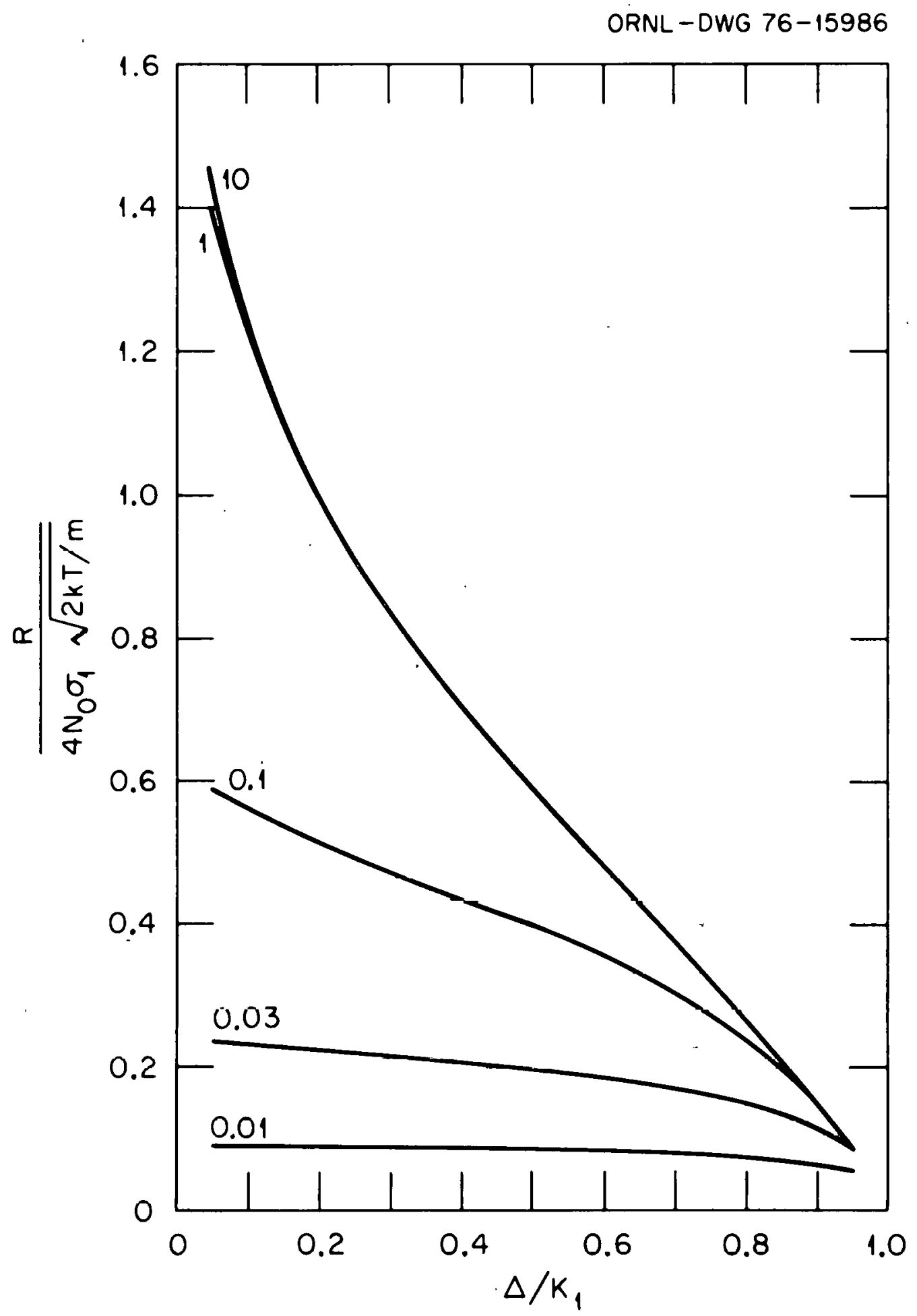

Figure 17. Fluorescence (case 1 with $\Gamma_{\circ O}=1.5$ and $\mathrm{z}_{\circ O}=$ 0.01 - 10). 


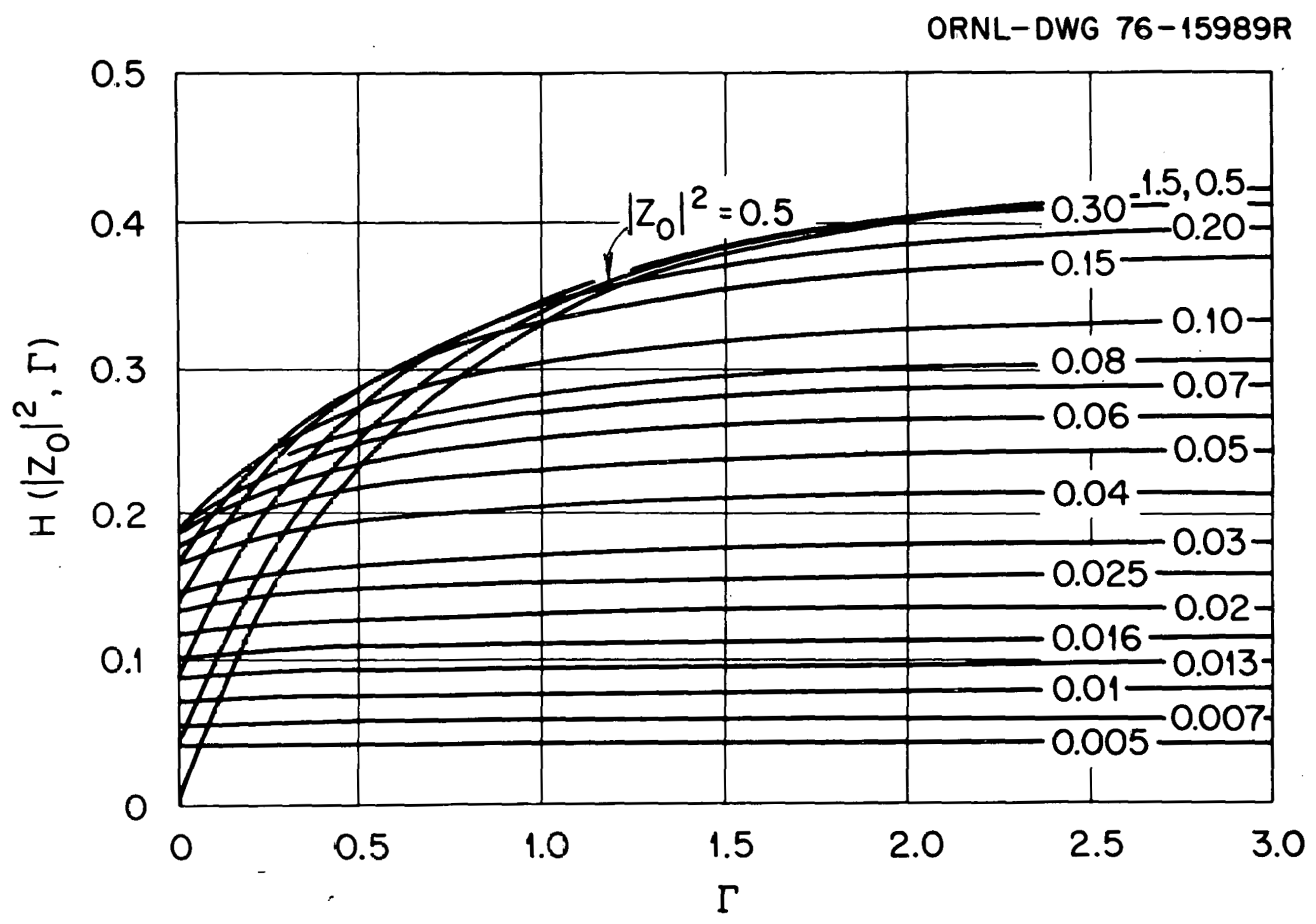

Figure 18. $H\left(\left|z_{0}\right|^{2}, I\right\}$. Spontaneous decay does not repopulate $|0\rangle$ state (case 2 ). 
$-67-$

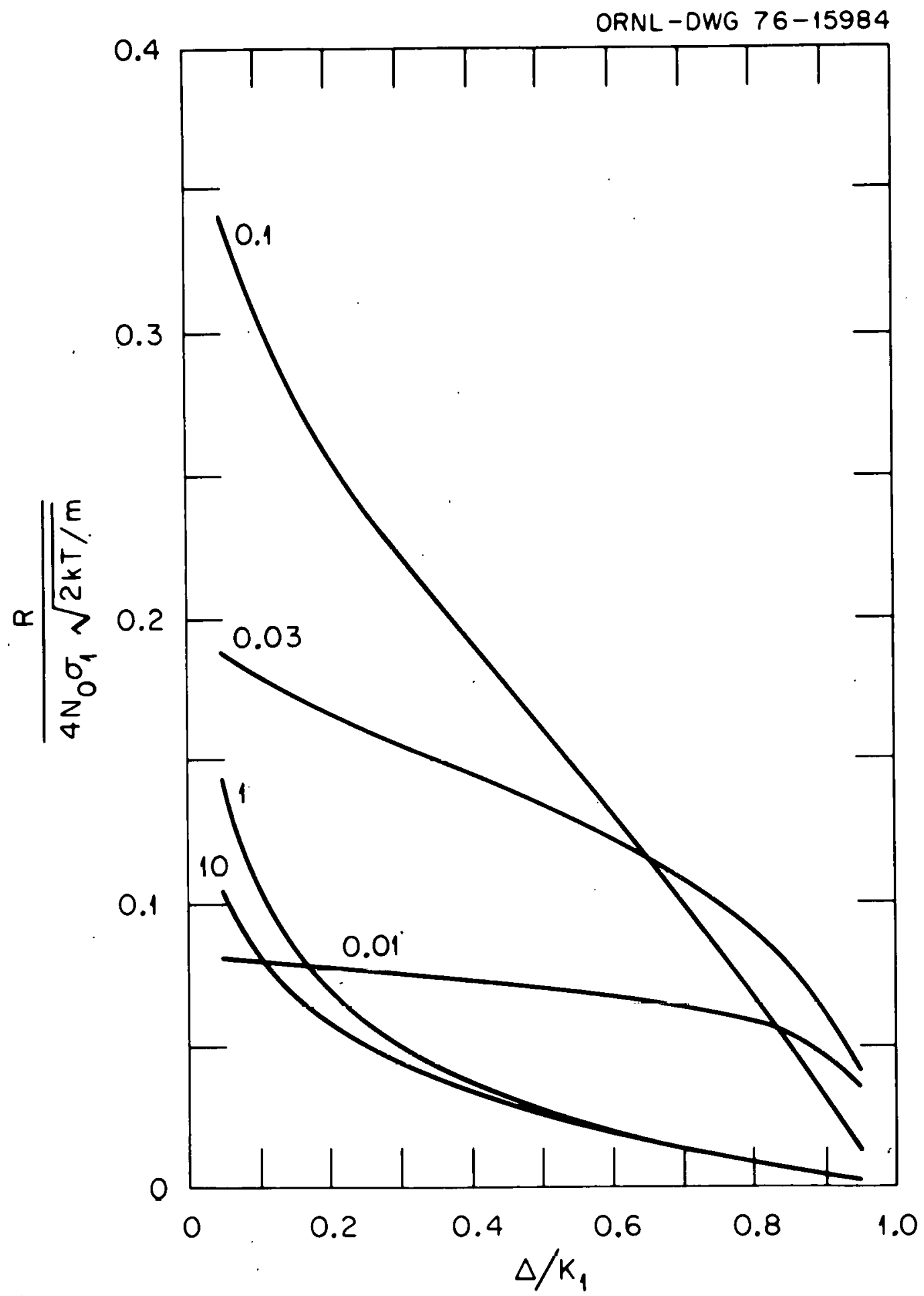

Figure 19. Fluorescence (case 2 with $\Gamma_{00}=0.05$ and $\mathrm{z}_{00}=$ 


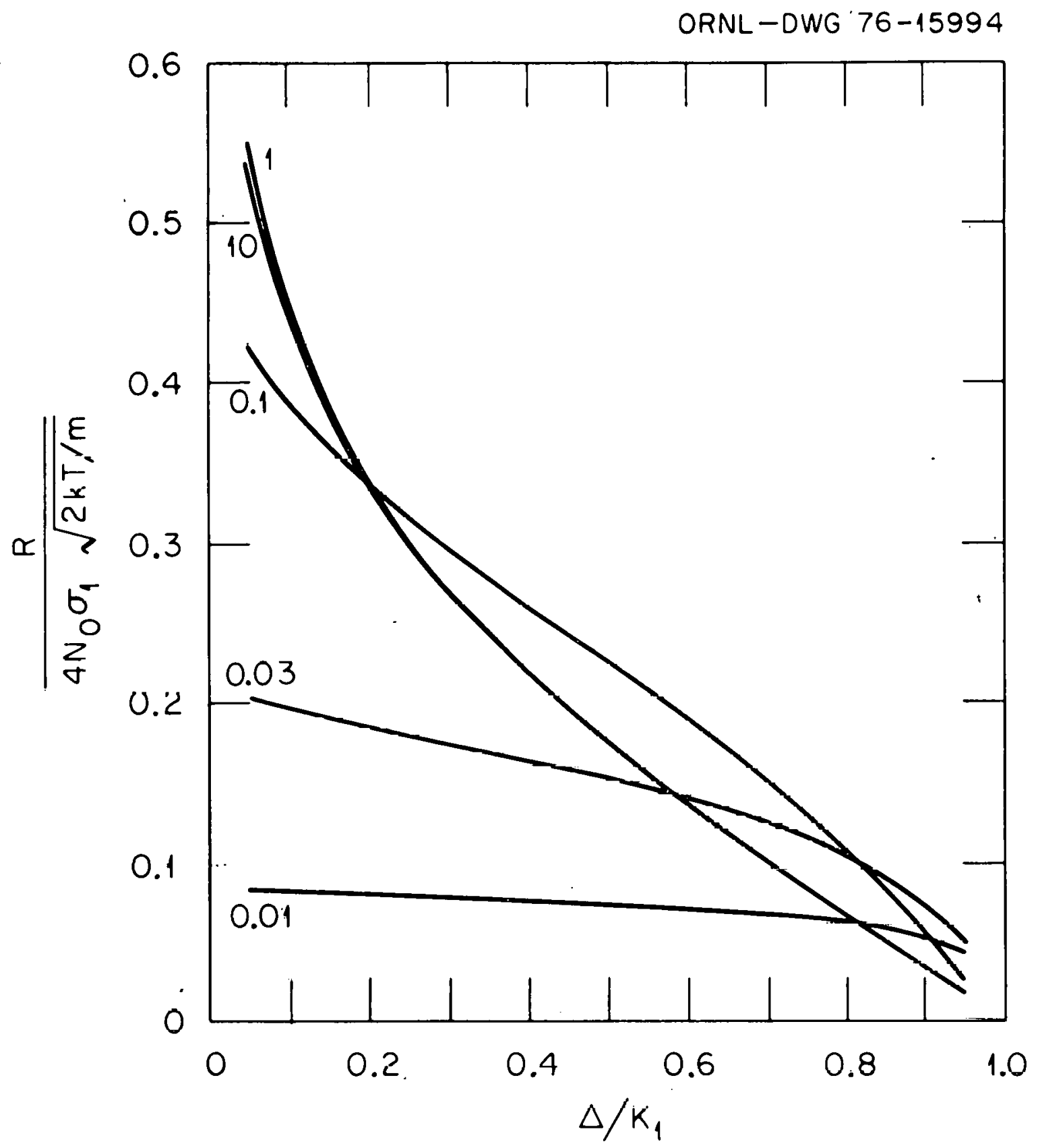
Figure 20. Fluorescence (case 2 with $\Gamma_{\circ O}=0.5$ and $\mathrm{z}_{\circ O}=$
$0.01-10$ ). 
$-69-$

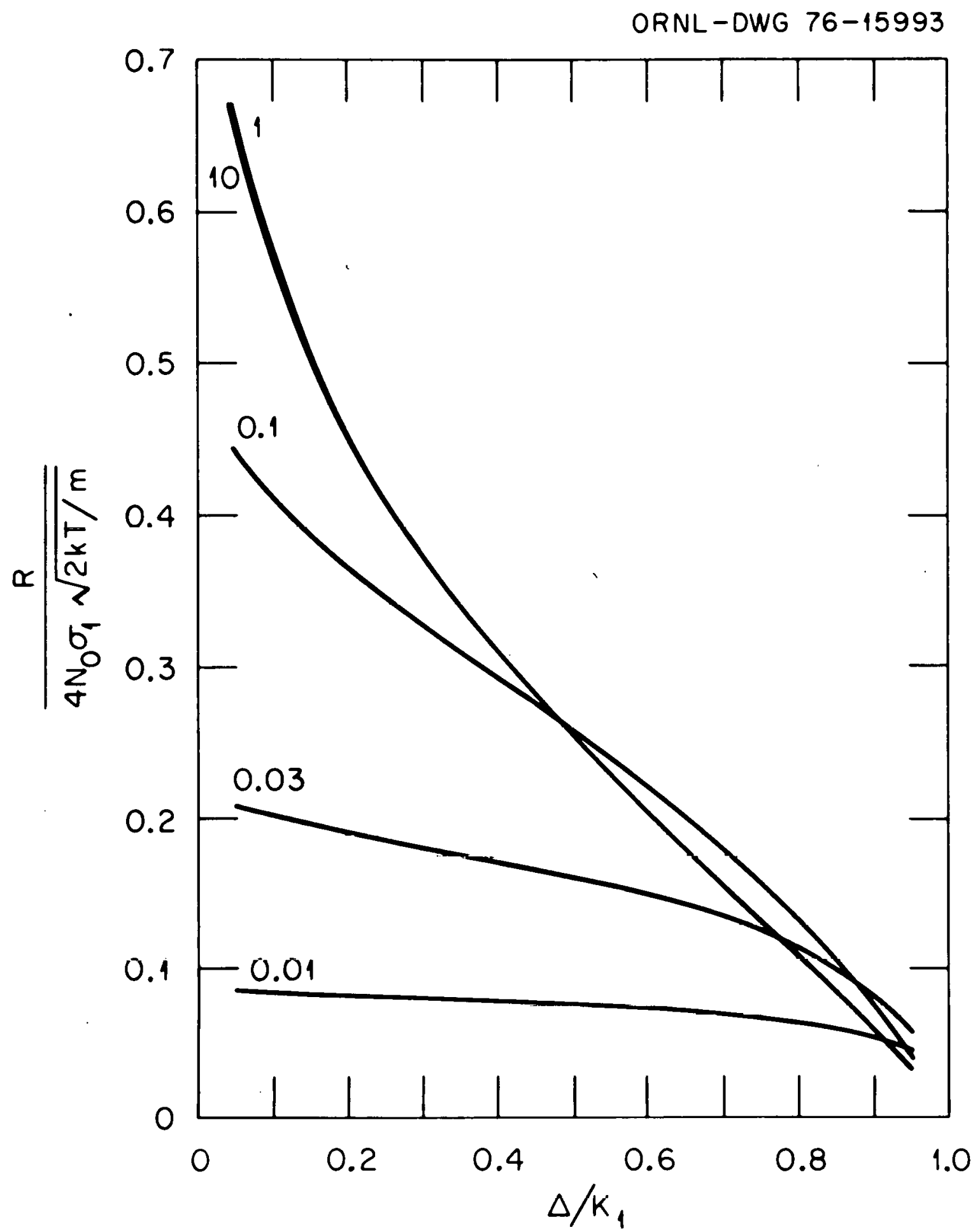

Figure 21. Fluorescence (case 2 with $\Gamma_{00}=1.0$ and $z_{00}=$
$0.01-10$ ). 


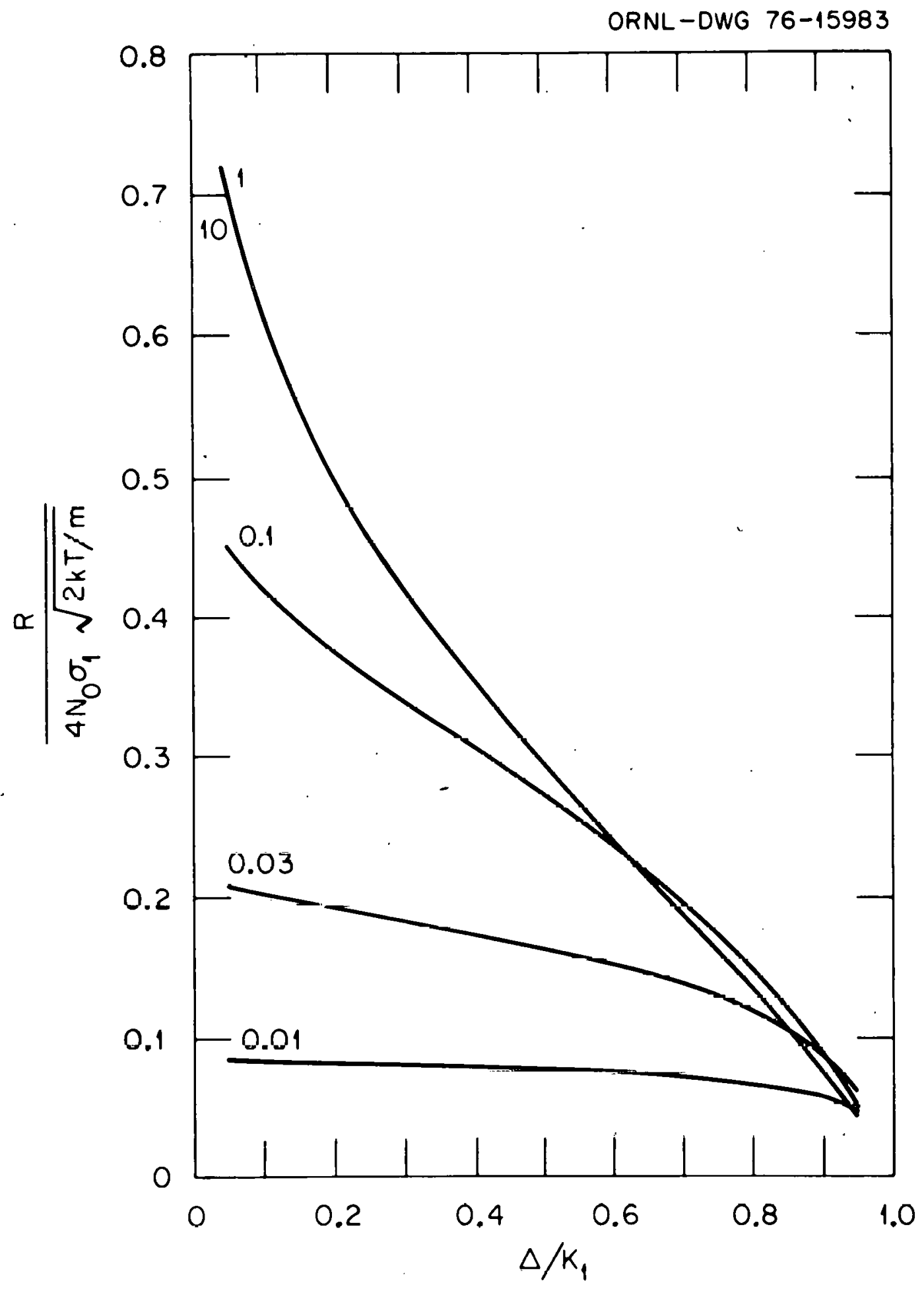
Figure 22. Fluorescence (case 2 with $\Gamma_{00}=1.5$ and $z_{\text {oo }}=$ 


\section{CHAPTER IV}

\section{TWO-PHOTON RESONANCE IONIZATION WITH PULSED LASERS}

We consider a problem solved earlier by Beers and 24

Armstrong for a fully quantitized single mode electromagnetic field of the square pulse type. In the present work the atom is treated quantum mechanically but the EM field is treated classically. This approximation should be valid for the high power levels that will be emphasized here and which were emphasized in Ref.24. The present work allows for the more general pulses of the form

$$
\begin{aligned}
\vec{E} & =\text { field intensity at }\left(x_{0}, y_{0}, z_{0}\right) \text { at } t i m e t \\
& =E_{0} \vec{i} g\left(S_{1} t\right) \cos \left(W t-k z_{0}+R\right) .
\end{aligned}
$$

where $g\left(s_{1} t\right)$ is a function of the type described (and named the same way) in section A of Chapter II. The atoms that interact with the laser beam are assumed to be very dilute in density (so that propagation effects and attenuation can be neglected) and to have no component of velocity parallel to the direction of propagation of the laser beam. The atoms are initially in the ground state $(i . e . \mid 0>)$ and $\hbar^{\prime}$ is nearly resonant for excitation of a state $|1\rangle$, and a 
second photon can photoionize state $|1\rangle$ as in Fig. 23 . In the latter situation, $|\psi(t)\rangle$ is approximately of the form

$$
\left.\left|\psi(t)>=a_{0}(t) e^{-i w_{0} t}\right| 0>+a_{1}(t) e^{i w_{1} t}\left|1>+\sum_{\mu} \int E_{c} c_{\mu}\left(E_{c^{\prime}}, t\right) e^{-i w_{c} t}\right| E_{c^{\prime}} \mu\right\rangle
$$

where

$$
\langle 0 \mid I\rangle=0,\left\langle E_{c^{\prime}}, \mu \mid E_{c^{\prime}}^{\prime}, \mu^{\prime}\right\rangle=\delta\left(E_{c^{\prime}}-E_{c^{\prime}}^{\prime}\right) \delta_{\mu, \mu},\left\langle i \mid E_{c^{\prime}}, \mu\right\rangle=0 .
$$

Now,

$$
\text { in } \frac{\partial}{\partial t}|\psi(t)>=\hat{H}| \psi(t)>\text {, }
$$

where

$$
\hat{H}=\hat{H}_{0}-\hat{P}_{x} E_{0} g\left(S_{1} t\right) \cos \left(w t-k z_{0}+B\right)-i \hbar \frac{\gamma_{l}}{2}|1><1| \text {, }
$$

and $\hat{\mathrm{H}}_{0}$ is the electronic Hamiltonian of the isulated atom, $\hat{\mathbf{p}}_{\mathrm{x}}$ is the $\mathrm{x}$ compunent of lie electric dipolc opcrator and $\vec{E}$ is plane-polarized parallel to the $x$-axis. We do not follow Beers and Armstrong in including other states which are far off resonance by an effective Hamiltonian method. This will, of course, lead to errors on the far wings of the line shape for photoionization. 


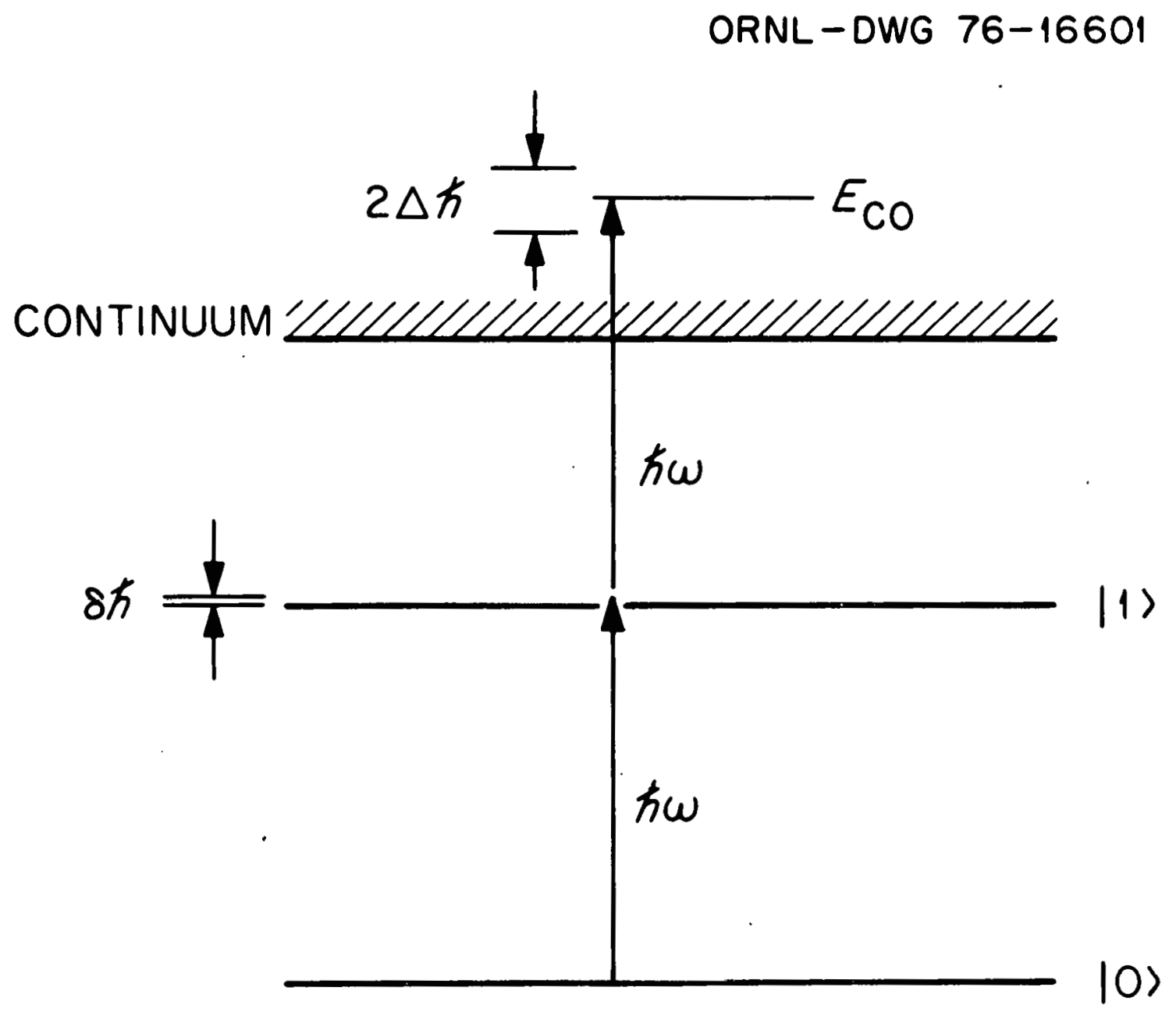

Figure 23. Energy Level Diagram of 2-Photon Transition with the Laser at $w$. 
Using the rotating wave approximation li.e., keeping only the low frequency oscillating part when $\cos x=\left(e^{i x}+\right.$ $\left.e^{-i x}\right) / 2$ combines with the complex exponentials], we find

$$
\begin{aligned}
& \frac{d a_{0}}{d t}=i w_{p} g\left(s_{1} t\right) e^{i\left(w-w_{1}+w_{0}\right) t} a_{1}, \\
& \begin{aligned}
\frac{d a_{1}}{d t}= & -\frac{\gamma_{1}}{2} a_{1}+w_{p}^{*} g\left(s_{1} t\right) e^{-i\left(w-w_{1}+w_{0}\right) t} a_{0} \\
& +i \sum_{\mu} \int d E_{c} c_{\mu}\left(E_{c}, t\right) e^{i\left(w_{1}-w_{c}+w\right) t} \alpha_{\mu}^{*}\left(E_{c}\right) g\left(s_{1} t\right),
\end{aligned} \\
& \frac{d c_{\mu}}{d t}\left(E_{c}, t\right)=i \alpha_{\mu}\left(E_{0}\right) g\left(s_{1} t\right) e^{-i\left(w_{1}-w_{c}+w\right) t} a_{1}
\end{aligned}
$$

where $w_{p}=\left\langle 0\left|\hat{P}_{x}\right| 1\right\rangle E_{0} / 2 \hbar, \alpha_{\mu}\left(E_{c}\right)=\left\langle E_{c}, \mu\left|\hat{P}_{x}\right| 1\right\rangle E_{0} / 2 \hbar$. Choosing $\Delta$ such that $\alpha_{\mu}\left(E_{c 0} \pm \hbar \Delta\right) \simeq \alpha_{\mu}\left(E_{c 0}\right)$ where $E_{c 0}=\hbar w_{0}+2 \hbar w$ and $|\Delta| \gg\left|\mathrm{da}{ }_{1} / \mathrm{dt}\right|$, we show that $\mathrm{C}_{\mu}\left(\mathrm{E}_{\mathrm{c}}, t\right)$ can be eliminated.

To eliminate $C_{\mu}\left(E_{r}, t\right)$, we integrate the last of Eq. (73)

$$
c_{\mu}\left(E_{c}, t\right)=i \alpha_{\mu}\left(E_{c}\right) \int_{-\infty}^{L} g\left(S_{1} t^{\prime}\right) e^{-i\left(w_{1}-w_{c}+w\right) t^{\prime}} a_{1}\left(t^{\prime}\right) d t^{\prime} .
$$


$-75-$

We now consider $\left|w_{c}{ }^{-w_{1}}{ }^{-w}\right| 2 \Delta$. with the restrictions $\left|d a_{1}(t) / d t\right| \ll \Delta$ and $s_{1} / \Delta \ll 1$ we can integrate by parts and neglect the remain integral.

$$
C_{\mu}\left(E_{c}, t\right) \simeq \frac{a_{\mu}\left(E_{c}\right) g\left(S_{1} t\right) a_{1}(t)}{w_{c} c_{1}^{-w}} e^{i\left(w_{c} c^{-w} w^{-w}\right) t},
$$

if $\left|w_{c}{ }^{-w_{1}}-w\right| \geq \Delta$. When $\left|w_{c}{ }^{-w}{ }_{1}^{-w}\right|<\Delta$ we can treat $\alpha_{\mu}\left(E_{c}\right)$ as a constant given by $\alpha_{\mu}\left(E_{c 0}\right)$. We have

$$
c_{\mu}\left(E_{c^{\prime}}, t\right)=i \alpha_{\mu}\left(E_{c 0}\right) \int_{-\infty}^{t} g\left(S_{1} t^{\prime}\right) e^{-i\left(w_{1}-w_{c}+w\right) t} a_{1}\left(t^{\prime}\right) d t^{\prime},
$$

if $\left|w_{c}{ }^{-w_{1}}-w\right|<\Delta$.

On substituting Eqs. (75) and (76) into second Eq. (73) the term involving $c_{\mu}\left(\tau_{c}, t\right)$ becomes

$$
\begin{aligned}
& I=\sum_{\mu} \int d E_{c} C_{\mu}\left(E_{c}, t\right) e^{i\left(w_{1}-w\right.} c^{+w) t} \alpha_{\mu}^{*}\left(E_{c}\right) g\left(S_{1} t\right) \\
& =\sum_{\mu} f \frac{\left|\alpha_{\mu}\left(E_{c}\right)\right|^{2} d E_{c}}{w_{c}-w_{1}-w} g^{2}\left(s_{1} t\right) a_{1}(t)
\end{aligned}
$$

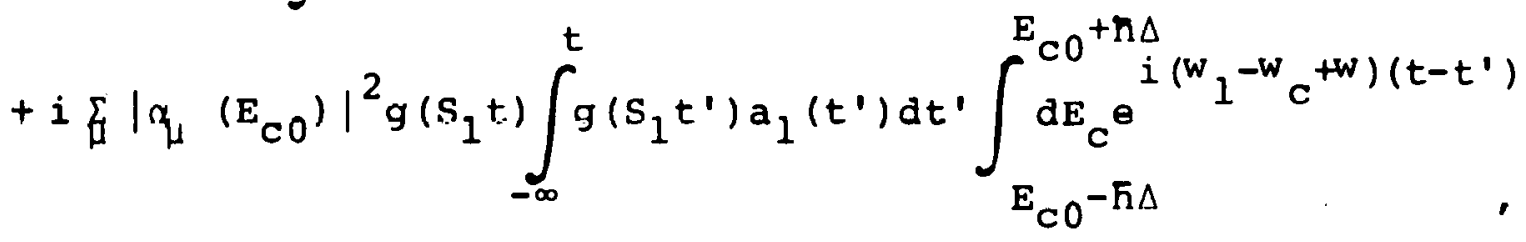


where $f$ means to delete the region of $E_{c}$ implied by $\left|w_{c}-w_{1}-w\right|<\Delta$. Since $\alpha_{\mu}\left(E_{c}\right)$ is extremely constant over the latter interval, $f$ can be replaced by a principal value integration. Thus,

$$
\begin{aligned}
I= & \bar{w} g^{2}\left(s_{1} t\right) a_{1}(t) \\
& +2 i \pi \sum_{\mu}\left|\alpha_{\mu}\left(E_{c 0}\right)\right|^{2} g\left(s_{1} t\right) \int_{-\infty}^{t} g\left(s_{1} t^{\prime}\right) a_{1}\left(t^{\prime}\right) e^{-i\left(w_{C 0}-w_{1}-w\right)\left(t-t^{\prime}\right)} \\
& \times \frac{\sin \Delta\left(t-t^{\prime}\right)}{t-t^{\prime}} d t^{\prime}
\end{aligned}
$$

with

$$
\bar{w}=P \int \frac{d E_{c} \sum_{\mu} \mid \alpha_{\mu}\left(E_{c}\right)^{2}}{w_{c}-w_{1}-w}
$$

With the assumptions that $|\delta|<<\Delta \quad\left(\delta=w_{60^{-}} w_{1}^{-w}\right)$ and that $\left(t-t^{\prime}\right)^{-1}$ sin $\Delta\left(t-t^{\prime}\right)$ behaves like a Dirac delta function with its peak at $t^{\prime}=t$, we. find

$$
\int_{-\infty}^{t} g\left(s_{1} t^{\prime}\right) a_{1}\left(t^{\prime}\right) e^{-i \delta\left(t-t^{\prime}\right)} \frac{\sin \Delta\left(t-t^{\prime}\right)}{t-t^{\prime}} d t^{\prime}=\frac{\pi}{2} g\left(\sigma_{1} t\right) a_{1}(t) .
$$

Thus,

$$
I=\bar{W} g^{2}\left(s_{1} t\right) a_{1}(t)+i P_{0} g^{2}\left(s_{1} t\right) a_{1}(t),
$$


where

$$
P_{0}=n \pi \sum_{\mu}\left|\alpha_{\mu}\left(E_{c 0}\right)\right|^{2} \text {. }
$$

In several other problems in the previous chapter we were faced with the inclusion of continuum states. A procedure which is completely analogous to the one described above was used to eliminate the continuum amplitude in each case.

With Eqs. (73) and (80)

$$
\begin{gathered}
\frac{d a_{0}}{d t}=i w_{p} g\left(s_{1} t\right) e^{i \delta t} a_{1}, \\
\frac{d a_{1}}{d t}=i w_{p}^{*} g\left(s_{1} t\right) e^{-i \delta t} a_{0}+\left(i \bar{w}-p_{0}\right) g^{2}\left(s_{1} t\right) a_{1}-\frac{\gamma_{1}}{2} a_{1},
\end{gathered}
$$

with $\delta=w-\left(w_{1}-w_{0}\right)$. Thus, we now have an effective two-state problem. Let $a_{1}(t)=b_{1}(t) \exp \left[i \bar{w} \int^{t} g^{2}\left(s_{1} t^{\prime}\right) d t^{\prime}\right]$, and

$$
\begin{gathered}
\frac{d a_{0}}{d t}=i w_{p} g\left(s_{1} t\right) e^{i \delta t} \exp \left[i \bar{w} \int_{-\infty}^{t} g^{2}\left(s_{1} t^{\prime}\right) d t^{\prime}\right] b_{1}, \\
\frac{d b_{1}}{d t}=-\left(\frac{\gamma_{1}}{2}+p_{0} g^{2}\left(s_{1} t\right)\right) b_{1}+i w_{p} g\left(s_{1} t\right) e^{-i \delta t} \\
\times \exp \left[-i \bar{w} \int_{-\infty}^{t} g^{2}\left(s_{1} t^{\prime}\right) d t^{\prime}\right] a_{0} .
\end{gathered}
$$


The coupling terms $w_{p} g \exp \left[i \delta t+i \bar{w} \int_{-\infty}^{t} g^{2}\left(s_{1} t^{\prime}\right) d t^{\prime}\right]$ have the property that the oscillating exponential is ineffective in decreasing the effectiveness of the coupling if $\left|w_{p} g\right|>>\left|\delta+\bar{w} g^{2}\right|$. Essentially, this means that $\left|w_{p} g\right|$ is so big that $a_{0}$ and $b_{1}$ can be changed by large amounts in a time which is small compared with the time for $\exp \left[i \delta t+i W \int_{\infty}^{t} g^{2}\left(s_{1} t^{\prime}\right) d t^{\prime}\right]$ to oscillate once. Thus, if $\left|w_{p}\right|>>|\mathbb{W}|$ the a.c. Stark shift due to coupling with the continuum states can be neglected for all $\delta$. We note further that unles $\left\langle 0\left|\hat{\boldsymbol{P}}_{\mathbf{x}}\right| 1\right\rangle$ is extremely small we will have both $\left|w_{p}\right|>>|\widetilde{w}|$ and $\left|w_{p}\right| \gg>p_{0}$ in any problems of this type. We also take the peak power to be very large so that $\left|w_{p}\right|>>\gamma_{1}$ and $\left|w_{p}\right| / s_{1}>>1$. In this situation the factorization method of Chapter II can be used as follows:

$$
\left(\frac{d}{d t}+y_{1}\right)\left(\frac{d}{d t}+y_{2}\right) u_{1}-0,
$$

with

$$
\begin{gathered}
g_{1}+g_{2}=i \delta-\frac{d}{d t} \operatorname{lng}+\left(\frac{\gamma_{1}}{2}+P_{0} g^{2}\right) \\
g_{1} g_{2}+\frac{d g_{2}}{d t}=\left|w_{p}\right|^{2} g^{2}+i \delta\left(\frac{\gamma_{1}}{2}+P_{0} g^{2}\right)-\left(\frac{\gamma_{1}}{2}+P_{0} g^{2}\right) \frac{d \cdot}{d t} \operatorname{lng}+P_{0} \frac{d}{d t} g^{2} .
\end{gathered}
$$

If $\gamma_{1} /\left|w_{p}\right| \ll 1$ and $p_{o} /\left|w_{p}\right| \ll 1$ we can neglect some of the terms and use 
$-79-$

$$
\begin{aligned}
& g_{1}+g_{2}=i \delta-\frac{d}{d t} \operatorname{lng}+\left(\frac{\gamma_{1}}{2}+P_{o} g^{2}\right), \\
& g_{1} g_{2}+\frac{d g_{2}}{d t} \simeq\left|w_{p}\right|^{2} g^{2}+i \delta\left(\frac{\gamma_{1}}{2}+P_{o} g^{2}\right) .
\end{aligned}
$$

With our assumptions the following $g_{1}$ and $g_{2}$ are adequate for good accuracy (we take $\gamma_{1} / s_{1} \ll 1$ for simplicity)

$$
\begin{aligned}
& g_{1}=\frac{i \delta+i \varepsilon K}{2}-\left(\frac{1}{2}+\frac{|\delta|}{2 K}\right) \frac{d}{d t} \operatorname{lng}+\left(\frac{1}{2}-\frac{|\delta|}{2 K}\right) P_{0} g^{2}-\frac{1}{2} \frac{d}{d t} \ln K, \\
& g_{2}=\frac{i \delta-i \varepsilon K}{2}-\left(\frac{1}{2}-\frac{|\delta|}{2 K}\right) \frac{d}{d t} \operatorname{lng}+\left(\frac{1}{2}+\frac{|\delta|}{2 K}\right) P_{0} g^{2}+\frac{1}{2} \frac{d}{d t} \ln K,
\end{aligned}
$$

where

$$
\begin{gathered}
\varepsilon=\delta /|\delta| \\
k-\sqrt{\delta^{2}+4\left|\omega_{p}\right|^{2} y^{2}} .
\end{gathered}
$$

Eq. (15) of Chapter II yields

$$
\left|a_{1}(t)\right|^{2}=\left(\frac{1}{2}-\frac{|\delta|}{2 K}\right) \exp \left[-p_{0} \int_{-\infty}^{t}\left(1-\frac{|\delta|}{k}\right) g^{2} d t^{\prime}\right] \text {. }
$$

The ionization probability $R$ is given by.

$$
R=1-\exp \left[-P_{0} \tau \int_{-\infty}^{\infty}\left(1-\frac{|\delta|}{K}\right) g^{2} d V\right]
$$


where $\tau=1 / s_{1}, V=t S_{1}$. $R$ can be put in the form

$$
R=1-\exp \left[-P_{o} \tau L_{g}\left(\left|\delta /\left(2 W_{p}\right)\right|\right)\right]
$$

where; assuming $g(-V)=g(V)$,

$$
L_{g}(x)=2 \int_{0}^{\infty}\left(1-x / \sqrt{x^{2}+g^{2}}\right) g^{2} d V
$$

Any smoothly varying function having a single maximum of unit amplitude at $t=0$ and approaching zero sufficiently rapidly at $t \rightarrow \pm \infty$ can be used. We take $g(v)=\left[1+v^{2}\right]^{-3 / 2}$ and tabulate $L_{g}(x)$. A graph of $\left(-P_{0} \tau\right)^{-1} \ln (1-R)$ versus $\left|\delta /\left(2 W_{p}\right)\right|$ is a graph of the function $L_{q^{*}}$ For our choice of $g$ a graph of $L_{g}$ is given in Fig. 24. We note that $L_{g}(0)=3 \pi / 8$ and for $x z_{.} 6$ we have $L_{g}(x) \simeq 0.3866 / x^{2}$. Thus, at high power levels the entire line shape has been calculated accurately by the factorization method.

With the same approximations and a square pulse

$$
\begin{aligned}
g^{2}\left(s_{1} t\right) & =g^{2}(V) \\
& =0, \quad V<0 ; \\
& =\frac{3 \pi}{8}, 0 \leq V \leq 1 ; \\
& =0, V>1 ;
\end{aligned}
$$

we find 


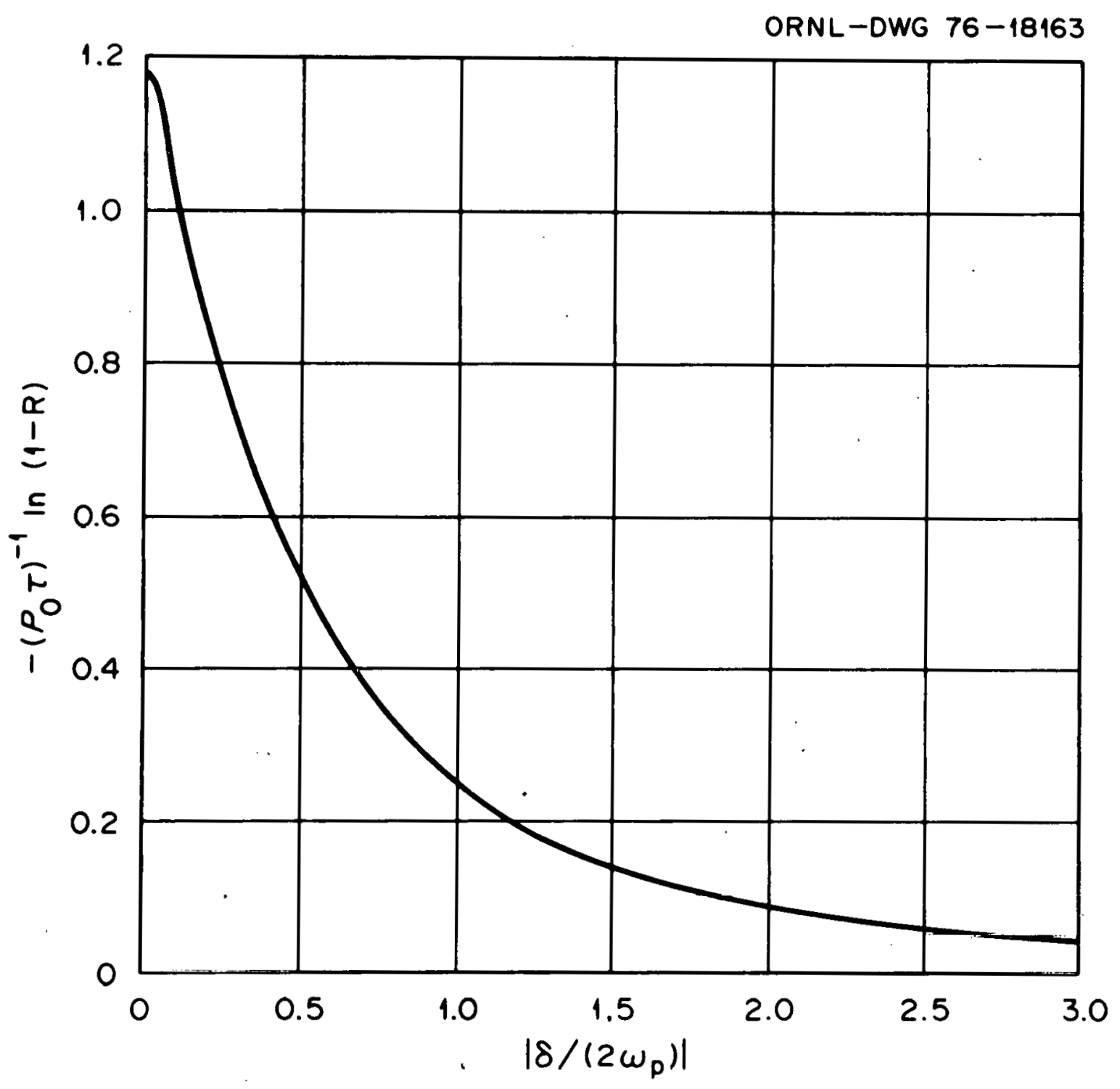

Figure 24. Photoionization Probability, $g(t)=[1+$ $(t / \tau) 2]-3 / 2,2$-Photon Transition. 


$$
R=\frac{1}{2} \frac{{ }_{O_{0} g^{2} \tau}}{1+x^{2}}\left[\frac{1-e^{-A}}{A}+\frac{1-e^{-B}}{B}\right]
$$

where

$$
\begin{aligned}
& x=\left|\delta /\left(2 W_{p}\right)\right|, \\
& A-P_{O} g^{2} \tau\left[1 \quad x / \sqrt{1+x^{2}}\right], \\
& B=P_{O} g^{2} \tau\left[1+x / \sqrt{1+x^{2}}\right] .
\end{aligned}
$$

If $x>1$, we obtain an asymptotic solution

$$
R=1-\exp \left[-P_{0} g^{2} \tau /\left(2 x^{2}\right)\right]
$$

In the square pulse case, $\gamma_{1}$ and $P_{0}$ can be included without the approximation $\gamma_{1} /\left|w_{p}\right|$ and $P_{o} /\left|w_{p}\right| \ll 1$ [see Eqs. (91), Appendix B] .

It is interesting to note that if $\mathrm{P}_{\mathrm{Q}} \tau \gg 1$, then both the smooth pulse and the square pulse yield similar line shapes $-R$ being $\simeq 1$ for both cases if $x<\sqrt{P_{0} \tau}$, with the smooth pulse $R$ dropping a bit faster on the far wing. Also, we note that when $P_{0}{ }^{\tau} \gg 1$ we can use the asymptotic forms of Eqs. (87) and (89) for all $\delta$. 
APPENDIX A

\section{TABULATION OF THE H FUNCTION}

In Section $C$ of chapter III we have derived analytical expression for photoionization probability

$$
R=1-\exp \left[-P_{O} \tau H\left(\frac{\delta}{\mu}, \mid \frac{\alpha}{\mu}\right)\right]
$$

where

$$
\begin{aligned}
& H\left(\frac{\alpha}{\mu},\left|\frac{\alpha}{\mu}\right|\right)=\int_{-\infty}^{\infty}\left[1-\frac{\varepsilon^{\prime}(2 \delta / \mu-g(v))}{\sqrt{(2 \delta / \mu-g(v))^{2}+4|\alpha / \mu|^{2} g^{2}(v)}}\right] g(v) d V, \\
& \text { if } \delta \neq 0 ; \\
&=\frac{3 \pi}{2}|\alpha / \mu|^{2}\left(1+4|\alpha / \mu|^{2}\right)^{-1}, \\
& \text { if } \delta=0 ;
\end{aligned}
$$

and $\varepsilon^{\prime}=\delta \mu /|\delta \mu|$.

We have tabulated $H\left(\frac{\delta}{\mu},\left|\frac{\alpha}{\mu}\right|\right)$ for $g(v)=\left(1+v^{2}\right)^{-3}$

and the results are given in the following table in the order $\frac{\delta}{\mu},\left|\frac{\alpha}{\mu}\right|$ and $H\left(\frac{\delta}{\mu},\left|\frac{\alpha}{\mu}\right|\right)$. 
TABLE 1

$\mathrm{H}\left(\frac{\delta}{\mu},\left|\frac{\alpha}{\mu}\right|\right)$

\begin{tabular}{|c|c|c|c|c|}
\hline$\frac{\delta}{\mu}$ & & $\left|\frac{\alpha}{\mu}\right|$ & & $H\left(\frac{\delta}{\mu}\left|\frac{\alpha}{\mu}\right|\right)$ \\
\hline 0.10000000 & 01 & 0.10000000 & 00 & $0.9712551 \mathrm{c}-02$ \\
\hline 0.10000000 & 01 & C. $2000000 \mathrm{~V}$ & $\mathrm{CO}$ & $0.36581 \leq 2 \mathrm{C}-\mathrm{Cl}$ \\
\hline 0.10000000 & 01 & 0.30000000 & CO & $0.7524913[-01$ \\
\hline 0.10000000 & 01 & 0.40000000 & 00 & 0.1200089000 \\
\hline $0.10000 \mathrm{COD}$ & 01 & 0.50000000 & $\mathrm{CO}$ & $0.1665224 \mathrm{DO} 00$ \\
\hline 0.10000000 & 01 & 0.60000000 & $\mathrm{CO}$ & 0.2121147000 \\
\hline $0.10000 \mathrm{COD}$ & 01 & 0.70000000 & co & $0.2553891 \mathrm{c} 00$ \\
\hline 0.10000000 & 01 & $0.8000000 \mathrm{D}$ & 00 & $0.2957536 \mathrm{C} \quad 00$ \\
\hline $0.9600000 \mathrm{D}$ & 00 & 0.10000000 & 00 & $0.11266950-01$ \\
\hline 0.96000000 & 00 & 0.20000000 & 00 & $0.4202336 \mathrm{D}-01$ \\
\hline $0.96000 \mathrm{COD}$ & 00 & 0.30000000 & 00 & $0.85341750-01$ \\
\hline $0.9600000 \mathrm{D}$ & 00 & 0.40000000 & 00 & 0.1343135000 \\
\hline 0.96000000 & 00 & 0.50000000 & 00 & 0.1841085000 \\
\hline 0.96000000 & 00 & 0.60000000 & 00 & 0.2320302000 \\
\hline 0.96000000 & 00 & 0.70000000 & 00 & $0.2768452 \mathrm{ECO}$ \\
\hline 0.96000000 & 00 & 0.80000000 & 00 & $0.7181550 \mathrm{r} .00$ \\
\hline 0.92000000 & 00 & 0.10000000 & 00 & $0.13227240-01$ \\
\hline 0.92000000 & 00 & 0.20000000 & 00 & $0.48732995-01$ \\
\hline $0.92000 \mathrm{COD}$ & 00 & 0.30000000 & $\mathrm{CO}$ & $0.97443270-01$ \\
\hline $0.9200000 \mathrm{D}$ & 00 & 0.40000000 & 00 & $0.1510110 \mathrm{C} 00$ \\
\hline $0.9200000 \mathrm{D}$ & 00 & $0.5000000 \mathrm{D}$ & 00 & 0.2041698000 \\
\hline $0.9200000 \mathrm{D}$ & 00 & 0.60000000 & 00 & 0.2543275000 \\
\hline
\end{tabular}




\begin{tabular}{|c|c|c|c|c|c|}
\hline $0.92000 \mathrm{COD}$ & 00 & C. 70000000 & co & 0.30051130 & 00 \\
\hline .92000000 & 00 & 0.80000000 & 00 & $0.3425718 \mathrm{C}$ & 0 \\
\hline $0.88000 \mathrm{COD}$ & 00 & 0.10000000 & 00 & $0.1574763 \mathrm{~L}$ & -0 \\
\hline $0.88000 \mathrm{COD}$ & 00 & $0.2000000 \mathrm{D}$ & 00 & $0.5711692 \mathrm{D}$ & -0 \\
\hline $0.88000 \mathrm{COD}$ & 00 & 0.30000000 & 00 & 0.11206440 & 0 \\
\hline $.88000 \mathrm{COD}$ & 00 & 0.40000000 & co & 0.17057270 & 0 \\
\hline $.8800000 \mathrm{D}$ & 00 & $0.5000000 \mathrm{D}$ & 00 & $0.2270846 \mathrm{E}$ & 0 \\
\hline $.88000 \mathrm{COD}$ & 00 & 0.60000000 & 00 & $792937 \mathrm{C}$ & 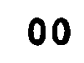 \\
\hline .88000000 & 00 & 0.70000000 & 00 & $266019 \mathrm{C}$ & $c$ \\
\hline $.88000 \mathrm{COD}$ & 00 & 0.80000000 & 00 & 6916530 & 0 \\
\hline .84000000 & 00 & 0.1 & $\mathrm{CO}$ & 9062500 & - \\
\hline .84000000 & 00 & 0.20000000 & 00 & 17746370 & -0 \\
\hline $.8400000 D$ & 00 & 0.30000000 & 00 & $8612 \mathrm{C}$ & $c$ \\
\hline .84000000 & 00 & C. 40000000 & 00 & $35585 \mathrm{C}$ & \\
\hline $.8400000 D$ & 00 & 0000000 & 00 & 127560 & 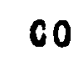 \\
\hline .84000000 & $0 \dot{0}$ & OU00000 & 00 & 723510 & 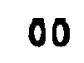 \\
\hline $.8400000 D$ & 00 & 0.700 & 00 & 533900 & 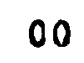 \\
\hline $.84000 \mathrm{COD}$ & 00 & 0.80000000 & 00 & 9809900 & 0 \\
\hline .80000000 & 00 & 000000 & 00 & 3541200 & - \\
\hline $0.8 C 000 C O D$ & 00 & 000000 & $\mathrm{CO}$ & 1434810 & -0 \\
\hline $.8000000 D$ & 00 & 0000 & 00 & 7260 & 0 \\
\hline 0.80000000 & 00 & OOOD & 60 & .062240 & 0 \\
\hline 0.80000000 & 00 & 000000 & 00 & 10 & 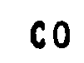 \\
\hline $0.80000 \mathrm{COD}$ & 00 & 0000 & 00 & 1847200 & 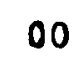 \\
\hline 0.80000000 & 00 & OOOOD & 00 & 0.38694730 & 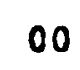 \\
\hline $0.80000 \mathrm{COD}$ & 00 & C. $8000000 D$ & 00 & $0.4295357 \mathrm{D}$ & \\
\hline
\end{tabular}




\begin{tabular}{|c|c|c|c|c|c|}
\hline $0.76000 \mathrm{COD}$ & 00 & 0.10000000 & 00 & \multicolumn{2}{|c|}{$0.29790770-01$} \\
\hline 0.76000000 & 00 & 0.20000000 & $\mathrm{CO}$ & $0.99352 \mathrm{E} 1 \mathrm{C}$ & -01 \\
\hline 0.76000000 & 00 & 0.30000000 & 00 & $0.1785566 \mathrm{D}$ & 00 \\
\hline 0.76000000 & 00 & 0.40000000 & 00 & 0.25251070 & 00 \\
\hline $0.76000 \mathrm{COD}$ & 00 & 0.50000000 & $\mathrm{CO}$ & 0.31736470 & 00 \\
\hline 0.76000000 & 00 & C. $6000000 \mathrm{D}$ & 00 & 0.37332550 & 00 \\
\hline $0.7600000 \mathrm{D}$ & 00 & 0.70000000 & 00 & 0.42164910 & 00 \\
\hline 0.76000000 & 00 & 0.80000000 & 00 & 0.46363370 & 00 \\
\hline $0.72000 \mathrm{COD}$ & 00 & 0.10000000 & CO & $0.3885827 \mathrm{D}$ & -01 \\
\hline 0.72000000 & 00 & $0.2000000 D$ & 00 & $0.12318 E 5 \mathrm{D}$ & CO \\
\hline $0.72000 \mathrm{COD}$ & 00 & C. $3000000 D$ & co & $0.2118172 \mathrm{D}$ & 00 \\
\hline $0.7200000 \mathrm{D}$ & 00 & 0.40000000 & 00 & 0.29004580 & 00 \\
\hline $0.72000 \mathrm{COD}$ & 00 & $0.50000 C 0 D$ & CO & $0.3562585 \mathrm{C}$ & 00 \\
\hline 0.72000000. & 00 & 0.60000000 & 00 & 0.41212670 & 00 \\
\hline $0.72000 \mathrm{COD}$ & 00 & 0.70000000 & 00 & $0.4596575 \mathrm{C}$ & 00 \\
\hline $0.72000 \mathrm{COD}$ & 00 & 0.80000000 & 00 & 0.50054380 & 00 \\
\hline ח. KAONOOOD & 00 & 0.10000000 & 00 & $0.5265032 \mathrm{D}$ & -01 \\
\hline 0.68000000 & no & 0.20000000 & 00 & 0.15535580 & Co \\
\hline 0.68000000 & 00 & 0.30000000 & 00 & $0.2529955 \mathrm{C}$ & 00 \\
\hline 0.68000000 & 00 & 0.40000000 & 00 & $0.33408 E 1 \overline{\mathrm{t}}$ & 00 \\
\hline $0.68000 \mathrm{COD}$ & 00 & 0.50000000 & 00 & $0.40037 \in 6 D$ & 00 \\
\hline 0.68000000 & 00 & 0.60000000 & 00 & $0.45516<0 \mathrm{C}$ & 00 \\
\hline $0.68000 \mathrm{COD}$ & 00 & $0.7000000 \mathrm{D}$ & 00 & $0.5011686 \mathrm{C}$ & 00 \\
\hline 0.68000000 & 00 & 0.80000000 & 00 & $0.5404048 \mathrm{D}$ & 00 \\
\hline
\end{tabular}




\begin{tabular}{|c|c|c|c|c|c|}
\hline 64000000 & 00 & 0.10000000 & 00 & $0.74838230-$ & -01 \\
\hline $64000 \mathrm{CCD}$ & 00 & C. 20000000 & co & 0.19918150 & 00 \\
\hline 64000000 & 00 & 0000000 & 00 & 0379190 & 60 \\
\hline 4000000 & 00 & 0000000 & 00 & $6 \mathrm{D}$ & 0 \\
\hline 1000000 & 00 & 0000000 & 00 & $501622 \mathrm{D}$ & \\
\hline $1000 C O D$ & 00 & DD & 00 & D & \\
\hline & 0 & & 00 & & \\
\hline D & 00 & & 00 & 10 & 0 \\
\hline 60000000 & 00 & OD & 00 & OD & 0 \\
\hline D & 00 & D & 00 & 0. & 0 \\
\hline OD & 00 & & 00 & & 0 \\
\hline D & 0 & & 00 & & 0 \\
\hline & $\mathrm{c}$ & & 00 & & \\
\hline & & & 00 & & \\
\hline .60000 & 00 & $0 D$ & 00 & 0.59 & 0 \\
\hline $6000000 \mathrm{D}$ & 00 & 0.8 & 00 & 170 & 0 \\
\hline 00000 & $O C$ & DD & 00 & & $\mathrm{c}$ \\
\hline D & 0 & D & co & D & \\
\hline D & & D & 0 & 20 & 00 \\
\hline 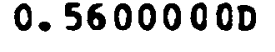 & 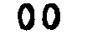 & D & 00 & D & \\
\hline $.5600000 \mathrm{D}$ & ( & D & 0 & 0.56 & 00 \\
\hline .56000000 & 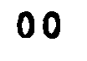 & D & 00 & 300 & 0 \\
\hline 6000000 & 政 & 0. & 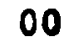 & 27030 & \\
\hline esere & & 0.80000000 & 00 & $0.6788332 \mathrm{D}$ & \\
\hline
\end{tabular}




\begin{tabular}{|c|c|c|c|c|c|}
\hline $0.52000 \mathrm{COD}$ & 00 & 0.10000000 & 00 & 0.30141810 & 00 \\
\hline 0.52000000 & 00 & $0.2000000 \mathrm{D}$ & Co & $0.4423623 \mathrm{C}$ & 00 \\
\hline $0.52000 \mathrm{COD}$ & 00 & C. 30000000 & CO & $0.5284195 \mathrm{D}$ & 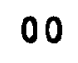 \\
\hline $0.52000 \mathrm{COD}$ & 00 & 0.40000000 & 00 & 0.58957700 & 00 \\
\hline 0.52000000 & 00 & C. 50000000 & 00 & $0.63643 E 2 \mathrm{D}$ & 00 \\
\hline $0.52000 \mathrm{COD}$ & 00 & .60000000 & 00 & $0.6740363 \mathrm{D}$ & \\
\hline $0.52000 C O D$ & 00 & C. 70000000 & co & $0.7051656 \mathrm{D}$ & \\
\hline 0.32000000 & 00 & .80000000 & 00 & 0.73153910 & \\
\hline 0.48000000 & 00 & 0.10000000 & CO & $0.4842734 \mathrm{D}$ & \\
\hline $0.4800000 \mathrm{D}$ & 00 & 0.20000000 & 00 & 5854550 & \\
\hline $0.48000 \mathrm{CCD}$ & 00 & OOD & 00 & 193770 & 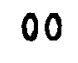 \\
\hline 0.48000000 & 0 & OOD & Co & $142 \mathrm{D}$ & \\
\hline 0.48000000 & 0 & OOD & 00 & 6D & \\
\hline 0.48000000 & 0 & DOD & 00 & O2D & \\
\hline $0.48000 \mathrm{COD}$ & 0 & $00000 D$ & 00 & 090 & 0 \\
\hline 0.48000000 & 0 & 000 & 00 & 0.78761640 & \\
\hline 0.44000000 & 0 & 0000 & $\mathrm{CO}$ & $9434 \mathrm{D}$ & \\
\hline - tha & $n$ & OD & 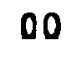 & 8D & 0 \\
\hline $0.4400000 \mathrm{D}$ & 0 & $C .3000000 D$ & 00 & SD & uc \\
\hline $0.4400000 \mathrm{D}$ & 0 & OOOD & 00 & 70 & 0 \\
\hline 0.44000000 & 0 & 000 & co & 720 & ) \\
\hline 0.44000000 & 0 & 0.60 & 00 & 70 & 0 \\
\hline $0.44000 \mathrm{COD}$ & 0 & 0.70000000 & 00 & 9940 & \\
\hline 0.44000000 & 00 & 0.80000000 & 00 & $0.8470935 \mathrm{C}$ & \\
\hline
\end{tabular}


$0.4000000000 \quad 0.1000000000 \quad 0.9137457000$

$0.40000 C O D 00 \quad 0.2000000 D 00 \quad 0.8660309000$

$0.4000000 D 00 \quad 0.3000000000 \quad 0.8606446000$

$0.40000 C 0000 \quad 0.40000000 C 0 \quad 0.8674847000$

$0.4000000000 \quad 0.50000000 C 0 \quad 0.8778473000$

$0.40000 C O D \quad 00 \quad 0.6000000000 \quad 0.8889336000$

$0.40000 C 0000 \quad 0.7000000000 \quad 0.8997617000$

$0.4000000 D 00 \quad C .8000000 D C 0 \quad 0.9099893000$

$0.3600000000 \quad 0.1000000 \mathrm{C} 00 \quad 0.1107712001$

$0.3600000000 \quad 0.2000000000 \quad 0.1022407001$

$0.3600000000 \quad 0.30000000 \quad 00 \quad 0.9866663000$

$0.36000000 \quad 00 \quad 0.40000000$ CO 0.9730233000

$0.3600000000 \quad 0.5000000000 \quad 0.96908590 \cdot C 0$

$0.36000000 \quad 00 \quad 0.6000000000 \quad 0.9696770000$

$0.3600000000 \quad 0.70000000 \quad 00 \quad 0.9724665000$

$0.36000 C C D \quad 00 \quad C .8000000 D \quad C O \quad 0.9763241000$

$0.32000 C 0 D 00 \quad 0.1000000 D C O \quad 0.1282320001$

$0.32000 C O D 00 \quad C .2000000000 \quad 0.1176572001$

$0.32000 C 0 D 00.0 .3000000000 \quad 0.11160460 \mathrm{Cl}$

$0.32000 C 0 D 00 \quad 0.4000000 D C 0 \quad 0.1083118 \mathrm{C} 01$

$0.32000 C 0 D \quad 00 \quad 0.5000000 D 00 \quad 0.1064864001$

$0.32000 C O D \quad 000.6000000 D 00 \quad 0.1054632001$

$0.32000 C 0 D \quad 000.7000000000 \quad 0.1049002 D 01$

$0.32000 C 0000 \quad 0.8000000000 \quad 0.1046133001$ 


\begin{tabular}{|c|c|c|c|c|c|}
\hline $0.28000 C O D$ & 00 & C. 10000000 & 00 & 0.14407780 & 01 \\
\hline $0.2800000 \mathrm{D}$ & 00 & 0.20000000 & 00 & 0.13259780 & \\
\hline $0.28000 \mathrm{COD}$ & 00 & .30000000 & $\mathrm{CO}$ & $0.1246806 \mathrm{D}$ & \\
\hline .28000000 & 00 & .40000000 & 00 & .11967150 & \\
\hline 0.28000000 & 00 & .50000000 & co & 0.11646870 & \\
\hline $0.28000 C 0 D$ & 00 & .60000000 & 00 & 0.11436080 & \\
\hline 0.28000000 & 00 & .70000000 & CO & $0.1129348 \mathrm{C}$ & \\
\hline 0.28000000 & OU & .80000000 & 00 & 0.11194880 & \\
\hline 0.24000000 & 00 & .10000000 & 00 & 0.15863890 & \\
\hline 0.24000000 & 00 & .20000000 & 00 & 0.14697 .300 & \\
\hline $0.24000 C 0 D$ & 00 & .30000000 & 00 & 6030 & \\
\hline $0.2400000 \mathrm{D}$ & 00 & $.4000000 \mathrm{D}$ & 00 & $129 \varepsilon 00$ & \\
\hline $0.2400000 D$ & 00 & OOD & 00 & 681590 & \\
\hline 0.24000000 & 00 & OOD & 00 & 6488ก & \\
\hline OOOCOD & 00 & 1000 & co & 135470 & \\
\hline 0.24000000 & 0 & OOD & 0 & & \\
\hline Do & nn & 0000000 & 00 & $8 \mathrm{D}$ & \\
\hline 0.20000000 & 00 & 0000 & 00 & $n$ & \\
\hline $0.20000 \mathrm{COD}$ & 00 & OOD & 00 & 0.15077170 & \\
\hline $0.2000000 \mathrm{D}$ & 00 & 40000000 & 00 & 0.14313820 & \\
\hline $0.20000 \mathrm{COD}$ & 00 & 50000000 & 00 & 0.13750640 & \\
\hline 0.20000000 & 00 & G.6000000D & 00 & 0.13332 E9C & \\
\hline $0.20000 \mathrm{COD}$ & 00 & 000000 & 00 & 0.13017650 & \\
\hline .20000000 & 00 & 0.80000000 & 00 & 0.12775030 & \\
\hline
\end{tabular}




\begin{tabular}{|c|c|c|c|c|}
\hline 16000000 & 00 & .10000000 & co & 0.18494040 \\
\hline 0.16000000 & 00 & .20000000 & 00 & 0.17411720 \\
\hline $16000 \mathrm{COD}$ & 00 & 30000000 & 00 & $.16369 \$ 2 D$ \\
\hline $16000 C 0 D$ & 00 & OD & 00 & $762 D$ \\
\hline 16000000 & 00 & 0000000 & 00 & 40 \\
\hline 16000000 & 00 & 10D & co & 50 \\
\hline D & 00 & OOD & 00 & \\
\hline OD & 0 & 30000000 & co & \\
\hline D & 00 & & 00 & \\
\hline $12000 C O D$ & 00 & & co & \\
\hline-12000000 & 00 & & OC & \\
\hline $.12000 C O D$ & 00 & D & 00 & \\
\hline $.1200000 \mathrm{D}$ & 0 & & 0 & \\
\hline$C O D$ & & & & \\
\hline 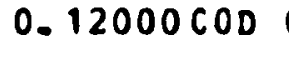 & $c$ & & r & \\
\hline $.12000 \mathrm{COD}$ & 00 & & 00 & \\
\hline $.800000 \mathrm{C}$ & & D & 00 & \\
\hline $.80000 \mathrm{COD}-$ & & & CO & \\
\hline .80000000 & & & c & \\
\hline $.80000000-0$ & & D & & \\
\hline .8000000 & & ( & & 9030 \\
\hline (5) & & D & 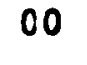 & 30 \\
\hline Cocosona & & D & 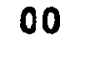 & 50 \\
\hline - & & 0 & - & 然 \\
\hline
\end{tabular}




\begin{tabular}{|c|c|c|c|c|}
\hline $0.40000000-01$ & C. $1000000 D$ & 00 & $0.2204289 \mathrm{C}$ & 01 \\
\hline $0.4000000 D-01$ & 0.20000000 & 00 & 0.21255410 & 01 \\
\hline $0.40000 \mathrm{COD}-01$ & 0.30000000 & 00 & 0.20293970 & 01 \\
\hline $0.4000000 D-01$ & 0.40000000 & $\mathrm{CO}$ & 0.19341920 & 01 \\
\hline $0.40000 \mathrm{COD}-01$ & 0.50000000 & 00 & $0.1848482 \mathrm{D}$ & 01 \\
\hline $0.4000000 D-01$ & $0.6000000 \mathrm{D}$ & 00 & $0.1774603 \mathrm{C}$ & 01 \\
\hline $0.40000000-01$ & $C .70000000$ & 00 & $0.1712022 \mathrm{D}$ & 01 \\
\hline $0.40000000-01$ & $0.8000000 \mathrm{D}$ & 00 & 0.16592310 & 01 \\
\hline 0.0 & $0.1000000 \mathrm{D}$ & 00 & $0.4531139 \mathrm{E}$ & .01 \\
\hline 0.0 & $0.2000000 \mathrm{D}$ & 00 & $0.1624960 \mathrm{C}$ & 00 \\
\hline 0.0 & C. $3000000 D$ & CO & 0.31184900 & 00 \\
\hline 0.0 & 0.40000000 & CO & 0.45974490 & 00 \\
\hline 0.0 & 0.50000000 & CO & $0.5890481 \mathrm{C}$ & 00 \\
\hline 0.0 & 0.60000000 & 00 & $0.6952699 \mathrm{C}$ & 00 \\
\hline 0.0 & C. 70000000 & 00 & $0.78009 \mathrm{CBC}$ & 00 \\
\hline 0.0 & $0.8000000 \mathrm{D}$ & 00 & 0.84717030 & 00 \\
\hline$-0.40000000-01$ & C. 10000000 & 00 & $0.1680226 \mathrm{C}$ & .01 \\
\hline$-0.4000000 D-01$ & 0.20000000 & 00 & $0.6295332 \mathrm{~L}$ & -01 \\
\hline$-0.40000 \mathrm{COD}-01$ & 0.30000000 & 00 & 0.12837820 & 00 \\
\hline$-0.40000000-01$ & 0.40000000 & 00 & 0.20237530 & 00 \\
\hline$-0.4000000 D-01$ & $C .5000000 D$ & 00 & 0.27700110 & 00 \\
\hline$-0.4000000 D-01$ & 0.60000000 & 00 & $0.3476276 \mathrm{D}$ & 00 \\
\hline$-0.40000 C 0 D-01$ & C. $7000000 D$ & 00 & $0.4121711 \mathrm{C}$ & 00 \\
\hline$-0.40000000-01$ & $0.8000000 \mathrm{D}$ & 00 & 0.47006520 & 00 \\
\hline
\end{tabular}


$-0.80000000-01$

0.1000000000

$0.13593830-01$

$-0.8000000 D-01$

0.2000000000

$0.51448320-01$

$-0.80000000-01$

$0.30000000 \mathrm{CO}$

0.1063956000

$-0.80000 \mathrm{COD}-01$

C. 4000000000

$0.1703532 \mathrm{C} 00$

$-0.80000000-01$

0.5000000000

0.2367458000

$-0.8000000 D-01$

0.6000000000

0.3013095000

$-0.80000000-01$

0.7000000000

$0.36174 \subseteq 1000$

$-0.80000000-01$

C. 8000000000

0.4871083000

$-0.1200000 \mathrm{D} \mathrm{00}$

0.1000000000

$0.11350180-01$

$-0.1200000000$

0.2000000000

$0.43283510-01$

-0.12000 COD 00

0.3000000000

$0.90482880-01$

$-0.1200000000$

$c .4000000000$

0.1466447 C 00

$-0.1200000000$

0.5000000000

0.2063089000

$-0.1200000000$

0.6000000000

0.2656157000

-0.12000 COD 00

0.7000000000

0.3222447000

$-0.12000 C O D 00$

C. 8000000000

$0.3750238 D^{\circ} 00$

$-0.1600000000$

0.1000000000

$0.9668576 \mathrm{C}-02$

$-0.1600000000$

0.2000000000

$0.37092450-01$

$-0.1600000000$

$0.30000000 \mathrm{CO}$

$0.7821542 \mathrm{D}-01$

$-0.16000 C O D O 0$

C. 4000000000

$0.1280378 \mathrm{C} 00$

$-0.1600000000$

0.5000000000

0.1819917000

$-0.1600000000$

0.6000000000

0.2366283 D 00

$-0.1600000000$

C. 7000000000

0.2896957 DCO 
$-0.20000 C 0 D 00$

C. 1000000000

$0.83583390-02$

$-0.2000000000$

0.2000000000

$0.32222590-01$

$-0.20000 C 0 D 00$

0.3000000000

$0.68434120-01$

$-0.2000000000$

0.4000000000

$0.1129718 \mathrm{CO}$

$-0.20000 C O D 00$

C. $50000000 \mathrm{CO}$

0.1619953 C 00

$-0.2000000000$

0.6000000000

0.2124440000

$-0.20000 \mathrm{COD} 00$

0.7000000000

$0.2621847 \mathrm{D} 00$

$-0.20000 C 0 D 00$

0.8000000000

$0.30989550 \mathrm{co}$

$-0.24000 C 0000$

$0.10000000 \mathrm{CO}$

$0.73101480-02$

$-0.2400000000$

0.2000000000

$0.2829575 D-01$

$-0.2400000000$

0.3000000000

$0.60455930-01$

$-0.2400000000$

0.4000000000

0.1005150000

$-0.2400000000$

0.5000000000

$0.1452413 C_{00}$

$-0.2400000000$

0.6000000000

0.1919171000

$-0.2400000000$

0.7000000000

0.2385568000

$-0.2400000000$

0.8000000000

$0.28384310 \quad 00$ 


\section{APPENDIX B}

EXACT SOLUTIONS FOR SQUARE PULSES, AND FOR THE GENERAL PULSES WITH $\delta=0$ AND $\gamma_{2}=0$

Eqs.(39) for square pulses can be written as

$$
\frac{d A_{0}}{d t}=i \alpha A_{2} \exp [i(2 \delta-\mu) t]
$$

$$
\frac{d A_{2}}{d t}=-\gamma A_{2}+i \alpha A_{0} \exp [-i(2 \delta-\mu) t]
$$

where $\gamma=\frac{\gamma_{2}}{2}+P_{0}$.

With the boundary conditions $A_{0}(0)=1$ and $A_{2}(0)=0$ we solve the second order differential equation and find the cxact Eolutions

$$
\begin{gathered}
A_{2}=\frac{i \alpha^{*}}{m_{1}-m_{2}}\left(e^{m_{1} t}-e^{m_{2} t}\right), \\
A_{0}=\frac{e^{i(2 \delta-\mu) t}}{m_{1}-m_{2}}\left[\left(m_{1}+\gamma\right) e^{m_{1} t}-\left(m_{2}+\gamma\right) e^{m_{2} t}\right],
\end{gathered}
$$

where

$$
m_{2}=\frac{-[\gamma+i(2 \delta-\mu)] \pm i \sqrt{4|\alpha|^{2}-[\gamma-i(2 \delta-\mu)]^{2}}}{2}
$$

and we choose $\sqrt{ }$ such that its real value is positive. 
If $\gamma<<|\alpha|$, then we can make an approximation and find

$$
\left|A_{2}(t)\right|^{2}=\frac{2|\alpha|^{2} e^{-\gamma t}}{(2 \delta-\mu)^{2}+4|\alpha|^{2}}\left[\cosh \frac{\gamma(2 \delta-\mu) t}{\sqrt{4|\alpha|^{2}+(2 \delta-\mu)^{2}}}\right.
$$

$$
\left.-\cos \sqrt{4|\alpha|^{2}+(2 \delta-\mu)^{2}} t\right]
$$

If $\frac{\gamma(2 \delta-\mu) \tau}{\sqrt{4|\alpha|^{2}+(2 \delta-\mu)^{2}}}<1,(0 \leq t \leq \tau)$, then $\cosh \frac{\gamma(2 \delta-\mu) t}{\sqrt{4|\alpha|^{2}+(2 \delta-\mu)^{2}}}$

$\simeq 1$ dropping 2 nd order smallness.

In the case of the pulse shape $g\left(\begin{array}{c}t) \\ t\end{array}\right.$ with $\gamma_{2}=0$

and $\delta=0$ and with the substitution $U=\int_{-\infty}^{t} g\left(t^{\prime}\right) d t^{\prime}$ Eq. (39) beccomes

$$
\begin{gathered}
\frac{d A_{0}}{d U}=i \alpha A_{2} \exp (-i \mu U), \\
\frac{d A_{2}}{d U}=-P_{0} A_{2}+i \alpha{ }^{*} A_{0} \exp (i \mu U),
\end{gathered}
$$

Which is the same type as Eqs. (90). 


\section{REFERENCES}

1. Vasilenko, L.S., V.P. Chebotaev anci A.V. Shishaev, JETP Letters 12,113 (1970).

2. Cagnac, B., G. Grynberg and F. Biraben, Phys. Rev. Lett. 32, 643 (1974).

3. Levenson, M.D. and N. Bloembergen, Phys. Rev. Lett. 32,645 (1974).

4. Häsch, T.W., S.A. Lee, R. Wallenstein and C. Wieman, Phys. Rev. Lett. 34, 307 (1975).

5. Hänsch, T.W., K. Harvey, G. Meisel and A.L. Schawlow, Opt. Comm. 11, 50. (1974).

6. Biraben, F., B. Cagnac and G. Grynberg, C. R. Acad. Sc. Paris 279, B5l (1974).

7. Liao, P.F. and J.E. Bjorkholm, Phys. Rev. Lett. 34 , 1 (1975).

8. Bjorkholm, J.E. and P.F. Liao, Phys. Rev. Lett. 33 $128(1974)$.

9. Patel, C.K.N., Laser Spectroscopy, ed. R.G. Brewer and A. Mooradian (Plenum Press, N.Y., 1974).

10. Ambartzumian, R.V., V.S. Letokhov, N.V. Chekalin, E.A. Ryabov Lett to JET Ph. 20, 597 (1974).

11. Ambartzumian, R.V., Yu. A. Gorokhov, V.S. Letokhov, and G.N. Makarov Lett tu JET Ph. 21, 375 (1975).

12. Lyman, J.L., R.J. Jensen, J. Rink, C.P. Robinson, and S.D. Rockwood, Preprint LA-UR 75707.

13. Ambartzumian, R.V., V.S. Doljikov, N.V. Chekalin, V.S. Letokhov, E.A. Ryabov, Chem. Phys. Lett. 25, 515 (1974), JET Ph. 68, N7 (1975).

14. Steinfeld, J. I., to appear in CRC Critical Reviews in Analytical Chemistry.

15. Fairbank, W.M., T.W. Hänsch, and A.L. Schawlow, J.․․․․… 65, 199 (1975). 
16. Hurst, G.S., M.G. Payne, M.H. Nayfeh, J.P. Judish, and E.B. Wagner, Phys. Rev. Lett. 35,82 (1975), Payne, M.G., G.S. Hurst, M.H. Nayfeh, J.P. Judish, C.H. Chen, E.B. Wagner, and J.P. Young, Phys. Rev. Lett. 35, 1154 (1975); Hurst, G.S., M.H. Nayfeh, and J.P. Young, "A Demonstration of One-Atom Detection," Appl. Phys. Lett. (in press); Hurst, G.S., M.H. Nayfeh, and J.P. Young, "One-Atom Detection Using Resonance Ionization Spectroscopy," (to be published).

17. Hänsch, T. and P. Toschek, IEEE J. Quant. Electron

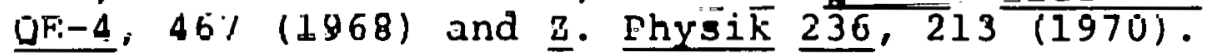

18. Holt, H.K., Phys. Rev. Lett. 20,410 (1968) and Phys.

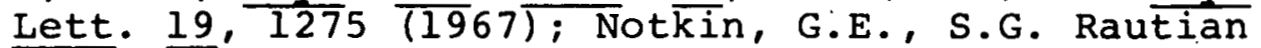
and A.A. Feoktistov, Zh. Eksp. Teor. Fiz. 52, 1673 (1967) [SOV. Phys. JETP $2 \overline{5}, 111 \overline{2(196 \overline{7)}]}$.

19. Brewer, R.G., Science 178, 247 (1972); see also Baklanov, E.V. and V.P. Chebotayev, Zh. Eksp. Teor. Fiz. 61, 922 (1972) [JETP $\underline{34}, \overline{490} \overline{(1972)]}$.

20. Hall, J.L., Lectures in Theoretical Physics (Gordon

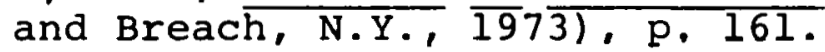

21. Bebb, H.B. and A. Gold, Phys. Rev. 14.3, 1 (1966);

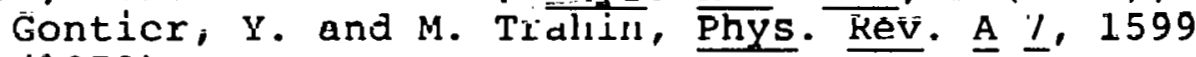
$(1972)$.

22. Lambropoulos, P., Phys. Rev. $\underline{A} \underline{9}, 1992$ (1.974).

23. Armstrong, L. and B.L. Beers, Phys. Rev. $\underline{\text { A } 12,1903}$ (1975).

24. Beers, B.L. and L. Armstrong, Phys. Rev. A 12, 2447 (1975); see also the references therein.

25. Zener, C., Proc. Roy. Soc. (London) Al37, 696 (1932).

26. Payne, M.G., unpublished work.

27. Payne, M.G. and M.H. Nayfeh, Phys. Rev. A $\underline{13}, 595$ $(1976)$.

28. Lau, A.M.F., Phys. Rev. A 14,279 (1976).

29. Rabi, I.I., Phys. Rev. 49, 324 (1936); Rabi, I.I., Phys. Rev. 51, $\overline{652}$ (1937). 
30. Tan-no, N., Y. Kenichi and H. Inaba, J. Phys. B : Atom. Molec. Phys. 8, 339 (1975); Tan-no, N., Y. Ken $\overline{i c h i}$ and H. Inaba, J. Phys. B: Atom. Molec. Phys. 8, 349 (1975).

31. Matsuoka, M., Optics Communications 15, 84 (1975).

32. Salomaa, R. and S. Stenholm, J. Phys. B: Atom. Molec. Phys. 8,1795 (1975).

33. Yatisv, S., W.G. Wagner, G.S. Picus and F.J. McClung, Phys. Rev. Lett. 15,614 (1965).

34. Grischkowsky, D. and M.M.T. Loy, Phys. Rev. $\underline{A} \underline{12}$, 1117 (1975).

35. Ward, J.F. and A.V. Smith, Phys. Rev. Lett. 35,653 (1975).

36. Takatsuji, M. , Phys. Rev. A $\underline{4}, 808$ (1971).

37. Semibalomut, V.M. and R.I. Sokolovskii, Opt. Spectrosc.. 38, 618 (1975). 
THIS PAGE

\section{WAS INTENTIONALLY \\ LEFT BLANK}


ORNL/TM-5754

INTERNAL DISTRIBUTION

\author{
1. Biology Library \\ 2-3. Central Research Library \\ 4. Reactor Division Library \\ 5-6. Laboratory Records Dept. (LRD) \\ 7. Laboratory Records (ORNL-RC) \\ 8. ORNL Patent office \\ 9. ORNL Y-12 Technical Library, \\ Document Reference section \\ 10. B. K. Annis \\ 11. J. A. Auxier \\ 12. C. F. Barnett \\ 13. C. E. Bemis \\ 14. R. D. Birkhoff \\ 15. T. A. Carlson \\ 16. C. H. Chen \\ 17-21. C. W. Choi \\ 22. L. G. Christophorou \\ 23. R. N. Compton
}

$\begin{aligned} 24 . & \text { S. Datz } \\ 25 . & \text { J. S. Faulkner } \\ 26 . & \text { W. R. Garrett } \\ 27 . & \text { L. W. Grossman } \\ \text { 28-32. } & \text { G. S. Hurst } \\ 33 . & \text { J. P. Judish } \\ 34 . & \text { C. E. Klots } \\ 35 . & \text { S. D. Kramer } \\ 36 . & \text { C. H. Krause } \\ 37 . & \text { M. H. Nayfeh } \\ \text { 38-42. } & \text { M. G. Payne } \\ 43 . & \text { H. Postma } \\ 44 . & \text { C. R. Richmond } \\ 45 . & \text { R. H. Ritchie } \\ 46 . & \text { H. C. Schweinler } \\ 47 . & \text { J. E. Turner } \\ 48 . & \text { T. A. Welton } \\ 49 . & \text { J. P. Young }\end{aligned}$

24. S. Datz

26. W. R. Garrett

L. W. Grossman

33. J. P. Judish

34. C. E. Klots

35. S. D. Kramer

36. C. H. Krause

43. H. Postma

44. C. R. Richmond

45. R. H. Ritchie

Schweinler

48. T. A. Welton

49. J. P. Young

EXTERNAL DISTRIBUTION

50. Lloyd Armstrong, Jr., Department of Physics, Johns Hopkins University, Baltimore, Maryland 21218

51. B. L. Beers, Department of Physics, Johns Hopkins University, Baltimore, Maryland 21218

52. J. E. Bjorkholm, Bell Telephone Laboratories, Holmdel, N.J. 07733

53. N. Bloembergen, Department of Engineering and Applied Physics, Harvard University, Cambridge, Massachusetts 02138

54. J. E. Boring, Research Laboratory of Engineering Science, University of Virginia, Charlottesville, Virginia 22901

55. Keith Boyer, Laser Research and Technology Division, LASL, Los Alamos, N.M. 87545

56. W. Brandt, Physics Department, New York University, New York, N.Y: 10003

57. R. S. Caswell, Radiation Physics Laboratory, NBS, Washington, D.C. 20234

58. L. W. Cochran, Vice President, University of Kentucky, Lexington, Kentucky 40506

59. G. Cowper, Radiation Dosimetry Branch, Atomic Energy of Canada Limited, Chalk River, Ontario, Canada

60. W. C. DeMarcus, Department of Physics and Astronomy, University of Kentucky, Lexington, Kentucky 40506 
61. James Dubrin, Lawrence Livermore Laboratory, P. O. Box 808, Livermore, California 94550

62-63. F. Gabbard, Department of Physics and Astronomy, University of Kentucky, Lexington, Kentucky 40506

64. S. Geltman, Joint Institute for Laboratory Astrophysics, University of Colorado, Boulder, Colorado 80309

65. T. F. George, Department of Chemistry, University of Rochester, Rochester, N.Y. 14627

66. B. R. Gossick, Department of Physics and Astronomy, University of Kentucky, Lexington, Kentucky 40506

67. D. Grischkowsky, IBM Thomas J. Watson Research Center, Yorktown Heights, N.Y. 10598

68. J. K. Hancock, Advanced Isotopes Separations Program, ERDA, Washington, D.C. 20545

69. T. W. Hansch, Department of Physics, Stanford University, Stanford, California 94305

70. S. E. Harris, Edward L. Ginzton Laboratory, W. W. Hansen Laboratories of Physics, Stanford University, Stanford, California 94305

71. M. Inokuti, Radiation Physics Division, Argonne National Laboratory, 9700 South Cass Avenue, Argonne, Illinois 60439

72. O'Dean Judd, Laser Rèsearch and Technology Division, Los Alamos Scientific Laboratory, P. O. Box 1663, Los Alamos, N.M. 87545

73. R. E. Knight, Department of Physics and Astronomy, University of Kentucky, Lexington, Kentucky 40506

74. P. P. Lambropoulos, Department of Physics, University of Southern California, University Park, Los Angeles, California 90007

75. A. M. F. Lau, Molecular Physics Center, Stanford Research Institute, Menlo Park, California 94025

76. G. W. Lehman, Department of Physics and Astronomy, University of Kentucky, Lexington, Kentucky 40506

77. P. K. Leichner, Department of Physics and Astronomy, University of Kentucky, Lexington, Kentucky 40506

78. P. F. Liao, Bell Telephone Laboratories, Holmdel, N.J. 07733

79. W. Lichten, Department of Physics and Engineering and Applied Science, Yale University, 15 Prospect Street, New Haven, ronnerticut 06520

80. J. L. Liverman, Assistant Administrator for Environment and Safety, ERDA, Washington, D.C. 20545

81. D. C. Lorents, Stanford Research Institute, Menlo Park, California 94025

82. M. M. T. LOY, IBM Thomas J. Watson Research Center, Yorktown Heights, N.Y. 10598

83. M. T. McEllistrem, Department of Physics and Astronomy, University of Kentucky, Lexington, Kentucky 40506

84. J, E. Parks, Department of Physics and Astronomy, Western Kentucky University, Bowling Green, Kentucky 42101

85. A. V. Phelps, Joint Institute for Laboratory Astrophysics, University of Colorado, Boulder, Colorado 80302 
86. C. P. Robinson, Applied Photochemistry Division, LASL, P. O. Box 1663, Los Alamos, N.M. 87545

87. W. C. Royster, Dean of the Graduate School, University of Kentucky, Lexington, Kentucky 40506

88. R. L. Schriever, Division of Laser Fusion, ERDA, Washington, D.C. 20545

89. R. Schrils, Department of Physics and Astronomy, University of Kentucky, Lexington, Kentucky 40506

90. Maxine Sheets, Division of Biomedical and Environmental Research, ERDA, Washington, D.C. 20545

91. R. F. Stebbings, Department of Space Physics, Box 1892, Rice University, Houston, Texas 77001

92. T. D. Strickler, Department of Physics, Berea College, Berea Kentucky 40403

93. J. E. Talmage, 114 Nasson Lane, Oak Ridge, Tennessee 37830

94. G. K. Walters, Department of Physics, Rice University, Houston, Texas 77001

95. W. H. Wing, Department of Physics, University of Arizona, Tucson, Arizona 85721

96. R. W. Wood, Division of Biomedical and Environmental Research, ERDA, Washington, D.C. 20545

97. ORAU Library

98-99. ORAU Fellowship Office

100. Research and Technical Support Division, ORO

101-127. Technical Information Center (TIC) 